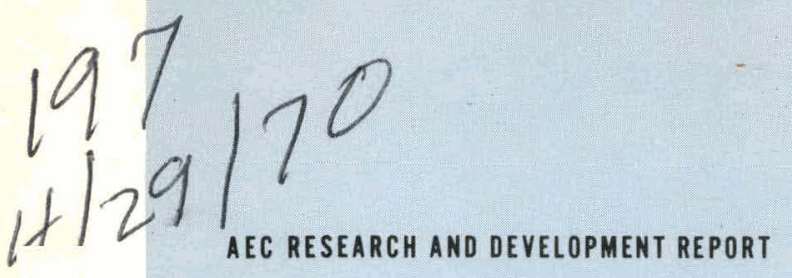

\title{
PREPARATION AND CHARACTERIZATION OF HYDROCARBON DERIVATIVES OF INDENE
}

\author{
W. E. Smith \\ B. Napier, Jr. \\ W. L. Harper
}

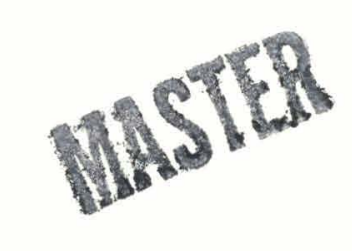

\section{UNION CARBIDE CORPORATION}

\section{NUCLEAR DIVISION} OAK RIDGE Y-12 PLANT

operated for the ATOMIC ENERGY COMMISSION under U. S. GOVERNMENT Contract W-7405 eng 26

UNION CARBIDE
OAK RIDGE Y-12 PLANT

P. O. BOX Y

OAK RIDGE, TENNESSEE 37830 


\section{DISCLAIMER}

This report was prepared as an account of work sponsored by an agency of the United States Government. Neither the United States Government nor any agency Thereof, nor any of their employees, makes any warranty, express or implied, or assumes any legal liability or responsibility for the accuracy, completeness, or usefulness of any information, apparatus, product, or process disclosed, or represents that its use would not infringe privately owned rights. Reference herein to any specific commercial product, process, or service by trade name, trademark, manufacturer, or otherwise does not necessarily constitute or imply its endorsement, recommendation, or favoring by the United States Government or any agency thereof. The views and opinions of authors expressed herein do not necessarily state or reflect those of the United States Government or any agency thereof. 


\section{DISCLAIMER}

Portions of this document may be illegible in electronic image products. Images are produced from the best available original document. 
Printed in the United States of America. Available from Clearinghouse for Federal Scientific and Technical Information, National Bureau of Standards,

U.S. Department of Commerce, Springfield, Virginia 22151

Price: Printed Copy $\$ 3.00$; Microfiche $\$ 0.65$

\section{LEGAL NOTICE}

This report was prepared as an account of Government sponsored work. Neither the United States, nor the Commission, nor any person acting on behalf of the Commission:

A. Makes any warranty or representation, expressed or implied, with respect to the accuracy, completeness, or usefulness of the information contained in this report, or that the use of any information, apparatus, method, or process disclosed in this report may not infringe privately owned rights; or

B. Assumes any liabilities with respect to the use of, or for damages resulting from the use of any information, apparatus, method, or process disclosed in this report.

As used in the above, "person acting on behalf of the Commission" includes any employee or contractor of the Commission, or employee of such contractor, to the extent that such employee or contractor of the Commission, or employee of such contractor prepares, disseminates, or provides access to, any information pursuant to his employment or contract with the Commission, or his employment with such contractor. 


\title{
UNION CARBIDE CORPORATION Nuclear Division
}

\author{
OAK RIDGE $Y-12$ PLANT.
}

Operated under Contract W-7405-eng-26

With the US Atomic Energy Commission

\section{PREPARATION AND CHARACTERIZATION OF HYDROCARBON DERIVATIVES OF INDENE}

\author{
W. E. Smith \\ B. Napier, Jr. \\ W. L. Harper
}

A.

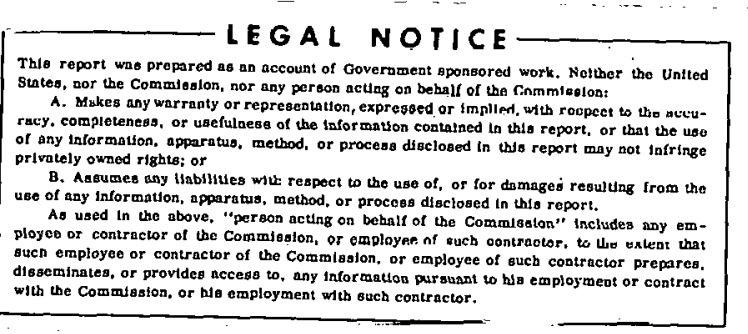

Oak Ridgc, Tennessee 
DISTRIBUTION

Aerojet-General

Swope, L. S./Funk, Campbell

Aerospace Corporation-EI Segundo

Blaes, H. M., II

Aerospace Corporation-San Bernardino

Schorr, W. E.

Aerotherm Corporation

Rodriquez, D. A.

Airco-Speer Carbon Company

Parker, W. E.

A. S. Thomas, incorporated

Shoffner, J. E.

Atomic Energy Commission

Keller, C. A.

Auburn University

Stevens, F. J.

Avco Applied Technical Division

Lurie, R. M. 
Avco Space Systems Division

Munson, T. R.

Battelle Memorial Institute

Duckworth, W. H.

Carborundum Company-Niagara Falls

Batha, H. D.

Carborundum Company-Sanborn

Wise, D. C.

Collier and Chemical Corporation

Scott, C. B.

Department of the Navy

Thompson, R. G.

General Electric

Gorsuch, P. D.

Great Lakes Carbon Corporation

Parry, S. J. S.

Great Lakes Research Corporation

Whittaker, M. P.

Gulf-General Atomic

Bokros, J. C.

Engle, G. B.

White, J. L. 
4

HITCO Corporation

Allison, $M$.

Kirtland Air Force Base

Gerber, J., Capt.

Rizzo, H., Col.

Lawrence Radiation Laboratory

Borough, G. D.

Hanson, E. R.

Maimoni, A.

Lockheed Missiles and Space Company

Johnson, A. C.

Los Alamos Scientific Laboratory

Armenis, N. P.

Baker, R. D.

Bowman, M. G.

Lyon, L. L.

Rowley, J. C.

Smith, M. C.

Taub, J. M.

Wewerka, E. M.

LTV Missiles and Space Division

Forcht, B. A.

LVT Research Center

Peterson, D. H.

McDonnell-Douglas Astronautics Company-Santa Monica

Meyer, R. A.

Shapiro, 1.

A

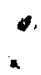

" 
McDonnell-Douglas Astronautics Company-St. Louis

$A$

Masek, R. V.

NASA-AMES Research Center

Larson, H. K.

Lundell, J. H.

NASA-Langley Research Center

Maahs, H. G.

Naval Ordinance Laboratory.

Barnet, F. R.

Oak Ridge Gaseous Diffusion Plant

Jordan, R. G.

Wilcox, W. J., Jr.

Oak Ridge National Laboratory

Eatherly, W. P.

Frye, J. H.

Grimes, W. R.

Harms, W. 0 .

Patriarca, P.

Rosenthal, M. W.

Strehlow, R. A.

Oak Ridge $Y-12$ Plant

Ardary, Z. L.

Ballenger, H.F. (2)

Beeson, H. C.

Bernander, N. K.

Briscoe, O.W.

Burkhart, L. E.

Cook, J. L.

Creech, E. T.Nilliams, N. W., Jr.

Evans, G.W.

Haøusler, K. R. 
Harper, W. L. (5)

Hemphill, L. F.

Kahl, K. G.

Keith, Alvin

Kite, H. T.

Marrow, G. B.

MCLendon, J. D.

MeWhorter, W. C.

Mitchel, G. W.

Napier, J. M.

Napier, B., Jr. (5)

Overholser, L. G.

Phillips, L. R.

Schreyer, J. M.

Smith, R. D,

Smith, W. E. (5)

Tench, F.M.

Trotter, T. C.

Warner, J. F.

Waters, J. L.

Wesley, R. L.

Yaggi, W. J./Googin, J. M.

Zocher, R. W.

$Y-12$ Central Files (10)

$Y-12$ Central Files (route)

$Y-12$ Central Files $(Y-12 R C)$

Paducah Gaseous Diffusion Plant

Winkel, R. A.

Penn State University

Walker, P. L., Jr.

Philco-Ford Corporation

Fassel, W. M., Jr.

Poco Graphite Company

Carlson, F.C. 


\section{U.S. ATOMIC ENERGY COMMISSION \\ MAJOR CONTRACTOR'S RECOMMENDATION FOR \\ DISPOSITION OF SCIENTIFIC AND TECHNICAL DOCUMENT}

Form AEC-426.

- (6/68)

CM 3201

(See Instructions on Reverse Side)

1. AEC REPORT NO.

$Y-1712$

2. SUBJECT CATEGORY NO.

UC-4, Chemistry

4. TYPE OF DOCUMENT (Check one):

囚 a. Scientific and technical report.

$\square$ b. Confererice paper not to be published in a journal:

Title of conference

Date of conference

Exact location of conference

Sponsoring organization

$\square$ c. Other (Specify)

5. COPIES TRANSMITTED (Check one or more applicable boxes):

\a. Copies being transmitted for standard distribution by AEC - DTI.

$\square$ b. Copies being transmitted for special distribution by AEC - DTI, per attached list.

$\square$ c. Two reproducible copies being transmittent to AEC - DTI.

6. RECOMMENDED DISTRIBUTION (Check one):

\. Normal handling (after patent clearance): no restraint on distribution except as may be required by the security classification.

$\square$ b. Normal handling in the U.S. (after patent clearance), but no foreign distribution.

$\square$ c. Make available only to U.S. Government agencies and their contractors.

$\square$ d. Make available only within AEC and to AEC contractors.

$\square$ e. Make available only within AEC.

$\square$ f. Make available only to those listod in itom 11, bclow.

$\square$ g. Other (Specify)

7. RECOMMENDED ANNOUNCEMENT (Check one):

$\square$ a. Normal procedure may be followed.

$\square$ b. Recommend following announcement limitations:

8. REASON FOR RESTRICTIONS RECOMMENDED IN 6. OR 7. ABOVE:

9. PATENT CLEARANCE (Check one):

$\bigotimes$ a. AEC patent clearance has been granted by responsible AEC patent group.

$\square$ b. Document has been sent to responsible AEC patent group for clearance.

10. DEFENSE INFORMATION (For classified document only. Check one):

Document a. $\square$ does b. $\square$ does not contain defense information other than restricted data.

11. ADDITIONAL INFORMATION OR REMARKS (Continue on separate sheet if necessary.):

. SUBMITTED BY: NAME AND POSITION (Please print or type)

M. A. Broders, Technical Information Sorviccs Supcrvisor

Organization

Union Carbide Corporation-Nuclear Division, Oak Ridge Y-12 Plant, Oak Ridge, Tennessee Signature
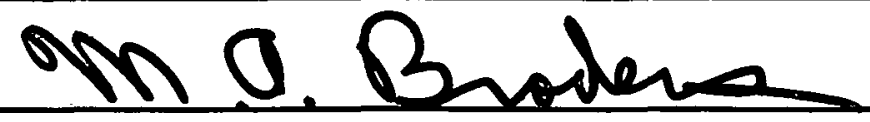

Date

March 19, 1970 
Who uses this Form: All AEC contractors except those specifically instructed by their AEC contract administrator to use the shorter Form AEC-427.

When to use: Submit one copy of this form with each document (except reprints of journal articles) or with each bulk shipment which is sent to AEC's Division of Technical Information (DTI) in accordance with the requirements of AEC Manual Chapter 3201. The Chapter specifies that preprints and manuscripts of journal articles, and manuscripts of conference papers which are to be published in a journal in substantially the same form and detail should not be sent to DTI. Reprints of journal articles may be sent to DTI, but no transmittal form should be used with reprints.

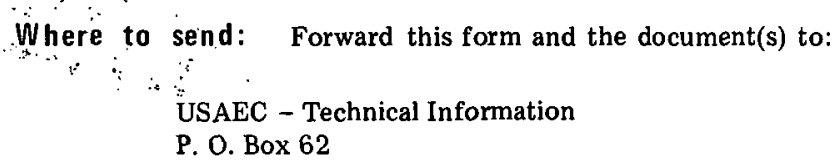

\section{Item instructions:}

Item 1. The first element in the number shall be a code to be determined as follows: (a) The responsible field office may request DTI approval of a unique code for a contractor, e.g., BNL, BMI, ORNL, etc.; (b) A program division may request DTI approval of a unique code for a program or series of reports, e.g., PNE, VUF, etc.; (c) An operations office may instruct a contractor to use the code approved for the operations office, i.e., NYO, COO, ORO, IDO, SRO, SAN, ALO, RLO, NVO; and (d) Program divisions shall use the code WASH for reports which they themselves prepare.

The code shall be followed by a sequential number, or by a contract number plus a sequential number, as follows: (a) Contractors or programs with unique cotes may complete the report number by adding a sequential number to the code, e.g., ORNL-101, ORNL-102, etc.; or PNE-1, PNE-2, etc.; or they may add the identifying portion of the contract number and a sequential number, e.g., $A B C-2105-1$, $\mathrm{ABC}-2105-2$, etc.; (b) Contractors using the operations office code shall complete the report number by adding the identifying portion of the contract number and a sequential number, e.g., NYO-2200-1, NYO-2200-2, etc.; and (c) Program divisions using the WASH code shall complete the report number by adding a sequential number which they request from D'TI's Document Management Branch in Oak Ridge.

Item 2. Insert the appropriate subject category from TID-4500 ("Standard Distribution for Unclassified Scientific and Technical Reports") or M-3679 ("Standard Distribution for Classified Scientific and Technical Reports") for both classified and unclassified documents, whether or not printed for standard distribution.

Item 3. Give title exactly as on the document itself unless title is classified. In that case, omit title and state "classified title" in the space for item 3.

Item 4. If box $\mathrm{c}$ is checked, indicate type of item being sent, e.g., thesis, translation, computer program, etc.
Item 5. a. The number of copies specified for the appropriate category or categories in M-3679 or TID -4500 shall be forwarded to DTI for distribution.

b. If box $c$ is checked, at least one copy shall be original ribbon or offset and be completely legible. A clear carbon copy is acceptable as a second reproducible copy.

Item 6. If box a is checked for an unclassified document, it may be distributed (after patent clearance) to addressees listed in TID -4500 for the appropriate subject category, to AEC depository libraries in the U.S. and abroad, to the Clearinghouse for Federal Scientific and Technical Information for sale to the public, and to authorized foreign recipients.

If box $a$ is checked for a classified document, it may be distributed to addressees listed in M.3679 for the appropriate subject category.

If a box other than a is checked, the recommended limitation will be followed if not inconsistent with AECM-2104, "Information for Official Use Only", and unless DTI receives other instructions from the responsible AEC program division.

Box g may be checked in order to specify special instructions, such as "Make available only as specifically approved by the program division", etc.

Item 7. a. Announcement procedures are normally determined by the distribution that is to be given a document. If box $a$ or $b$ in item 6 is checked for an unclassified document, it will normally be listed in DTI's "Weekly Accessions List of Unlimited Reports" (TID-4401) and may be abstracted in "Nuclear Science Abstracts" (NSA).

A classified document, or an unclassified document for which box $c, d$, $e, f$, or $g$ is checked, will normally be listed in DTI's "Weekly Accessions List of Limited Distribution Reports" (TID-4400) and may be abstracted in "Abstracts of Limited Distribution Reports" (ALDR).

b. Check $7 \mathrm{~b}$ if the normal announcement procedures described in $7 \mathrm{a}$ are not appropriate and indicate recommended announcement limitations.

Item 8. If a box other than a is checked in item 6 , or if $7 \mathrm{~b}$ is checked, state reason for the recommended restriction, e.g., "preliminary information", "prepared primarily for internal use", etc.

Item 9. It is assumed that there is no objection to publication from the standpoint of the originating organization's patent interest. Otherwise explain in item 11.

Item 10. The purpose of this item is to determine whether a given classified document can be distributed to access permittees. If box a is checked, it cannot be made available to them (Code of Federal Regulations, 10 CFR, Part 35, subpart 25.6); if box b is checked, DTI will determine whether or not to make it available.

Item 11. Use this space if necessary to expand on answers given above, e.g., item $6 \mathrm{f}$ and item 9 .

Item 12. Enter name of person to whom inquiries concerning the recommendations on this form may be addressed. 
Raytheon Company

Pappis, J.

SAMSO (SMT/AFMI)

Hjelm, L./MAAS

SAMCO/SMYSE

Swartz, T., Capt. (2)

Sandia-Albuquerque

Acton, R. U.

Braasch, R. H.

Frye, E. R.

Heckman, R. C.

McDonald, J. E.

Schmitt, W. H.

Sandia-Livermore

Adolphson, D. R.

Davies, L. E.

Southern Research Institute

Pears, C.

Space Nuclear Propulsion Office-Albuquerque

Cully, J. C.

Hessing, $\mathrm{H}$.

Space Nuclear Propulsion Office-Cleveland

Bosse, E.W.

Lombardo, S.

Thielke, N. R. 
Space Nuclear Propulsion Office-Washington

Scheib, W. S.

Schwenk, F.C.

Slivka, W. R.

Stackpole Carbon Company

Shobert, E. I.

Super-Temp Corporation

Smith, W.

TRW Systems Group

Bohn, J. R.

Union Carbide Corporation, Carbon Products Division

Browning, J. B.

Singer, L.

Townsend, H. N.

Union Carbide Corporation, Chemical and Plastics Division

Shechter, L.

University of Tennessee

Eastham, J.F.

US Army Materials and Mechanics Research Agency

Scala, P.

Westinghouse Astronuclear Corporation-Pittsburgh

Holmgren, J. D.

Wright-Patterson Air Force Base

Dimiduk, R./MAYT

Forney, D./MAC (2) 
Harsacky, F./MAT

Latva, J./MAAC

Minges, M./MAAS

Pratt, C./MAAS

Rowan, R. R./MAMN

Schmidt, D./MANC

In addition, this report is distributed in accordance with the category Chemistry, as given in the "USAEC Standard Distribution Lists for Unclassified Scientific and Technical Reports", TID-4500. 


\section{ABSTRACT}

A search for compounds that give high volume and weight yields of carbon on pyrolysis, prompted an evaluation of indene $\left(\mathrm{C}_{9} \mathrm{H}_{8}\right)$ and indene-derived compounds having high $\mathrm{C} / \mathrm{H}$ atom ratios. By taking advantage of the reactivity of the unsaturated bond and methylene group that are inherent in an indene molecule, various derivatives of indene were prepared by polymerization, vinylation, and condensation reactions. These hydrocarbon compounds, including polyindene, vinylindene, the benzofulvenes, truxene, and isotruxene, were characterized. An initial evaluation of these materials as carbon precursors indicates that truxene, isotruxene, and certain benzofulvene compounds have potential value as high-carbon-yield precursor materials. 


\section{CONTENTS}

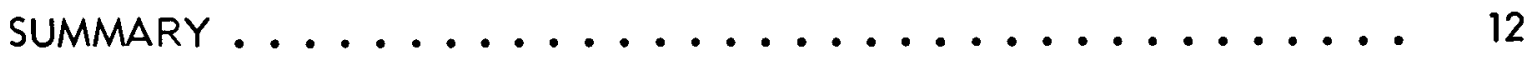

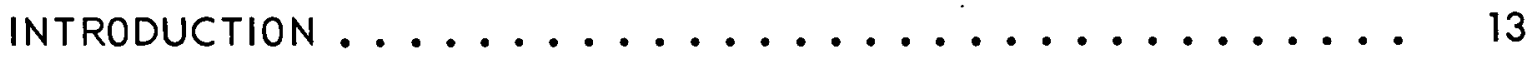

EXPERIMENTAL WORK WITH INDENE AND ITS DERIVATIVES . . . 15

Structure and Properties of Indene ................. 15

Preparative Procedures .................... 17

Polymerization of Indene by Acid Catalysts .......... 17

Vinylation of Indene and Polyindene ............. . 20

Synthesis of Diene Compounds by Reactions of Indene with Halogenated Hydrocarbons ......... 25

Synthesis of Benzofulvene Compounds by Reactions of Indene with Carbonyl Compounds .......... 31

Synthesis of Isotruxene from Reactions of Indene and 1,4naphthoquinone ................... 36

Synthesis of Isotruxene Using Other Amines and Carbonyl

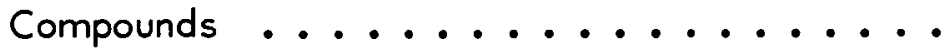

Synthesis of Truxene from Reactions of Indene and Terephthaldehyde ..................

Synthesis of Isomeric Mixtures of Truxene and Isotruxene by Autoclave Treatment of Indene ........ 60

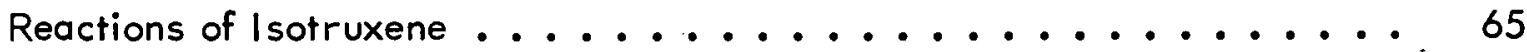

Electrophilic Substitution Reactions ............ 65

Vinylation Reactions .................. 69

Oxidation Reactions .................... 69

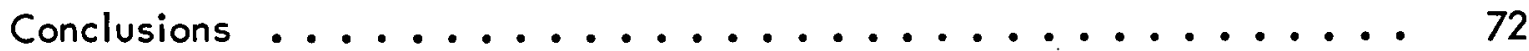

REFERENCES .......................... 74

ACKNOWLEDGEMENTS ........................ 76 


\section{SUMMARY}

Indene $\left(\mathrm{C}_{9} \mathrm{H}_{8}\right)$ was evaluated as a possible starting material for a series of carbon precursor compounds having high $\mathrm{C} / \mathrm{H}$ atom ratios. Various compounds derived from indene were prepared and characterized. Preparative procedures that were used included:

1. Polymerization of indene with acid catalysts.

2. Vinylation of indene, polyindene, and isotruxene by heating under acetylene pressure.

3. Synthesis of diene compounds by reactions of indene with halogenated hydrocarbons.

4. Condensation reactions of indene with carbonyl compounds to form benzofulvene derivatives.

5. Trimerization of indene to produce truxene and isotruxene.

An in-depth study of the formation and properties of truxene and isotruxene was carried out since these materials appear to have greater potential as carbon precursors. 


\section{INTRODUCTION}

Increased sophistication in structural designs increases, in turn, demands for speciality forms of structural materials. To obtain these materials, more stringent controls must be maintained over as many process variables as possible, and consistent specifications must be achieved on the raw materials used in these processes.

There is a need for rigid controls over any inconsistencies in the properties of the carbons used in various fabrication processes; hence, an investigation of several carbon precursor materials is imperative in order to arrive at and classify a precursor system from which consistent carbon properties can be derived. Properties of a given carbon are dictated, for the most part, by the nature of the precursor; and, to a lesser degree, by the processing methods. The latter may be standardized. Thus, nonuniform precursor materials, the majority of which are derived from natural sources, can be the cause for a variation in the carbon properties. The composition of petroleum-derived pitches is dependent on the source of the crude and the process methods used in removing the lighter fractions.

A desirable carbon precursor system would be versatile in that it should: (1) be fluid at or near $25^{\circ} \mathrm{C},(2)$ have reproducible properties, (3) have a high weight and volume yield on pyrolysis, (4) be a precursor to both the binder and substrate carbon, and (5) allow control over the graphitizability of the resulting carbon. The present search for carbon precursor materials is centered on polynuclear aromatic hydrocarbons having high $\mathrm{C} / \mathrm{H}$ atom ratios.

This report describes efforts to synthesize and characterize certain products derived from indene. It is planned to describe, in a subsequent report, an evaluation of the se materials as carbon precursors.

Reactions of compounds containing actiye methylene groups have received considerable attention in the literature, $(1-3)$ and condensation reactions of indene with carbonyl compounds have been described. $(4-7)$ The use of metal salts of indene as a synthetic intermediate was reported; $(7)$ the behavior of indene under autoclave conditions has been described.(8) Evaluating indenederived compounds as possible carbon precursor compounds represents an initial effort within the Oak Ridge Y-12 Plant. (a)

(a) Operated for the US Atomic Energy Commission by the Union Carbide Corporation's Nuclear Division. 
THIS PAGE

WAS INTENTIONALLY

LEFT BLANK 


\section{EXPERIMENTAL WORK WITH INDENE AND ITS DERIVATIVES}

\section{STRUCTURE AND PROPERTIES OF INDENE}

Indene ( $\mathrm{C} 9 \mathrm{H} 8)$ was evaluated as a starting material for synthesis of a series of carbon precursors because of its availability and its reactivity to form polynuclear hydrocarbon products having favorable $\mathrm{C} / \mathrm{H}$ atom ratios. Physical properties of indene are listed in Table ${ }_{1 ;}\left({ }^{(9)}\right.$ the structure of the compound is:

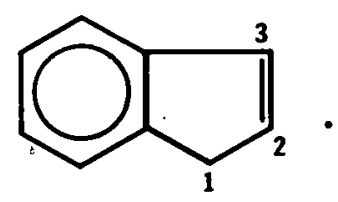

Infrared (IR) and nuclear magnetic resonance (NMR) spectra of indene are presented in Figures 1 and 2, respectively. The latter spectra clearly differentiate between the methylenic and olefinic protons that are present in the five-member ring of the indene molecule.

Analysis of commercial grades of indene using gas chromatography (GC) indicated the presence of volatile impurity phases, as shown by a typical scan in Figure 3. Though not verified, studies indicated that the impurity material was probably indane.

The chemical reactivity of indene is largely due to the functional groups that are inherent in the five-member ring of the molecule; namely, an unsaturated bond and an active methylene group. Due to the lability of the methylenic protons, displacement occurs with strong bases, leading to the formation of salts. These acid-base reactions are promoted, in part, by an increase in the resonance stabilization or aromaticity as indene is converted to an anion having six $\pi$

Table 1

PHYSICAL PROPERTIES OF INDENE

\begin{tabular}{ll}
\hline \multicolumn{1}{c}{ Property } & \multicolumn{1}{c}{ Value } \\
\hline Melting Point $\left({ }^{\circ} \mathrm{C}\right)$ & -2 \\
Boiling Point $\left({ }^{\circ} \mathrm{C}\right)$ & $182.2-182.4$ \\
Density $(\mathrm{gm} / \mathrm{cc})$ & 0.9915 (at $20^{\circ} \mathrm{C}$, compared to $\mathrm{H}_{2} \mathrm{O}$ at $4^{\circ} \mathrm{C}$ ) \\
Molecular Weight & 116.1 \\
Refroctive Indox & $1.5612^{20}$ \\
\hline
\end{tabular}




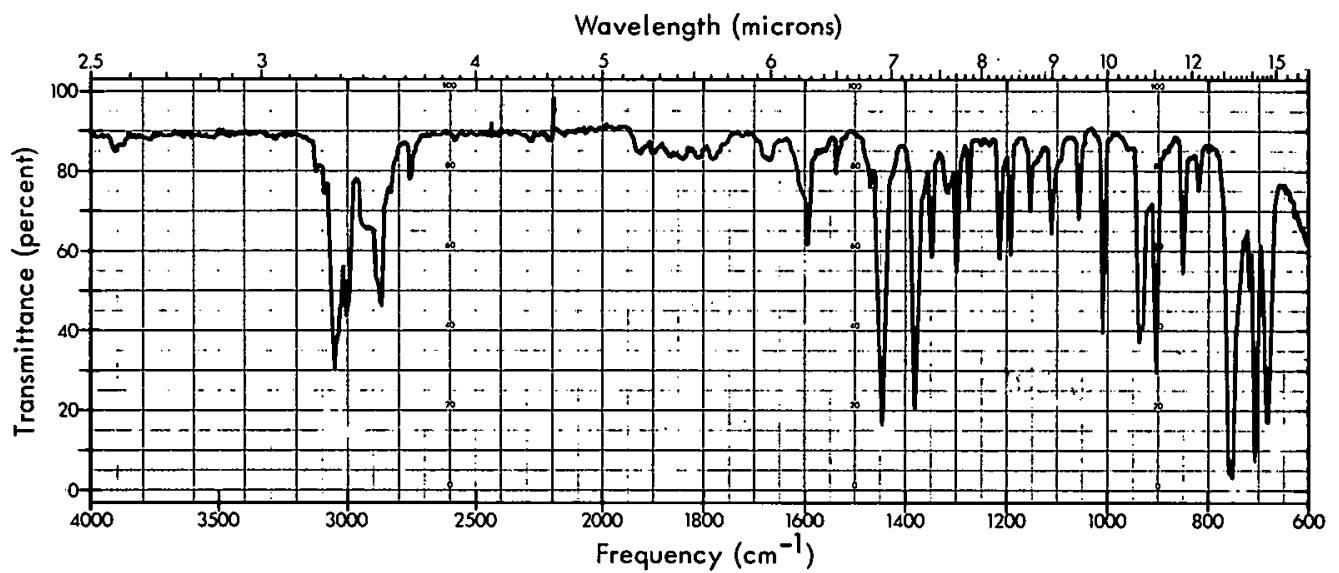

(a) Indene

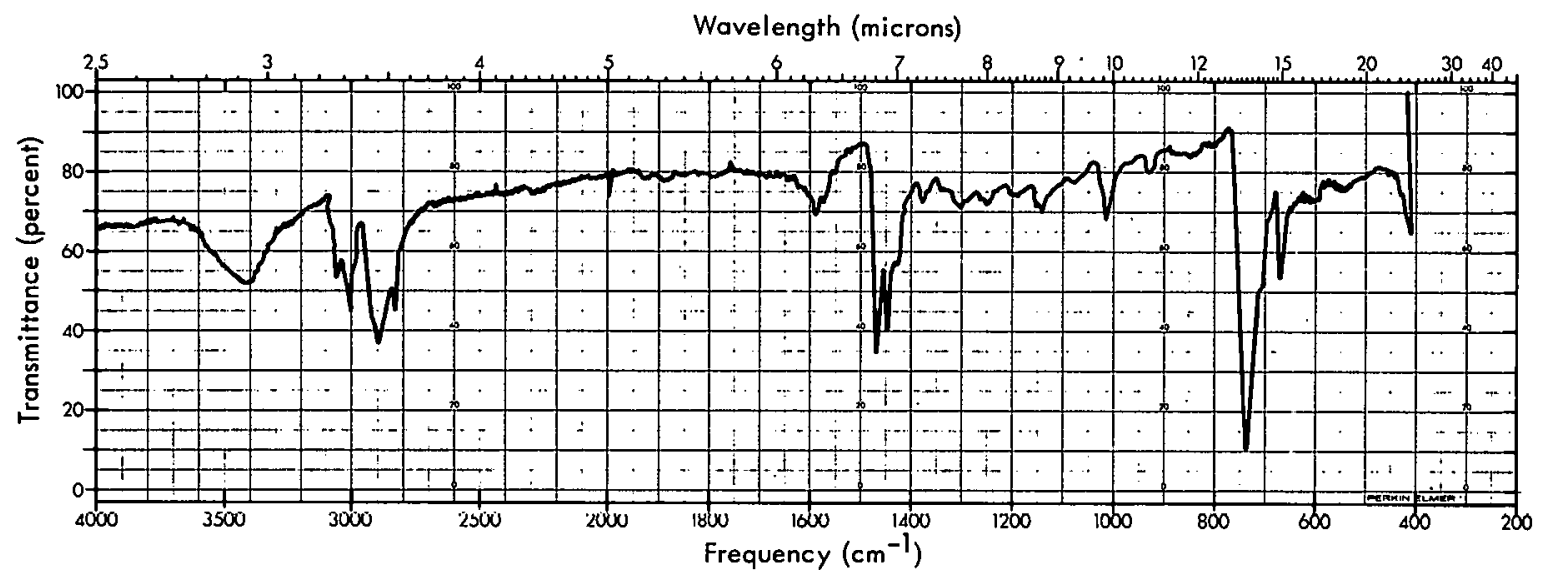

(b) Polyindene

Figure 1. INFRARED SPECTRA OF INDENE AND POLYINDENE.

electrons in the five-member ring, allowing resonance similar to that of a sixmember aromatic ring. Carbonyl groups react with the methylene group by an aldol-type condensation to produce benzofulvene derivatives. These derivatives, in turn, allow coupling carbonyl compounds with indene through a doublebond linkage that is in conjugation with the olefinic bond in indene. Indene does not appear to be sensitive to anionic polymerization catalysts, but the compound is highly sensitive to acid catalysts which produce high-molecular-weight polymers.

Since indene in the monomeric form has a significant vapor pressure, little residual carbon $(<10 \%)$ is observed when samples are pyrolyzed at atmospheric pressure. Thus, to function as a source of carbon, indene must be converted into derivatives that will polymerize and carbonize without significant 


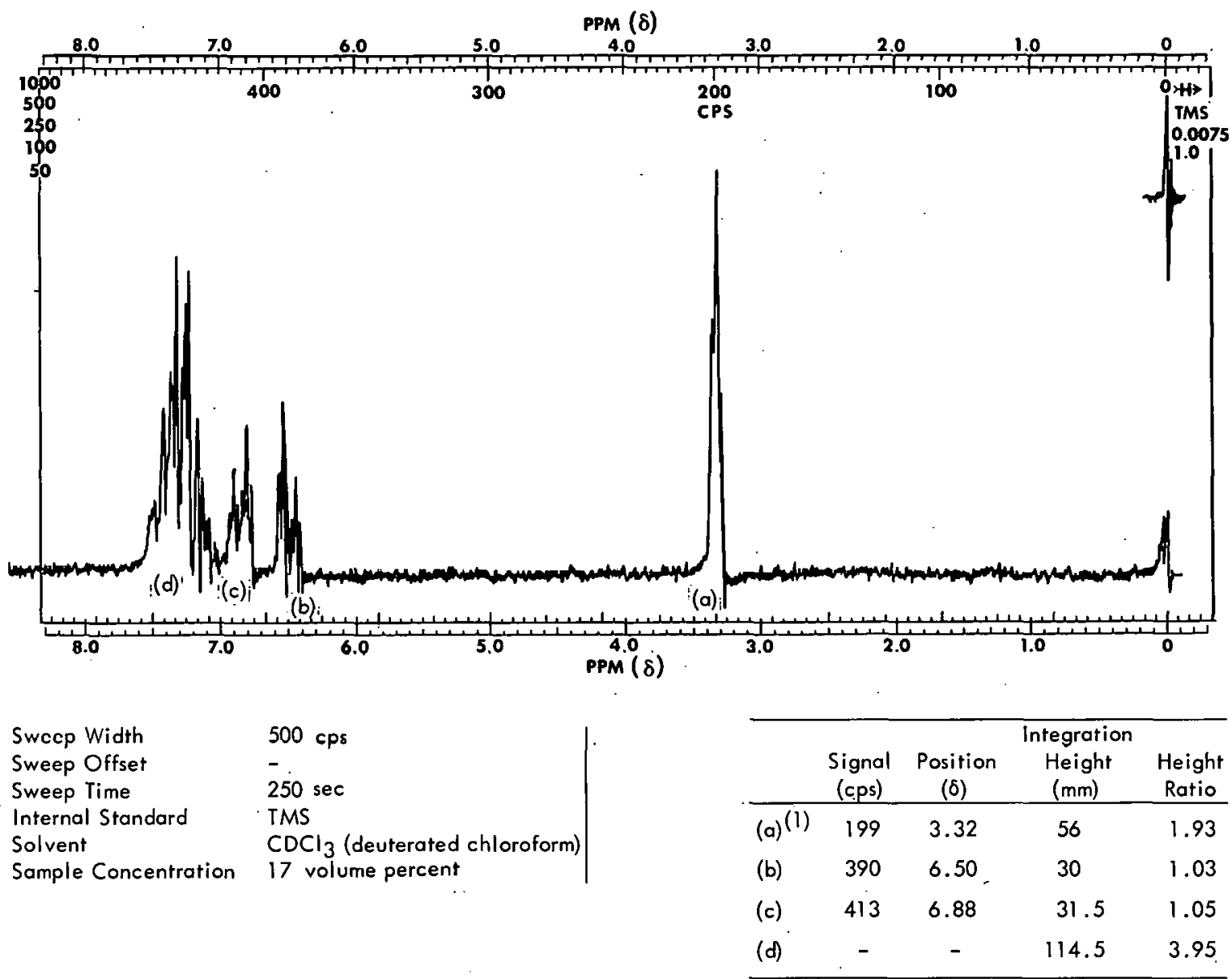

(1) Indene

(d)<smiles>[18O]C1=C(Cl)c2ccccc21</smiles>

Fiqure 2. NUCLEAR MAGNETIC RESONANCE SPECTRUM OF INDENE.

loss of carbon through volatilization. The synthesis of various derivatives is described in the sections that follow.

\section{PREPARATIVE PROCEDURES}

\section{Polymerization of Indene by Acid Catalysts}

Acid-catalyzed polymerization of indene is presumed to occur in a manner analogous to olefinic-type polymerization, producing essentially a linear polymer. This conversion is depicted in the following equation: 

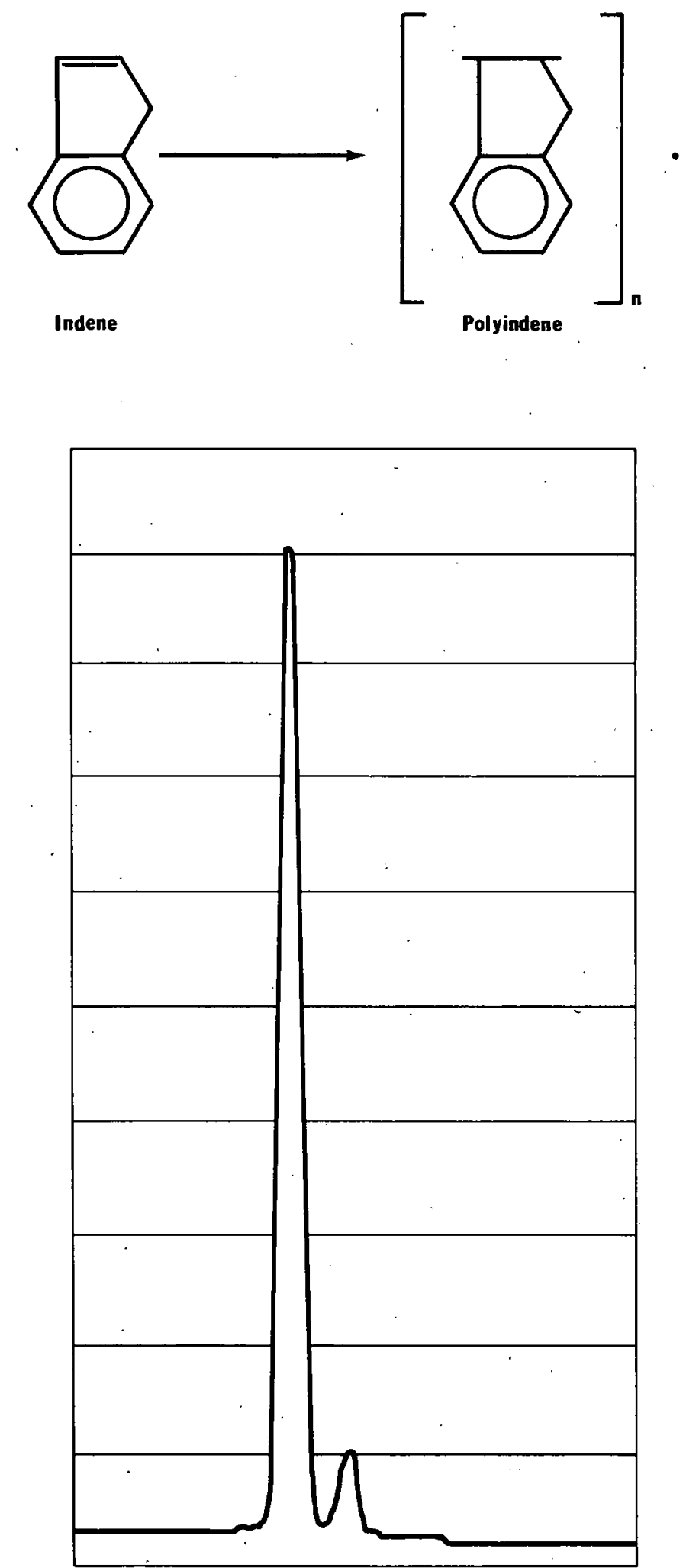

Figure 3. GAS CHROMATOGRAPHIC SCAN OF A COMMERCIAL GRADE OF INDENE. 
A series of indene samples were polymerized with several acid catalysts $\left[\mathrm{eg}, \mathrm{BF}_{3} \cdot\left(\mathrm{C}_{2} \mathrm{H}_{5}\right)_{2} \mathrm{O}, \mathrm{H}_{2} \mathrm{SO}_{4}\right.$, and $\left.\mathrm{SnCl}_{4}\right]$. The procedure consisted of dissolving the samples in benzene followed by a slow addition of this solution into a well-agitated solution of benzene containing the acid catalyst. The more or less viscous solution that resulted was added slowly with stirring to an equal volume of methanol in order to free the product from monomer and lowmolecular-weight resinous products by precipitation. Collection of the product was made by filtration if it was a solid; by decantation if it was semisolid. The process of dissolution in benzene and reprecipitation with methanol was repeated for additional purification.

Data on the polymeric products obtained by acid catalysis are reported in Table 2. The molecular distribution of a typical product (Sample 2, Table 2) is shown in Figure 4. The IR spectra in Figure 1 allow a comparison to be made of the absorption characteristics of indene in the monomeric and polymeric forms. The degree of polymerization, as indicated by the average molecular weights listed in Table 2, varied with the type of catalyst. The highest-molecularwoight polymers $(6,4,000)$ were produced by using the boron trifluoride derivative $\left[\mathrm{BF}_{3} \cdot\left(\mathrm{C}_{2} \mathrm{H}_{5}\right)_{2} \mathrm{O}\right]$, while the lowest $(\mathrm{N}, 000)$ resulted from the use of sulfuric acid. Polymers of intermediate molecular weights $(2,000)$ were obtained when the chlorides of titanium and tin were used. The average molecular weights resulting through the use of a single catalyst were inversely proportional to the initial concentration of indene in the benzene solutions, as more dilute solutions yielded higher-molecular-weight products. Though not evaluated, theory would predict an inverse relationship between the average molecular weight and the temperature at which the polymerization was carried out since, for a given number of monomer molecules, more chain reactions should be initiated per unit time as the temperature increased. Thus, each polymeric chain would be correspondingly smaller. (10)

Table 2

DATA ON THE POLYMERIZATION OF INDENE IN THE PRESENCE OF ACID CATALYSTS

\begin{tabular}{ccclc}
\hline $\begin{array}{c}\text { Sample } \\
\text { Number }\end{array}$ & $\begin{array}{c}\text { Indene } \\
\text { Volume } \\
(\mathrm{m} / \mathrm{s})\end{array}$ & $\begin{array}{c}\text { Benzene } \\
\text { Volume } \\
(\mathrm{m} / \mathrm{s})\end{array}$ & \multicolumn{1}{c}{ Catalyst $(1)$} & $\begin{array}{c}\text { Average } \\
\text { Molecular } \\
\text { Weight(2) }\end{array}$ \\
\hline & 100 & 100 & $\mathrm{SnCl}_{4}$ & 1,799 \\
1 & 50 & 100 & $\mathrm{SnCl}_{4}$ & 1,838 \\
2 & 100 & 100 & $\mathrm{TiCl}_{4}$ & 1,568 \\
3 & 100 & 200 & $\mathrm{TiCl}_{4}$ & 2,154 \\
5 & 100 & 100 & $\mathrm{H}_{2} \mathrm{SO}_{4}$ & 982 \\
6 & 50 & 100 & $\mathrm{H}_{2} \mathrm{SO}_{4}$ & 1,323 \\
7 & 100 & 100 & $\mathrm{BF}_{3} \cdot\left(\mathrm{C}_{2} \mathrm{H}_{5}\right)_{2} \mathrm{O}$ & 4,057 \\
8 & 50 & 100 & $\mathrm{BF}_{3} \cdot\left(\mathrm{C}_{2} \mathrm{H}_{5}\right)_{2} \mathrm{O}$ & 4,225 \\
\hline
\end{tabular}

(1) Two milliliters of the catalyst were used for each sample.

(2) Molecular weights determined by vapor pressure osmometry. 


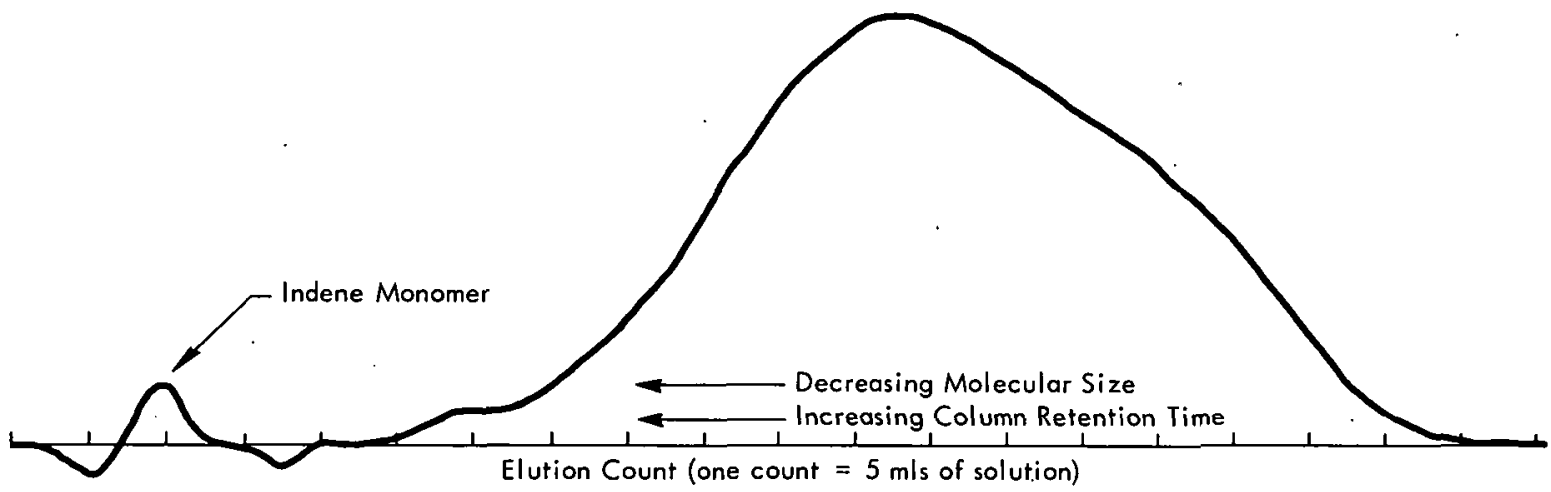

Figure 4. Gel PERMEATION ChROMATOGRAPHIC SCAN OF POLYINDENE. (See Somple 2, Table 2)

Pyrolysis of these polyindene samples at atmospheric pressure resulted in low coke yields $(10-15 \%)$. The low yields are believed to be due to the production of essentially volatile fragments on thermal degradation of the polymer. This behavior is analogous to that of other olefinic-type polymers such as polyethylene and polystyrene. Therefore, this polymeric form of indene does not appear to be a desirable carbon procursor material when restricted to carbonization under atmospheric pressures.

\section{Vinylation of Indene and Polyindene}

Incorporation of vinyl groups into the molecules of indene and polyindene was used as a method of inducing crosslinking into polymeric systems in order to reduce loss on heating through thermal degradation and volatilization. As reported elsewhere in the literature, ${ }^{(11)}$ compounds containing active methylene groups will react with acetylene under pressure to produce vinylated derivatives, as shown for indene in the following equation:

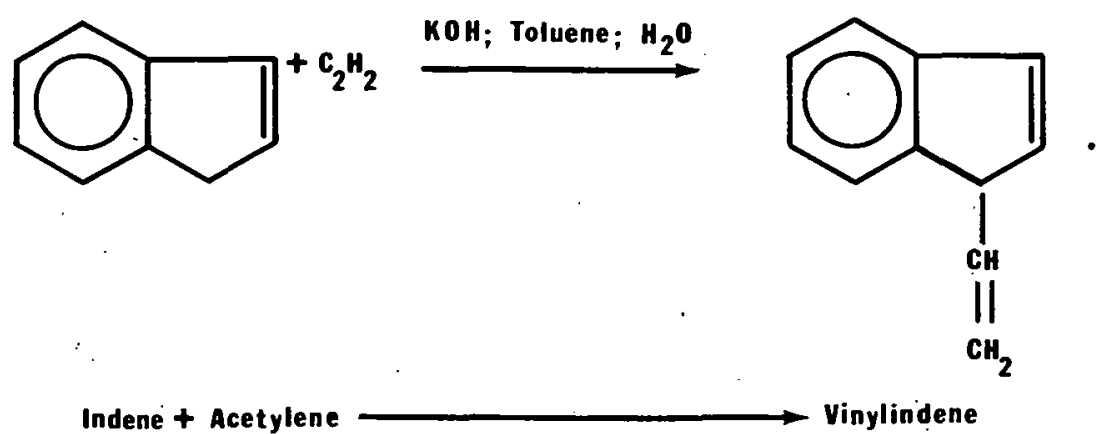

Reactions of acetylene with indene and polyindene were carried out in a twoliter autoclave at temperatures between $150-250^{\circ} \mathrm{C}$ and pressures of 400 700 psi. In practice, the autoclave, which was located behind a sandbagged 
barrier with external valving and electrical controls, was charged with indene (or polyindene), toluene, potassium (or sodium) hydroxide, and water. The system was well purged with nitrogen prior to pressurization with acetylene, then the charge was heated with stirring for periods ranging from 5 to 20 hours. On cooling, the residual gases were vented and the system again purged with nitrogen prior to opening the pressure vessel. This procedure yielded a reaction mixture consisting of a tolvene solution of various hydrocarbon derivatives of indene, and an insoluble residue of potassium (or sodium) acetate. (The acetate was formed by oxidation of the acetylene.) Experiments indicated that the acetate salts did not promote the vinylation reaction. Removal of the salts by filtration or water wash left a hydrocarbon solution from which the solvent (toluene) was removed by evaporation under vacuum. Data on these reactions and the resulting reaction products are listed in Table 3.

Toble 3

REACTION PRODUCTS RESULTING FROM THE REACTION OF INDENE AND ACETYLENE

\begin{tabular}{|c|c|c|c|c|c|c|c|c|}
\hline $\begin{array}{c}\text { Batch } \\
\text { Number }(1)\end{array}$ & $\begin{array}{c}\text { Initial } \\
\text { Acetylene } \\
\text { Pressurie (2) } \\
\text { (psi) } \\
\end{array}$ & $\begin{array}{c}\text { Reaction } \\
\text { Temperature } \\
\left({ }^{\circ} \mathrm{C}\right)\end{array}$ & $\begin{array}{c}\text { Maximum } \\
\text { Reaction } \\
\text { Pressure } \\
\text { (psi) } \\
\end{array}$ & $\begin{array}{l}\text { Final } \\
\text { Reaction } \\
\text { Pressure } \\
\text { (psi) } \\
\end{array}$ & $\begin{array}{l}\text { Residual } \\
\text { Pressure } \\
\text { at } \\
\text { Ambient } \\
\text { Conditions } \\
\text { (psi) } \\
\end{array}$ & $\begin{array}{c}\text { Reaction } \\
\text { Time } \\
\text { (hrs) }\end{array}$ & $\begin{array}{c}\text { Average } \\
\text { Molecular } \\
\text { Weight }\end{array}$ & $\begin{array}{l}\text { Calculated } \\
\text { Molecular } \\
\text { Weight(3) } \\
\end{array}$ \\
\hline $10-13-68$ & 264 & 210 & 440 & 367 & 142 & 11.0 & 331 & 348 \\
\hline $10-17-68$ & 200 & 210 & 402 & 255 & 110 & 21.0 & 338 & 327 \\
\hline $10-18-68$ & 200 & 215 & - & 284 & 106 & 5.0 & 406 & 379 \\
\hline $10-20-68(4)$ & 200 & 205 & 400 & 194 & 40 & 5.5 & $194(5)$ & 189 \\
\hline $10-21-68$ & $150(6)$ & 215 & 250 & 183 & 35 & 6.0 & $256(5)$ & 264 \\
\hline $10-22-68(7)$ & $200(6)$ & 215 & - & 238 & 62 & 10.0 & 954 & - \\
\hline $10-29-68$ & 200 & 210 & 427 & 313 & .128 & 9.0 & 304 & 340 \\
\hline $10-47-68(8)$ & - & 200 & - & - & - & 5.0 & 198 & 173 \\
\hline
\end{tabular}

(1) Reactions were carried out in a one-liter autoclave that contained 29 gms indene, 4.5 gms potassium hydroxide. $1.5 \mathrm{mls}$ water, and $200 \mathrm{~m} / \mathrm{s}$ tolvene.

(2) Pressure before heating; pressurized while stirring.

(3) Calculations based on the weighted average of the masses indicated in GPC scans.

(4) Sodium hydroxide $(3.2 \mathrm{gms})$ used rather than potassium hydroxide.

(5) Gas chromatography indicated 50 percent residual indene.

(6) Pressurized without stirring.

(7) Polyindene (average molecular weight $=1,838$ ) used rather than monomer.

(8) Acetylene was omitted from this reaction.

Indene, vinylindene, and low-molecular-weight polymers of these two compounds were the components of the hydrocarbon mixture resulting from the vinylation of indene. Analysis by mass spectrometer indicated that material of Masses 258 and 284 were present in addition to Masses 116 (indene), 142 (vinylindene), and 92 (residual tolvene). Mass 258 corresponds to a dimeric molecule composed of indene and vinylindene, while Mass 284 corresponds to a dimer of vinylindene. Higher masses were not determined, but the presence of higher-molecular-weight 
products was indicated by the data in Table 3 and by the molecular distributions obtained on analysis by gel permeation chromatography (GPC).

To determine the behavior of indene under reaction conditions that omitted acetylene, a "blank" reaction (Batch 10-47-68, Table 3) was staged in which nitrogen' rather than acetylene was used to pressurize the vessel. As shown by the molecular distribution in Figure 5 , these conditions produced a polymeric mixture with a significant dimer content (17\%) and smaller quantities of highermolecular-weight products. The inclusion of acetylene, however, increased greatly the degree of polymerization since vinylindene is less stable to polymerization conditions than indene. This fact was apparent from the molecular weight data in Table 3 and from the molecular distribution shown in Figure 6 which includes mass assignments of the various fractions represented. The mass range assigned each molecular species (eg, monomer or dimer) included the possibility that molecules of that species may be composed of indene, vinylindene, or a combination of these materials. These mass assignments receive some support from the molecular weight data in Table 3 , which allows a comparison of the average molecular weights with the computed molecular weights based on the distributions obtained from GPC scans. The mass assignments shown in Figure 6 also lend support, assuming that indene and vinylindene are distributed equally in each fraction.

Though the latter assumption was not proven, some data on the distribution within the monomer fraction were obtained by correlating GPC data with the

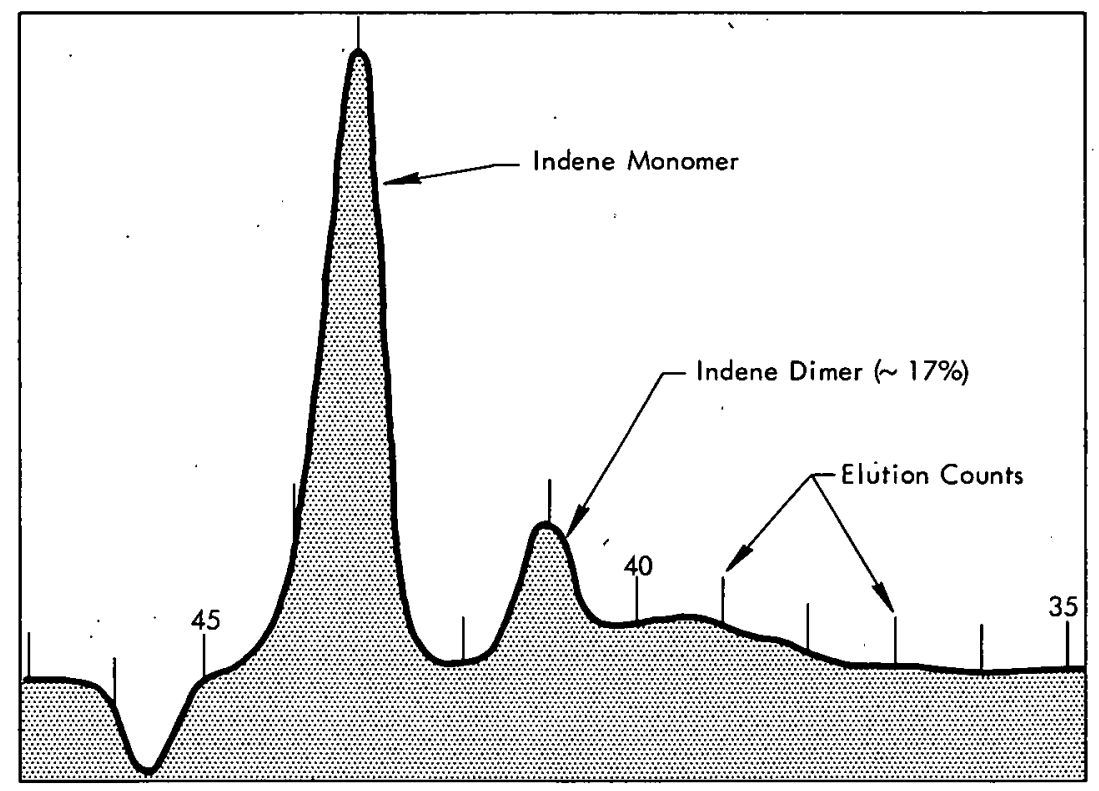

(one elution count $=5 \mathrm{mls}$ of solution)

Figure 5. GEL PERMEATION CHROMATOGRAPHIC SCAN OF HEAT-TREATED INDENE. (Batch 10-47-68) 


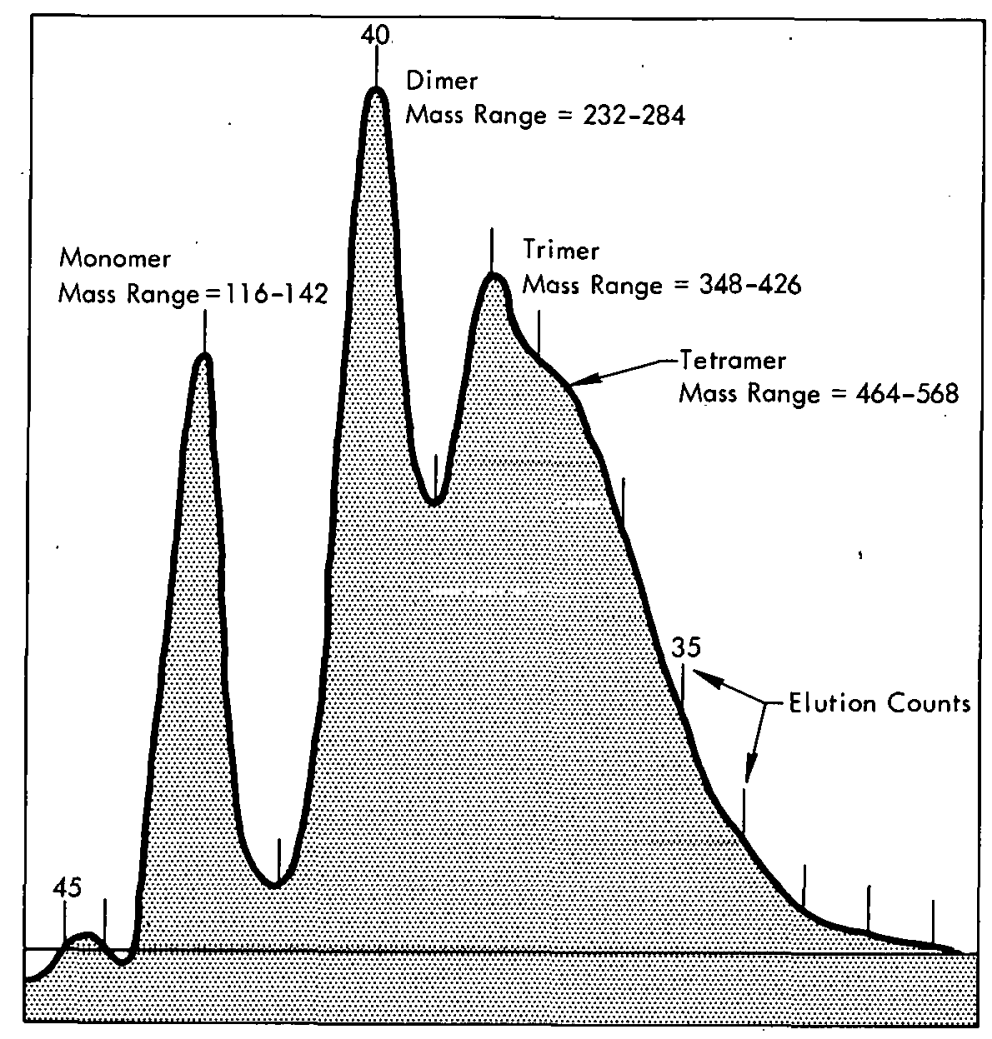

(one elution count $=5 \mathrm{mls}$ of solution)

Figure 6. GEL PERMEATION CHROMATOGRAPHIC SCAN OF A VINYLATED INDENE PRODUCT MIXTURE. (Batch 10-13-68)

results obtained by using GC techniques. The total monomer content in a given sample can be determined by GPC, but resolution of similar molecules such as indene and vinylindene is not possible. However, GC allowed an approximation of the indene content in a sample by comparing the instrument response with that of a standard indene sample of equal volume since vinylindene and highermolecular-weight materials did not elute. Vinylindene appeared to be unstable when in contact with column substrates at temperatures of $\sim 180^{\circ} \mathrm{C}$. With the exception of Batches 10-20-68 and 10-21-68, the vinylated products listed in Table 3 showed little or no indene content when analyzed by GC, and indicated that the majority of the monomeric content was vinylindene. Analysis by GC indicated that a significant indene content ( $50 \%$ ) was present in Batches 10-20-68 and 10-21-68, the molecular distributions of which can be seen in Figures 7 and 8 , respectively. In the former experiment, sodium hydroxide was used rather than potassium hydroxide. The latter experiment employed a lower acetylene pressure than that used in the other experiments.

Evaporation of the solvent (toluene) from the mixtures of vinylated indene derivatives leaves a pliable resin which slowly cures on exposure to air in a 


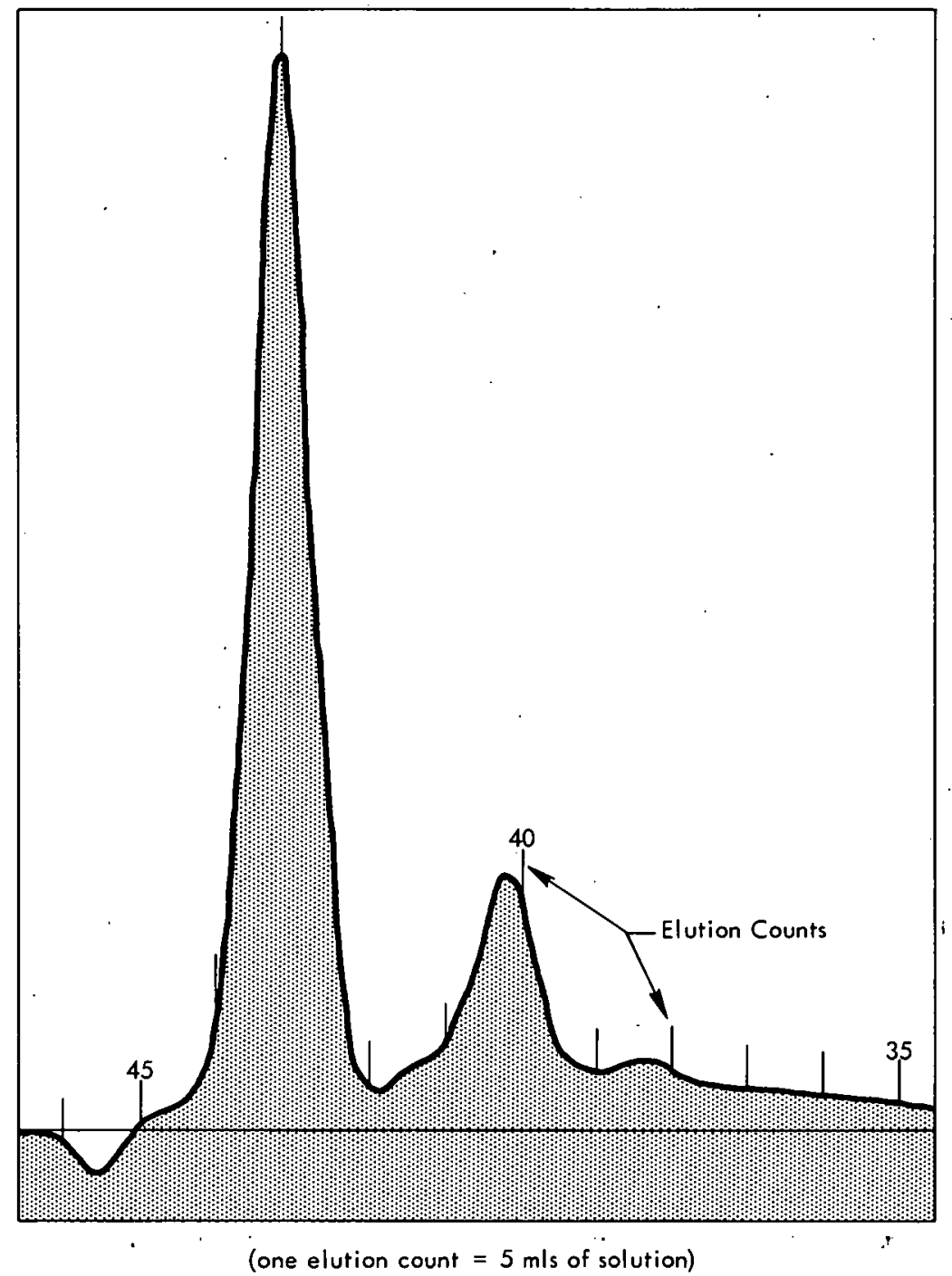

Figure 7. GEL PERMEATION CHROMATOGRAPHIC SCAN OF A VINYLATED INDENE PRODUCT MIXTURE. (Batch 10-20-68)

manner analogous to drying oils, making the mixture amenable to the formation of surface films.

A sample of polyindene, the molecular distribution of which is indicated in $F$ igure 4 , was reacted with acetylene in a manner identical to that described for indene. Data for this reaction (Batch 10-22-68) are included in Table 3. The average molecular weight of the vinylated product (954) indicated some degradation of the polymer during the reaction since the average molecular weight of the starting material was 1,838 . The uptake of acetylene indicated that the degradation was accompanied by vinylation. In subsequent experiments, samples of polyindene (average molecular weight $=1,268$ ) were heated under acetylene pressures at 150,200 , and $250^{\circ} \mathrm{C}$ in order to correlate the degree of polymer degradation with 


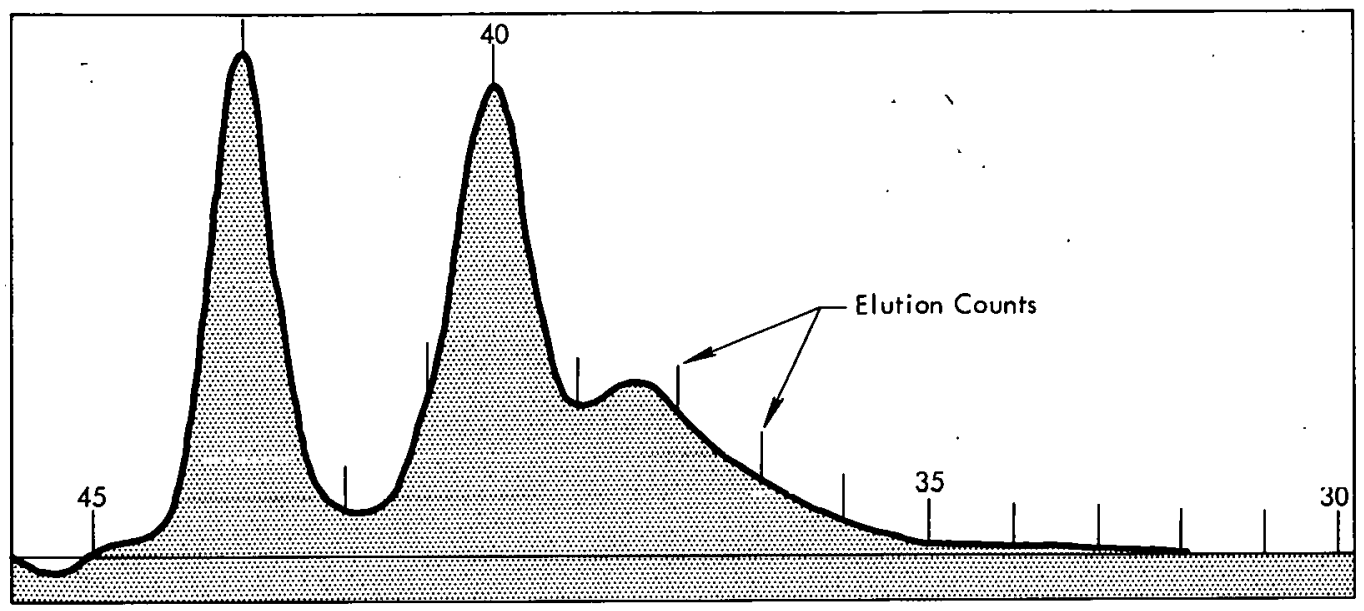

(one elution count $=5 \mathrm{mls}$ of solution)

Figure 8. GEL PERMEATION CHROMATOGRAPHIC SCAN OF A VINYLATED INDENE PRODUCT MIXTURE. (Batch $10-21-68)$

the reaction temperature. Average molecular weights of the products were 967, 786 , and 452 , respectively.

Coke yields of both indene and polyindene were enhanced by vinylation. One product mixture obtained on vinylation of indene (Batch 10-17-68) had a coke yield of 27 percent. Increases in the coke yield of polyindene on vinylation were more significant as a value of 45 percent was obtained, compared to $10-15$ percent prior to the vinylation reaction.

In summary, higher acetylene pressures produced greater conversion of indene to vinylindene, and an increased polymeric content due to the instability of the vinylated product. This same trend was observed when potassium hydroxide rather than sodium hydroxide was used in the reaction formulation. The degree of polymerization can be followed not only by GPC analysis, but is also indicated by comparing the intensities of the $\mathrm{C}-\mathrm{H}$ stretch frequencies in the range of $3,100-2,800 \mathrm{~cm}^{-1}$ for aromatic, vinyl, and aliphatic bonding as the intensity of the aliphatic stretch frequency increases with increasing degree of polymerization. IR spectra of two samples of varying molecular weights may be compared in Figure 9. The increased coke yields that were obtained after vinylation of indene and polyindene show that the process of vinylation is a useful method of inducing crosslinking into polymeric systems.

Synthesis of Diene Compounds by Reactions of Indene with Halogenated Hydrocarbons

Compounds having diene-type structures were synthesized by incorporating one or more indene molecules into large molecular units. These derivatives of indene 
were prepared by reacting indenyllithium $(\mathrm{C} g \mathrm{H} 7 \mathrm{Li})$ with molecules containing one or more atoms of bromine. The reaction sequence used in the preparation of $\underline{p}$-xylyleneindene typifies this approach, and is:

2<smiles>[Tl]C1C=Cc2ccccc21</smiles><smiles>Cc1ccc(Br)cc1</smiles><smiles>Cc1ccc(C2(N)C=Cc3ccccc32)cc1</smiles>

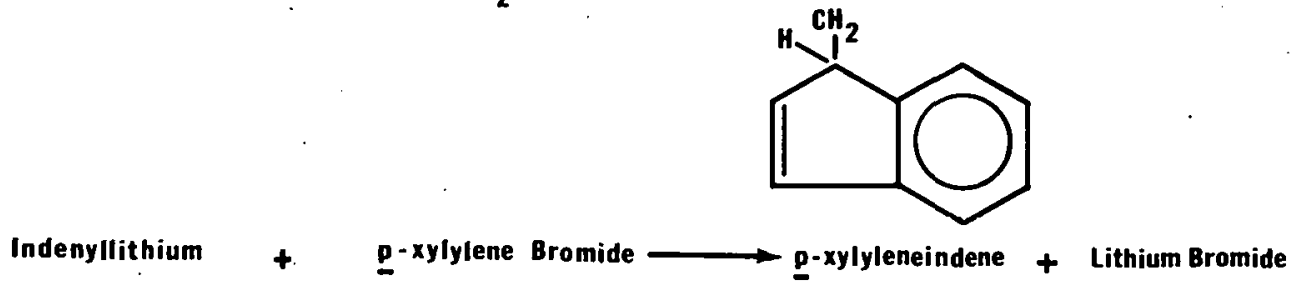

Allylindene and 1,2-diindenylethane were prepared in like manner from allyl bromide and ethylene bromide, respectively. Their structural formulas are:

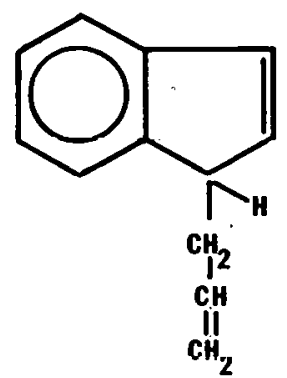

1 - allylindene<smiles>CC1C=Cc2ccccc21</smiles><smiles>CCC1C=Cc2ccccc21</smiles>

1.2 - diindenylethane

Descriptions of the synthetic procedures used are given in the subsections that follow, and data on the reactants and products are included in Table 4.

Preparation of Indenyllithium ( $\mathrm{C} 9 \mathrm{H} 7 \mathrm{Li}$ ) - Solutions of indenyllithium in tetrahydrofuran (THF) were used as intermediates in preparing derivatives of indene 


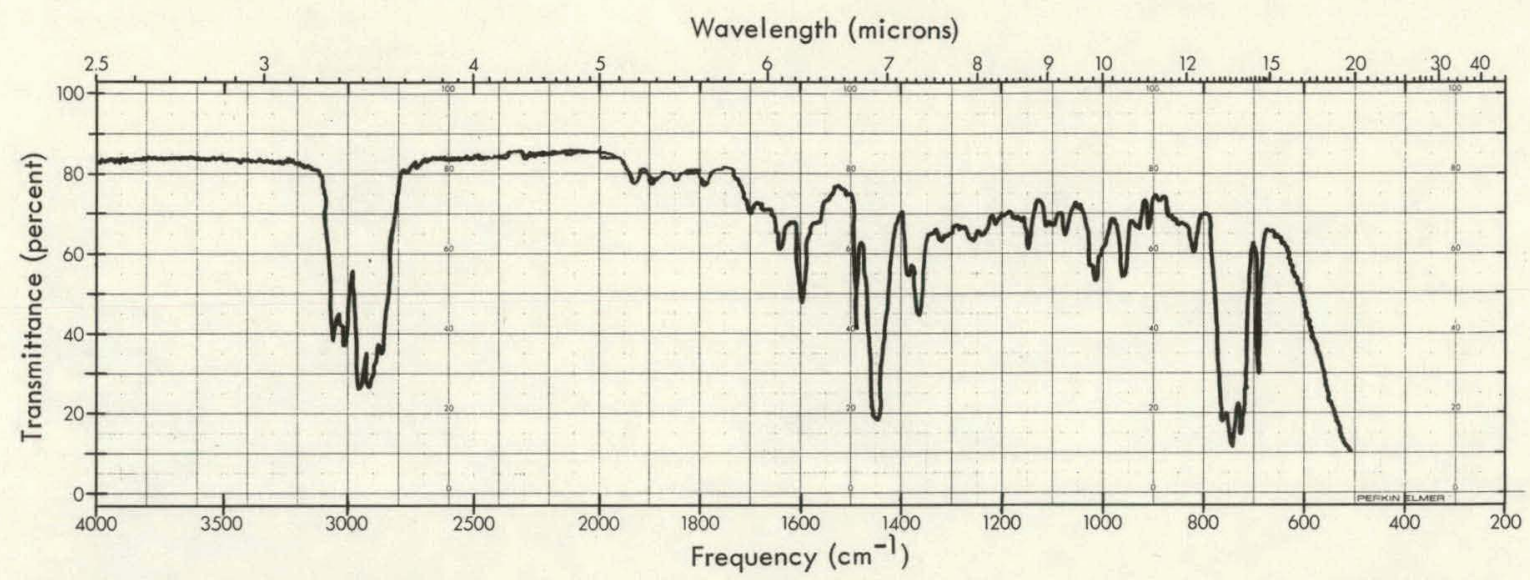

(a) Batch $10-18-68$ (av mol wt $=406)$

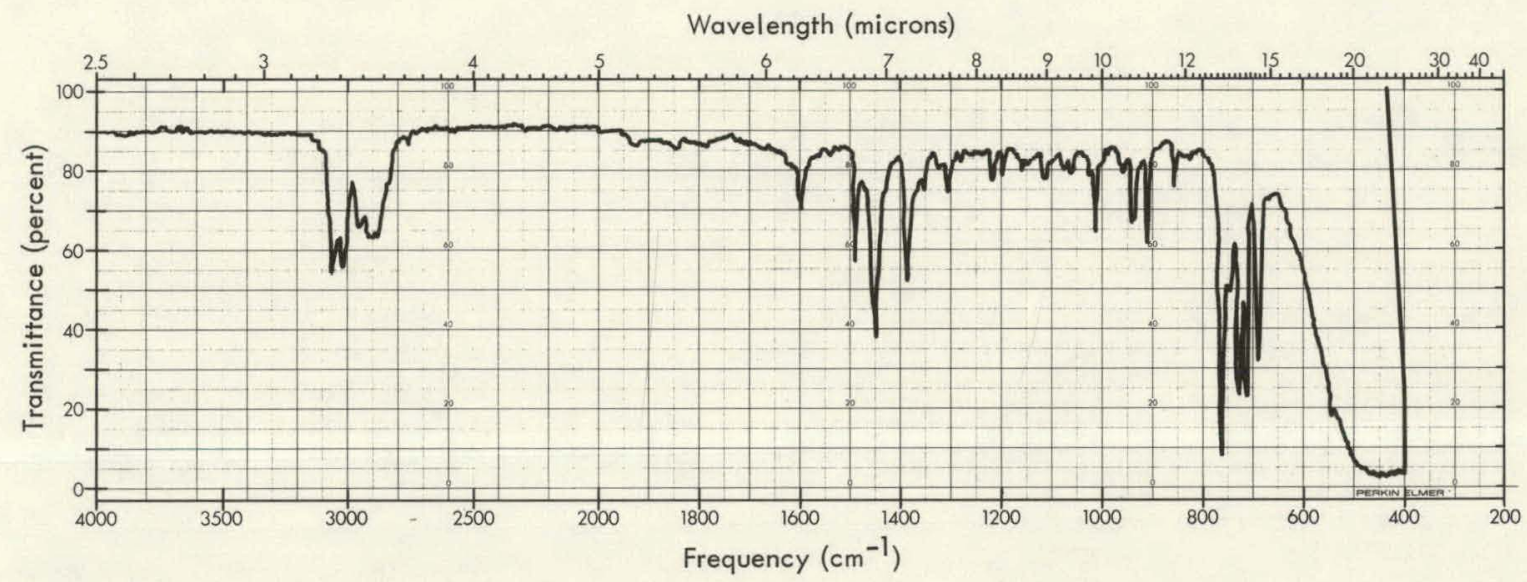

(b) Batch 10-20-68 (av mol wt = 194)

Figure 9. INFRARED SPECTRA OF VINYLATED INDENE DERIVATIVES.

from brominated hydrocarbons. These THF solutions of indenyllithium were prepared by adding, dropwise, benzene solutions of butyllithium $\left(\mathrm{C}_{4} \mathrm{H}_{9} \mathrm{Li}\right)$ to an equimolar quantity of indene in THF. The reaction sequence is:

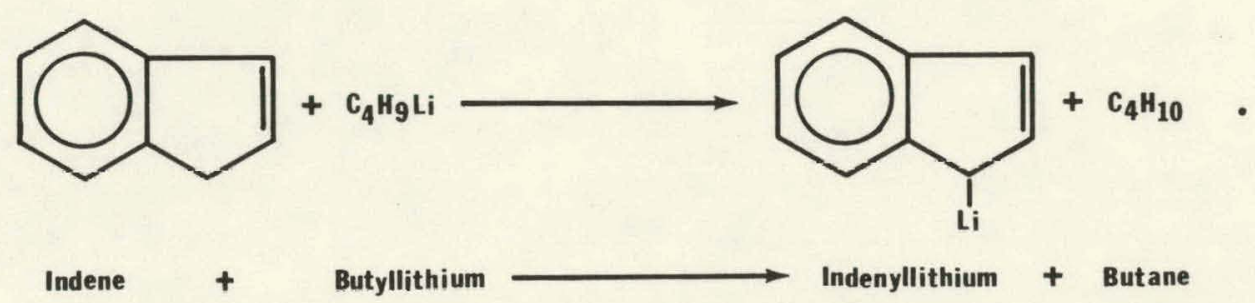

The reaction is exothermic, but the generation of heat may be controlled by controlling the drop rate of butyllithium, or by providing external cooling. These solutions of indenyllithium were used without additional treatment. 
THIS PAGE

WAS INTENTIONALLY

LEFT BLANK 
Table 4

DATA ON THE SYNTHESIS OF DIENE COMPOUNDS INCORPORATING INDENE

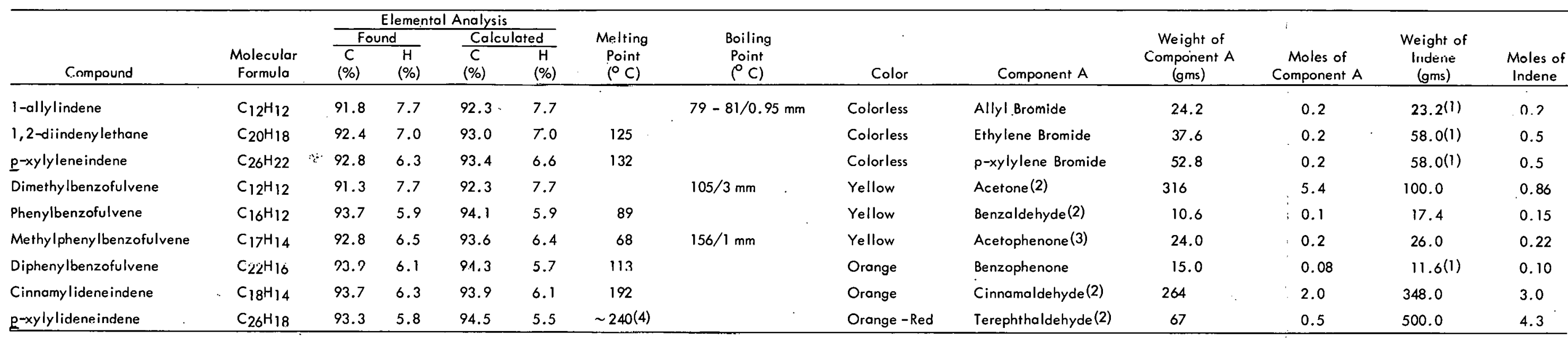

(1) Indene was initially converted to indenyllithium prior to its reaction with Component $A$ compounds.

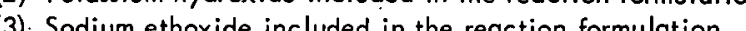

(4) Muterial polymerizes without melting an slow heating, but is observed to fuse prior to resinification when instantaneously heated to $240^{\circ} \mathrm{C}$. 
Synthesis of 1-allylindene $\left(\mathrm{C}_{12} \mathrm{H}_{12}\right)$ - Allylindene was prepared by adding indenyllithium (via a THF solution as previously described) to an equimolar quantity of allkyl bromide in THF (24.2 gms allyl bromide per $50 \mathrm{cc}$ THF) and allowing the mixture to stir at room temperature for 16 hours. The mixture was added to water, neutralized, and the organic portion extracted with benzene. The extract was washed with water and dried over molecular sieves. Excess solvent was evaporated and the residue fractionally distilled under vacuum to produce a colorless liquid ( $42 \%$ yield; bp $=79-81^{\circ} \mathrm{C} / 0.95 \mathrm{~mm}$ ).

Synthesis of 1,2-diindenylethane $\left(\mathrm{C}_{20} \mathrm{H}_{18}\right)$ - Preparation of 1,2-diindenylethane was accomplished by the addition of a double molar quantity of indenyllithium (via the THF solution) to ethylene bromide $\left(\mathrm{CH}_{2} \mathrm{BrCH} 2 \mathrm{Br}\right)$ dissolved in THF ( $37.6 \mathrm{gms}$ of the bromide per $100 \mathrm{mls}$ of THF), followed by heating $\left(-50^{\circ} \mathrm{C}\right.$ ) for 16 hours. The reaction mixture was poured into water and subsequently neutralized. The organic phase was extracted with benzene, then the extract was washed and subsequently dried over molecular sieves. Evaporation of the solvent and recrystallization of the residue from benzene returned an off-white product ( $30 \%$ yield) having a melting point of $125^{\circ} \mathrm{C}$.

Synthesis of p-xylyleneindene $\left(\mathrm{C}_{26} 6 \mathrm{H}_{22}\right)$ - Indenyllithium $(0.5$ mole $)$ was added dropwise at room temperature (via a THF solution) to $p$-xylylene bromide ( 52.8 gms) in 100 milliliters of THF. After the addition was completed, the reaction 'mixture was warmed $\left(50^{\circ}\right.$ C) for 16 hours, then poured into water. After neutralization, the mixture was extractod with benzene, lien the extract washed with water and dried over molecular sieves. On evaporation of the solveril, the crystalline residue, representing greater than the theoretical yield due to the absorption of indene, was observed to melt at $125-130^{\circ}$ C. Recrystallization from hot benzene produced a colorless crystalline product that melted at $132^{\circ} \mathrm{C}$.

To summarize, the hydrocarbon materials that were formed by the reaction of indenyllithium with brominated hydrocarbons incorporated a diene-type structure although the unsaturated bonding was not in conjugation. The latter fact is substantialed by the fact that these products are colorless, whereas bonding that is conjugated with the unsaturated bond in the five-member ring of the indene molecule imparts color. Residual carbon obtained on pyrolysis of allylindene represented a yield of approximately 11 percent; that of $p$-xylyleneindene and 1,2diindenylethane was in the range of $30-35$ percent. Optimum polymerization and carbonization conditions for these materials were not determined, but the use of these materials as crosslinking agents in carbon precursor mixtures seems plausible. 
Synthesis of Benzofulvene Compounds by Reactions of Indene with Carbonyl Compounds

Various derivatives of benzofulvene were prepared by the reaction of indene with carbonyl compounds. The structure of the parent compound is:

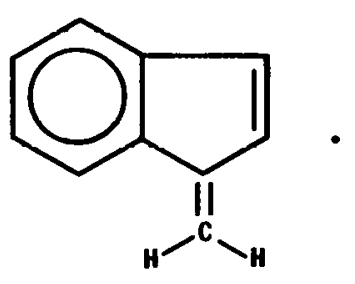

The reactions involve an aldol-type condensation between methylene and the carbonyl groups, $(12)$ producing unsaturated bonding in conjugation with that in the indene portion of the molecule. The reaction sequence for acetone is:

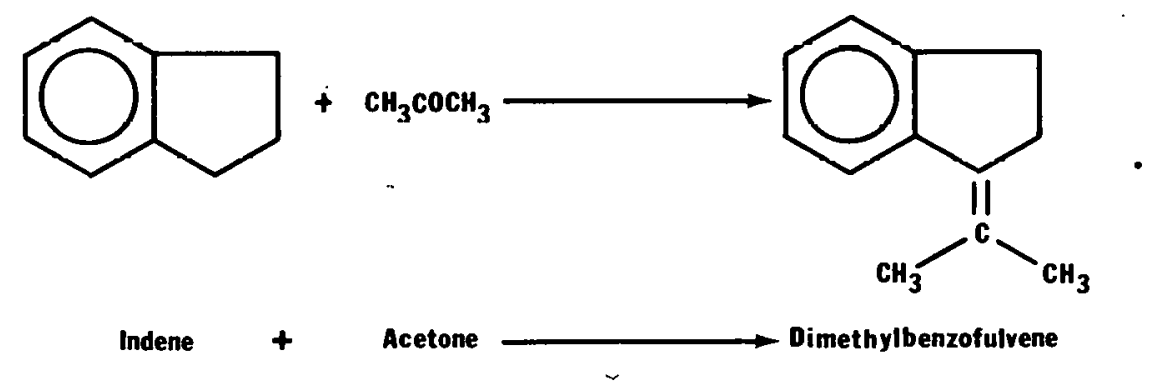

In general, these materials have lower vapor pressures and greater unsaturation than indene, both of which are favorable toward the production of carbon residues on pyrolysis.

In addition to acetone, indene was reacted with benzaldehyde, acetophenone, benzophenone, cinnamaldehyde, and terephthaldehyde. Some of the carbonyl compounds, especially benzaldehyde and cinnamaldehyde, promoted formation of a secondary product by the reaction of the carbonyl groups at both Positions 1 and 3 of the indene molecule. For benzaldehyde, $(4,5)$ the product is: 


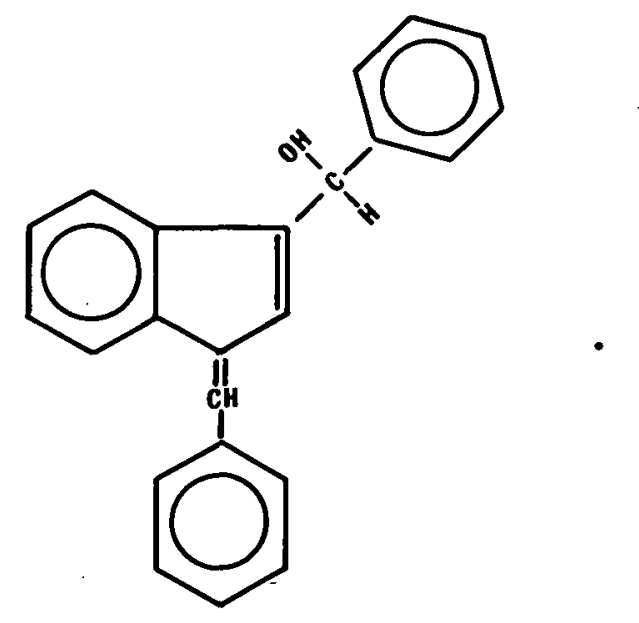

Experiments indicated that a slow addition of the carbonyl compound to an excess of indene decreased the amount of contamination from this secondary reaction. Data on the preparation of various benzofulvene derivatives are included in Table 4; descriptions of the synthetic procedures are given in the subsections that follow.

Synthesis of Dimenthylbenzofulvene $\left(\mathrm{C}_{12} \mathrm{H} 12\right)$ - Dimenthylbenzofulvene ${ }^{(5)}$ was prepared by the reaction of indene and acetone in the presence of potassium hydroxide. In practice, methanolic potassium hydroxide $(6 \mathrm{gms} \mathrm{KOH}$ in $20 \mathrm{mls}$ $\mathrm{CH}_{3} \mathrm{OH}$ ) was added to a solution of indene (100 gms) and acetone (316 gms), and the mixture heated under reflux for two hours. The cooled reaction mixture was poured into water, then the organic layer was separated, neutralized, washed with water, and allowed todry over molecular sieves. The product was recovered (60\% yield) by fractionation under vacuum to produce a light yellow liquid $\left(\mathrm{bp}=105^{\circ} \mathrm{C} / 3 \mathrm{~mm}\right.$; literature ${ }^{(5)}$ gives $\left.142^{\circ} \mathrm{C} / 16 \mathrm{~mm}\right)$.

Synthesis of Phenylbenzofulvene ( $\mathrm{C} 16 \mathrm{H} 12)$ - The preparation of phenylbenzofulvene $(4,13)$ was accomplished by adding benzaldehyde $(10.6 \mathrm{gms}$ dissolved in $\left.100 \mathrm{mls} \mathrm{CH}_{3} \mathrm{OH}\right)$ dropwise to a solution of indene $(17.4 \mathrm{gms})$ and potassium hydroxide (28 gms) in methanol $(200 \mathrm{mls})$. This reaction mixture was stirred at room temperature for 24 hours. The orange-yellow crystalline precipitate that formed was collected by filtration (67\% yield) and was observed to melt at 87 - $89^{\circ} \mathrm{C}$ (literature $(13)$ gives $88^{\circ} \mathrm{C}$ ). Purification may be accomplished by recrystallization from hot ethanol.

Synthesis of Methylphenylbenzofulvene $\left(\mathrm{C}_{\left.17 \mathrm{H}_{14}\right)}\right.$ - Methylphenylbenżofulvene(5) was prepared by adding, dropwise, a solution of acetophenone (24 gms) and indene 
(26 gms) to a boiling ethanol solution containing sodium ethylate (4 gms $\mathrm{Na}$ in $200 \mathrm{mls} \mathrm{C} 2 \mathrm{H} 5 \mathrm{OH}$ ). After heating under reflux for six hours, the mixture was allowed to cool, then was poured into water. The organic layer was separated, neutralized, washed with water, and dried over molecular sieves. The product, recovered ( $20 \%$ yield) by fractional distillation under vacuum, had the appearance of a yellow oil (bp $=156^{\circ} \mathrm{C} / 1 \mathrm{~mm}$; literature ${ }^{(5)}$ gives $\left.178-179^{\circ} \mathrm{C} / 5 \mathrm{~mm}\right)$. Synthesis of Diphenylbenzofulvene $\left(\mathrm{C}_{22} \mathrm{H}_{16}\right)$ - Diphenylbenzofulvene $(5)$ was prepared by using butyllithium which was initially reacted with indene to form indenyllithium. Butyllithium ( $0.1 \mathrm{~mole}$ ) was added (via a $25 \%$ solution of $\mathrm{C} 4 \mathrm{HgLi}$ in $\left.\mathrm{C}_{6} \mathrm{H}_{6}\right)$ dropwise under nitrogen gas to a solution of indene $(11.6 \mathrm{gms}, 0.1$ mole) in tetrahydrofuran ( $100 \mathrm{mls})$. To the resulting solution of indenyllithium was added a solution of benzophenone (15 gms) in tetrahydrofuran (100 m/s). This reaction mixture was heated overnight under reflux. Insoluble salts were removed by filtration and the product recovered by evaporation of the solvent. After recrystallization from hot ethanol, $11.2 \mathrm{gms}$ ( $40 \%$ yield) of an orange-yellow product was isolated and observed to melt at $113^{\circ} \mathrm{C}$ (literature ${ }^{(5)}$ gives $\left.114.5^{\circ} \mathrm{C}\right)$.

Synthesis of Cinnamylideneindene $\left(\mathrm{C}_{18} \mathrm{H}_{14}\right)$ - Cinnamylideneindene $(13)$ was prepared by the dropwise addition of a solution of cinnamaldehyde (264 gms) and methanol $(500 \mathrm{mls})$ to a well-stirred mixture of indene (348 gms), methanol $(2,000 \mathrm{mls})$, and potassium hydroxide $(80 \mathrm{gms})$. Formation of a precipitate was observed in the early stages of the addition period. After completion of the addition, an orange-colored product was collected by filtration ( $60 \%$ yield) and was observed to fuse over a range of temperatures $\left(172-193^{\circ} \mathrm{C}\right)$. Recrystallization of the product from hot benzene resulted in a product melting at $192^{\circ} \mathrm{C}$ (literature ${ }^{(13)}$ gives $190^{\circ} \mathrm{C}$ ). An IR spectrum of the product is seen in Figure 10.

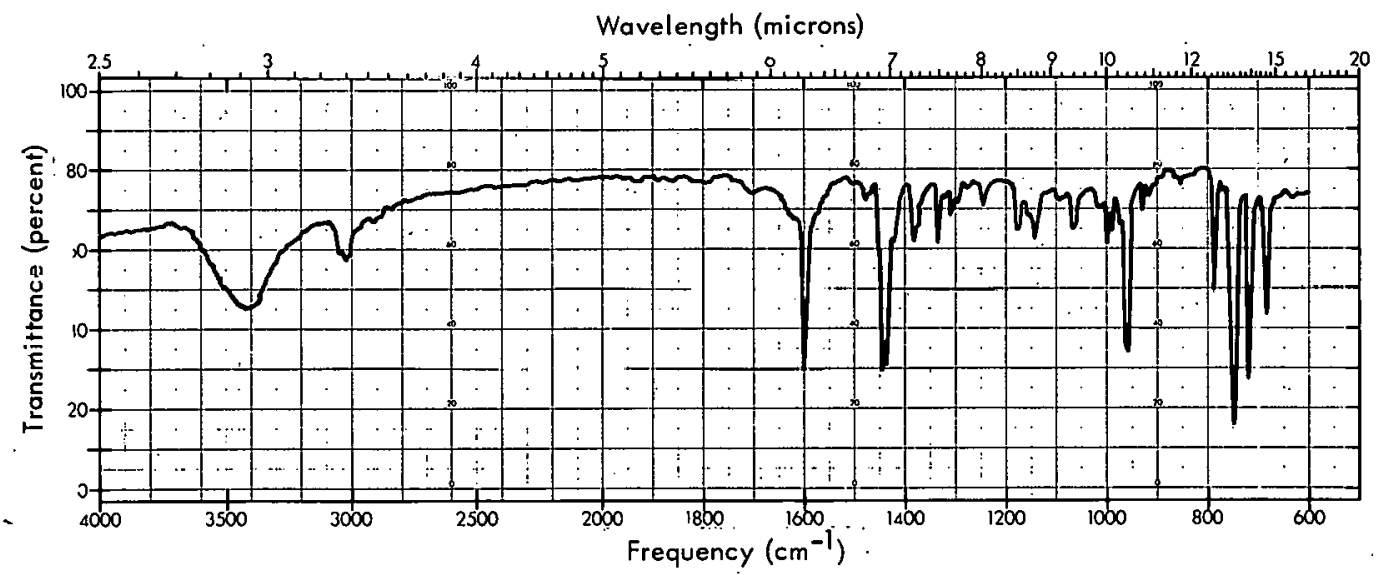

Fioure 10. INFRARED \$PECIIRUM OF EINIVAMYYLIDEIVEINDERVE. (Bulchi 11-03-62A) 
Cinnamylideneindene is sensitive to thermal polymerization conditions and can readily be converted to polymeric resins by heating at temperatures in the range of $200-250^{\circ} \mathrm{C}$. The GPC scans in Figure 11 show the molecular distribution of cinnamylideneindene before and after thermal polymerization. The reactivity is due to the highly conjugated system of unsaturated bonding that exists in a cinnamylideneindene molecule. The reaction for the production of cinnamylideneindene and the structure of the molecule is given by:

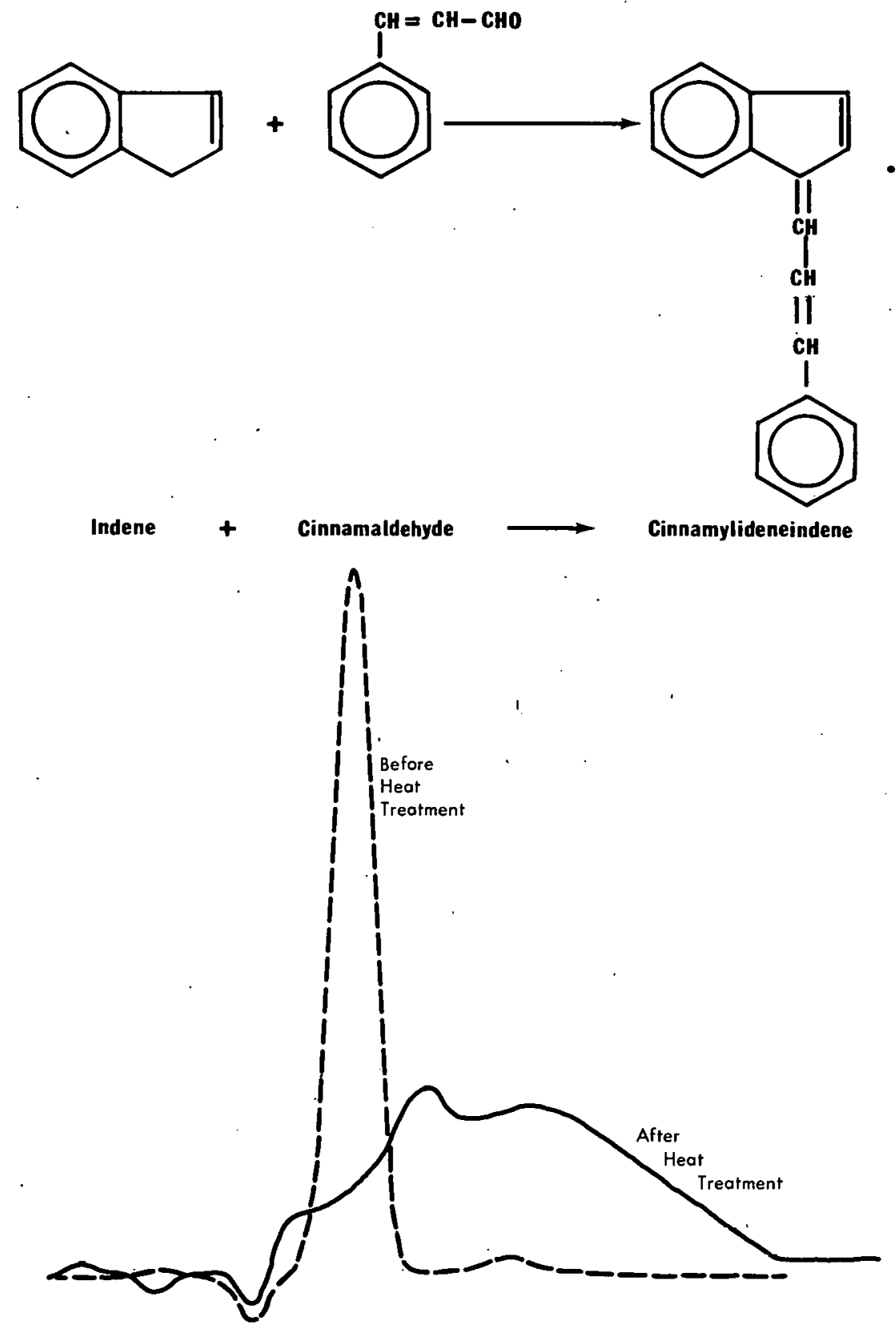

Figure 11. GEL PERMEATION CHROMATOGRAPHIC SCANS OF CINNAMYLIDENEINDENE BEFORE AND AFTER HEAT TREATMENT AT $250^{\circ} \mathrm{C}$ FOR FOUR HOURS. 
Synthesis of $\mathrm{p}$-xylylideneindene $\left(\mathrm{C}_{26} \mathrm{H}_{18}\right)$ - The synthesis of $\mathrm{p}$-xylylideneindene was accomplished by adding, dropwise, a saturated solution of terephthaldehyde $(67 \mathrm{gms})$ in indene to a mixture of potassium hydroxide ( $28 \mathrm{gms}$ ) and methanol $(500 \mathrm{mls})$. The insoluble product was collected by filtration and allowed to dry. Analysis indicated that products formed by this procedure contained approximately three percent oxygen, which probably represented an impurity phase formed by reactions occurring at Position 3 of the indene constituent. This secondary reaction was previously discussed (Page 31). The molecular distribution in Figure 12 shows this impurity phase.

The structure of p-xylylipdeneindene shows a highly conjugated system of unsaturated bonding:

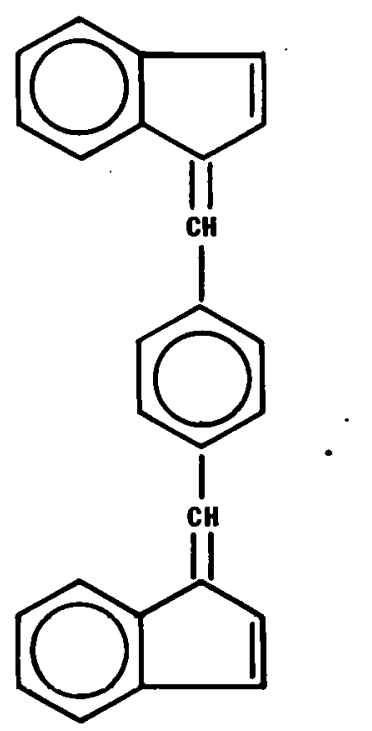

Because of this structure, the compound is highly sensitive to polymerization conditions, as evidenced by the fact that nofusion was observed when the material was heated slowly. When placed on a preheated block at or above $240^{\circ} \mathrm{C}$, the compound was observed to initially fuse and subsequently polymerize. With a prior heat treatment in air, the compound did not fuse, even during pyrolysis. Carbon yields of approximately 75 percent may be realized for $\underline{p}$-xylideneindene.

By way of a summary it can be stated that the carbon yields obtained on pyrolysis of these benzofulvene derivatives were greater than those realized for indene, ranging from 20 percent for dimethylbenzofulvene to 75 percent for $\mathrm{p}$-xylylideneindene. Due to the conjugation of unsaturated bonds, these compounds exhibit colors ranging from yellow to orange. Of the compounds evaluated, cinnamylideneindene and $p$-xylylideneindene appeared to have the greatest potential for use as carbon precursors. 
Synthesis of Isotruxene from Reactions of Indene and 1,4-naphthoquinone

Reactions of indene with quinone compounds were attempted in the presence of various basic catalysts in efforts to duplicate the reactions that indene was observed to undergo with various mono and difunctional aldehyde compounds. The structure of 1,4-diindenylidene-1,4-dihydronaphthalene:

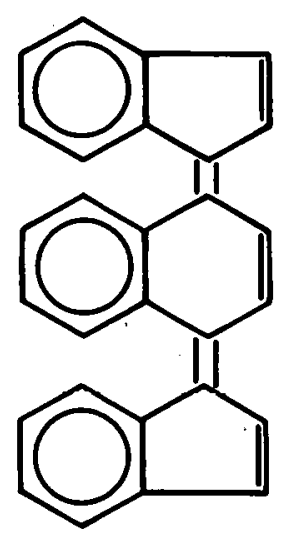

would result from aldol-type condensations at each of the carbonyl groups of 1,4-naphthoquinone, and represents a planar compound having three possible conformations in space.

However, the proposed compound was not isolated when indene and 1,4-napthoquinone were mixed under various reaction conditions, including the use of such bases as: amines, alkali metal hydroxides, sodium ethoxide, and butyllithium. The lack of the desired reaction is indicative of a reduced tendency of quinones to undergo reactions considered typical of carbonyl compounds, such as aldoltype condensations. In this case, sterichinderance would be one inhibiting factor.

Though the proposed product was not isolated, numerous other products were isolated from reaction mixtures incorporating indene, 1,4-naphthoquinone, and an amine. Principal among these products was a material isolated after an extended heating period ( 24 - 48 hours). Though subsequently identified as isotruxene $\left(\mathrm{C}_{2} 7 \mathrm{H}_{18}\right)$, classical methods of analysis did not disprove a tentative identification of the compound as having the theoretical structure previously proposed since the composition and molecular weight of isotruxene (342) and those of the proposed compound $\left(\mathrm{C}_{28} \mathrm{H}_{18} ; 354\right)$ were quite similar. The preparation of isotruxene and characterization of the reaction which produces it are discussed in the subsections that follow. 


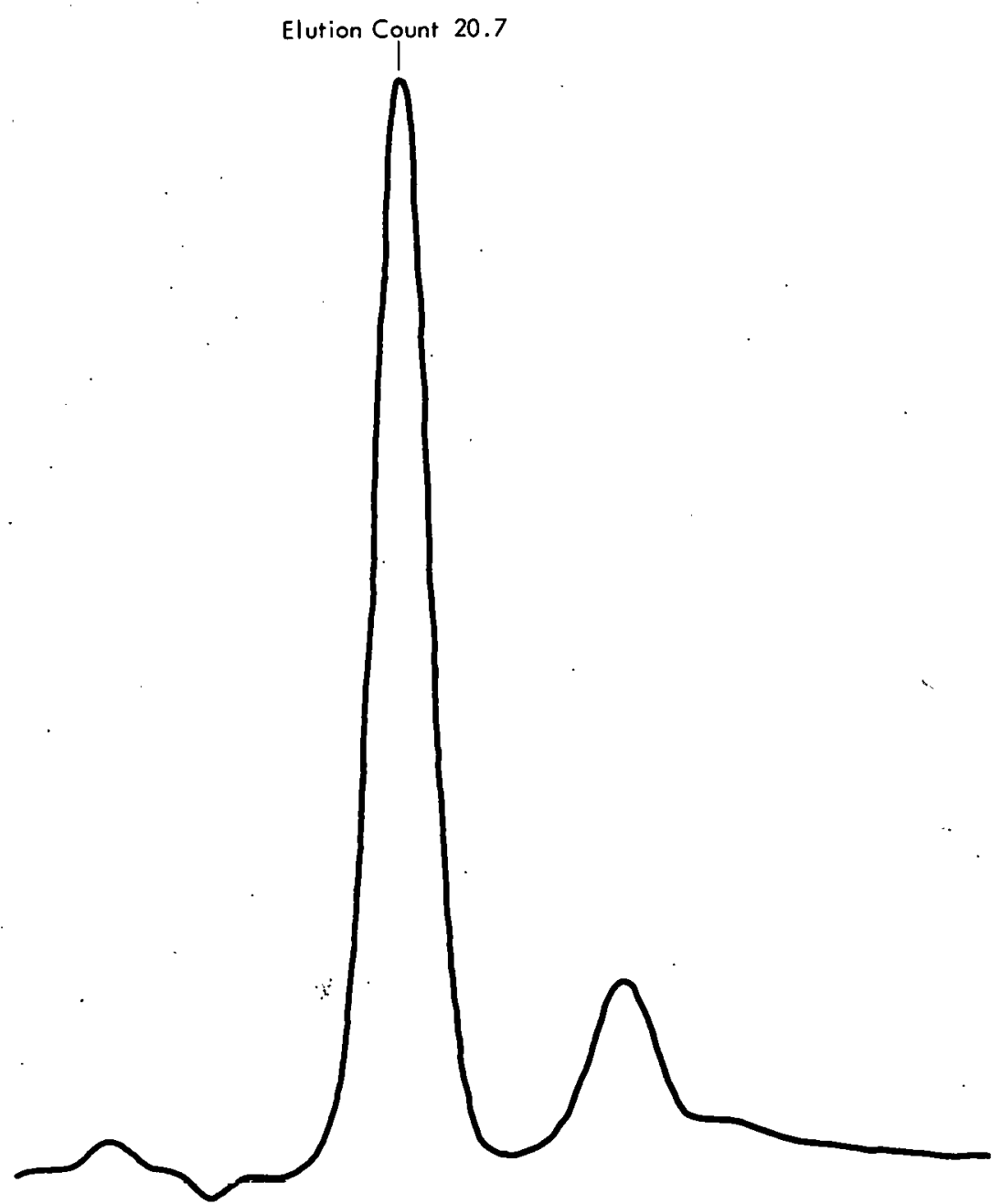

Figure 12. GEL PERMEATION CHROMATOGRAPHIC SCAN OF $p$-XYLINENEINDENE. (Botch 7-43-67)

Preparation Procedure - Isotruxene was prepared from a reaction mixture of indene, 1,4-naphthoquinone, and N,N, $N^{\prime}, N^{\prime}$-tetramethyl-1,3-butanediamine (TMBDA). Indene (100 parts) and TMBDA (1 part) were mixed in a flask equipped with a motor-driven stirrer, a condenser with a trap for collecting water, a thermometer, and a gas inlet to allow an inert-gas sweep as the reaction proceeded. A diagram of the apparatus used is presented in Figure 13. To the mixture of indene and TMBDA was added 1,4-naphthoquinone (10 parts), and the combined mixture was thoroughly blended prior to the application of heat. The reaction mixture was subsequently heated under reflux $\left(180^{\circ} \mathrm{C}\right)$ for periods ranging from 24 to 40 hours. Water was observed to collect in the trap during the initial stages of the heating period, with the major portion collecting during the initial one to two hours. At the conclusion of the heating period, the molten mixture was transferred to a beaker and, on cooling to 


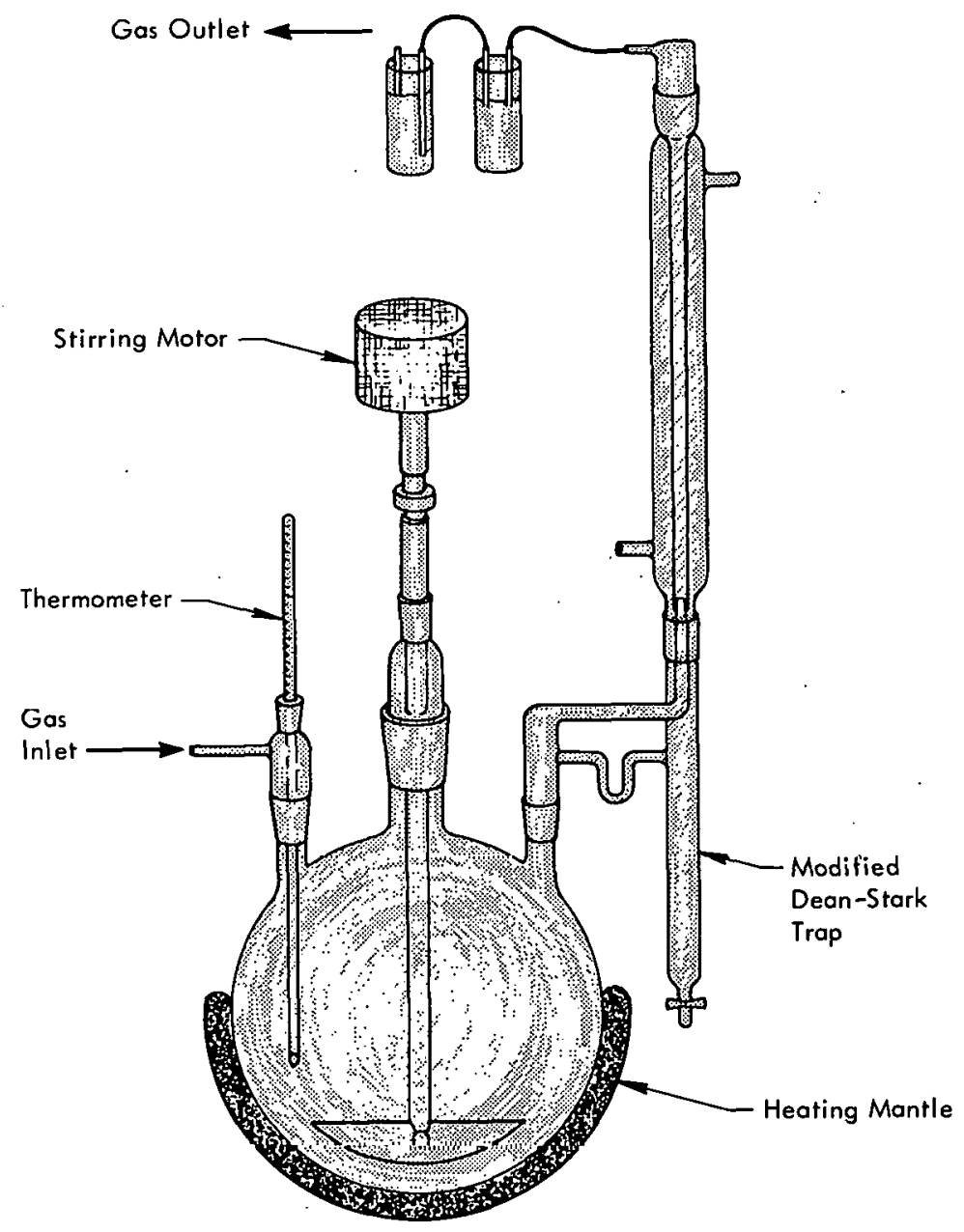

Higure 13. APYAKAIUS USED IIN THE PREPARATIOIN OF ISOTRUXETIE.

$\sim 100^{\circ} \mathrm{C}$, an equal volume of methyl ethyl ketone (MEK) was added with stirring. Stirring was discontinued when the mixture had cooled to room temperature. The resulting solid product was collected by filtration, washed with additional MEK, and allowed to dry in an oven at $60^{\circ} \mathrm{C}$. The crude product, a yellow-tan material melting at $210-220^{\circ} \mathrm{C}$, was recovered with an approximate 20 percent yield (based on the starting weight of indene). A correlation of product yield with reflux time is given by the graph of Figure 14. Purity of these products as a function of the reflux time is discussed later (Page 46).

Characterization - Identification of isotruxene as the product from the reaction of indene, 1,4-naphthoquinone, and TMBDA was made by IR, NMR, and mass spectrometric analyses. The structure of this compound is: 


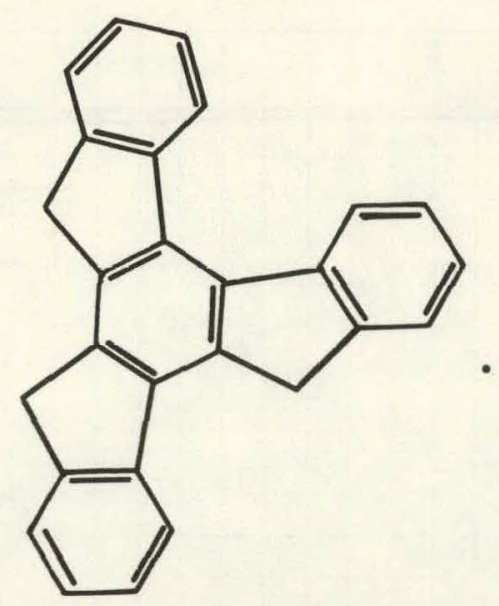

Mass spectrometric analysis of the product indicated a molecular weight of 342 , which tended to eliminate the fulvene-type structure initially proposed for this reaction product. NMR spectra, one of which is shown in Figure 15, indicated the presence of six methylenic protons in the compound and no olefinic protons. This fact was in agreement with an isotruxene structure, but was opposite to the data that would be expected from the proposed structure in which the methylenic protons were replaced and the olefinic bonds retained. The response at $\delta=3.63$ on the NMR scan in Figure 15 indicated an impurity. The structural assignment was confirmed by preparing isotruxene by a known procedure $(8)$ and comparing the properties of the known and unknown compounds. The IR spectrum of the unknown compound (isotruxene), shown in Figure 16, matched that of the known sample of isotruxene.

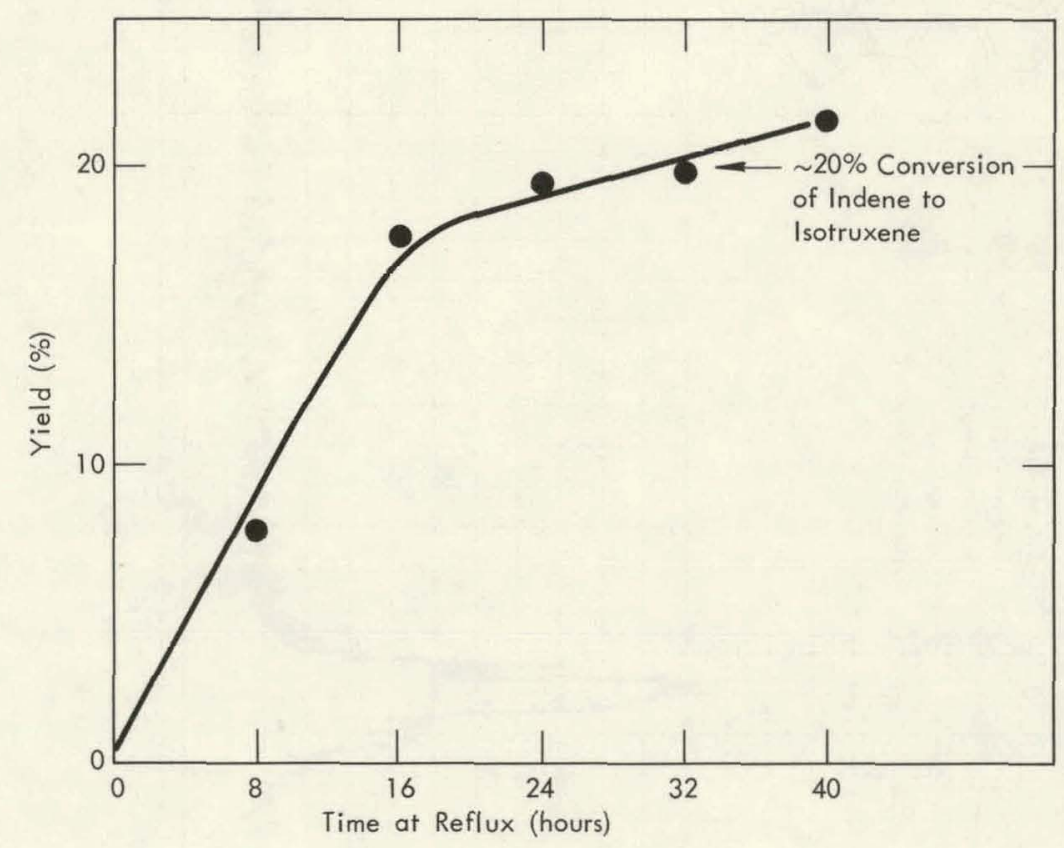

Figure 14. YIELD OF ISOTRUXENE AS A FUNCTION OF THE TIME HELD AT THE REFLUXX TEMPERATIIIRF. 


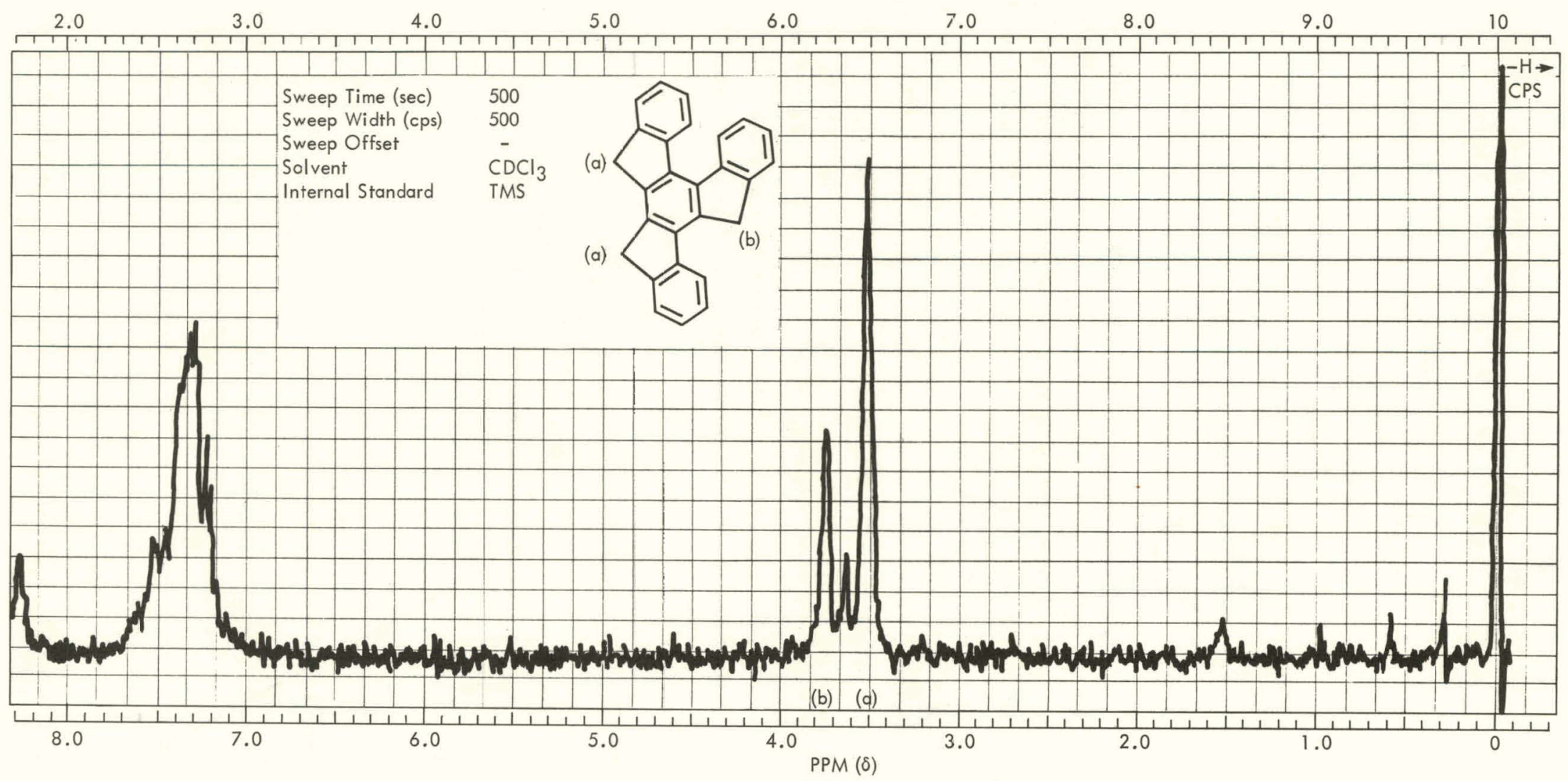

Figure 15. NUCLEAR MAGNETIC RESONANCE SCAN OF ISOTRUXENE. 

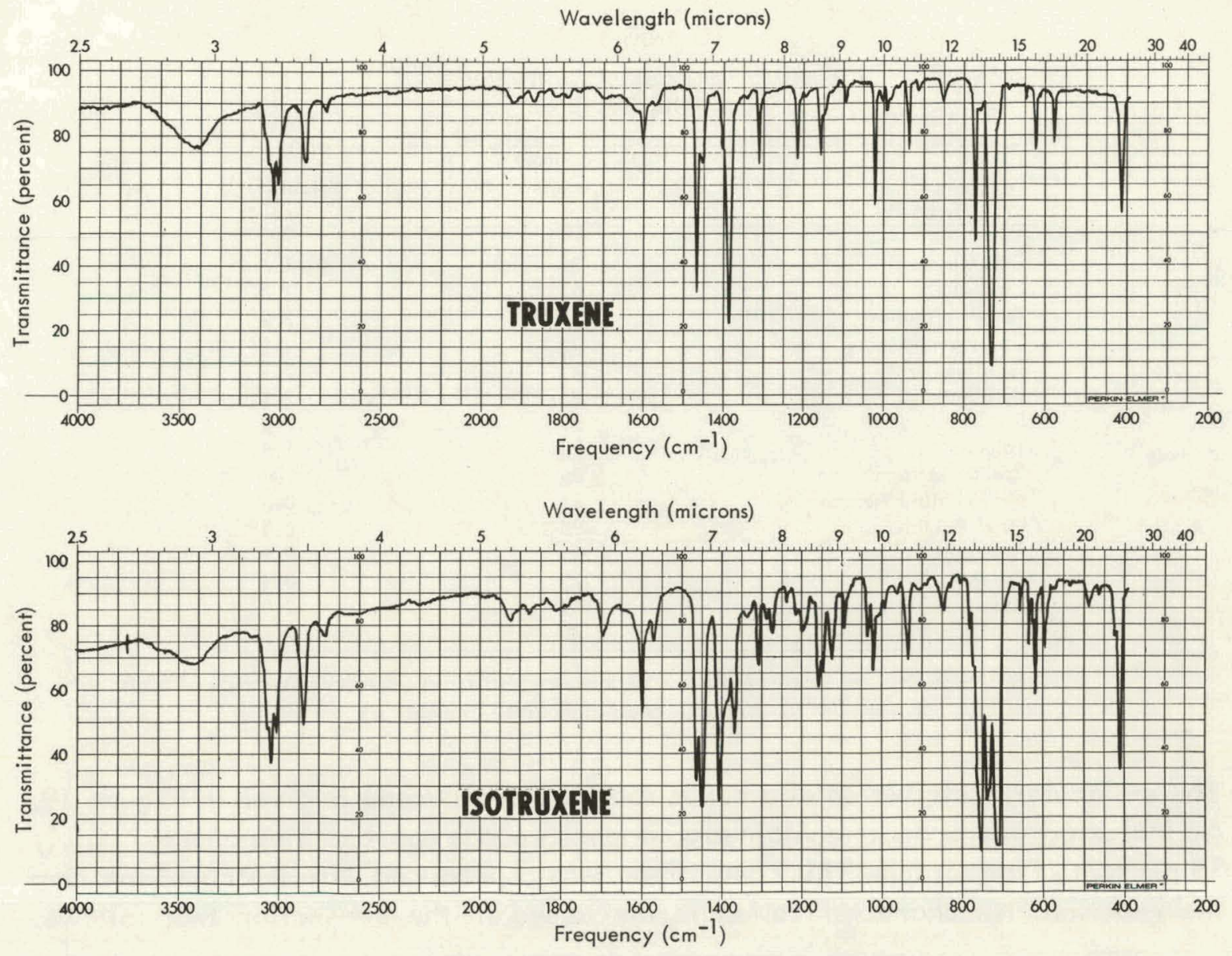

Figure 16. INFRARED SCANS OF TRUXENE AND ISOTRUXENE.

The solubility of isotruxene in various solvents was estimated by adding a known quantity of isotruxene to 100 milliliters of solvent followed by collecting and weighing the insoluble content. These data, listed in Table 5, show isotruxene to have a low solubility in most solvents, with chloroform appearing to be the best solvent at room temperature. At elevated temperatures, isotruxene was observed to have a high solubility in xylene.

Figure 17 shows a thermogram of isotruxene. No significant weight loss was observed at temperatures below $400^{\circ} \mathrm{C}$; the major loss occurring between 450 and $550^{\circ} \mathrm{C}$. The endotherm at approximately $220^{\circ} \mathrm{C}$ corresponds to the melting point of isotruxene, and the exotherm at approximately $550^{\circ} \mathrm{C}$ indicated pyrolysis.

The viscosity of molten isotruxene (Figure 18) was determined over the temperature range from 225 to $325^{\circ} \mathrm{C}$. These data show a rapid decrease in viscosity with increasing temperatures in the range $225-275^{\circ} \mathrm{C}$, with viscosities above $275^{\circ} \mathrm{C}$ being much less sensitive to temperature variations. 
Table 5

SOLUBILITY OF ISOTRUXENE IN SEVERAL ORGANIC SOLVENTS

\begin{tabular}{lcc}
\hline \multicolumn{1}{c}{ Solvent } & $\begin{array}{c}\text { Approximate } \\
\text { Temperature } \\
\left({ }^{\circ} \mathrm{C}\right)\end{array}$ & $\begin{array}{c}\text { Solubility (I) } \\
\text { (gms) }\end{array}$ \\
\hline Chloroform & 25 & 7.7 \\
Chloroform & 61 & 9.7 \\
Tetrahydrofuran & 25 & 2.9 \\
Chlorobenzene & 25 & 2.5 \\
Pyridine & 25 & 2.1 \\
Dioxane & 25 & 2.1 \\
Benzene & 25 & 1.8 \\
Toluene & 25 & 1.5 \\
Carbon Tetrachloride & 25 & 1.0 \\
Methyl Ethyl Ketone & 25 & 0.6 \\
Ethyl Acetate & 25 & 0.4 \\
Acetonitrile & 25 & 0.1 \\
Xylene & 25 & 0.4 \\
Xylene & 140 & 42.0 \\
Cyclohexane & 25 & 0.1 \\
\hline
\end{tabular}

(1) Solubility was estimated by mixing known quantities of solute in $100 \mathrm{mls}$ of solvent, followed by collecting and weighing the insoluble content.

The molecular distribution of a crude sample of isotruxene is given in Figure 19. As indicated, the product contained an impurity phase representing approximately 15 percent of the sample. This contaminant was coproduced with isotruxene during the reaction. Its characterization is discussed in the subsection that follows.

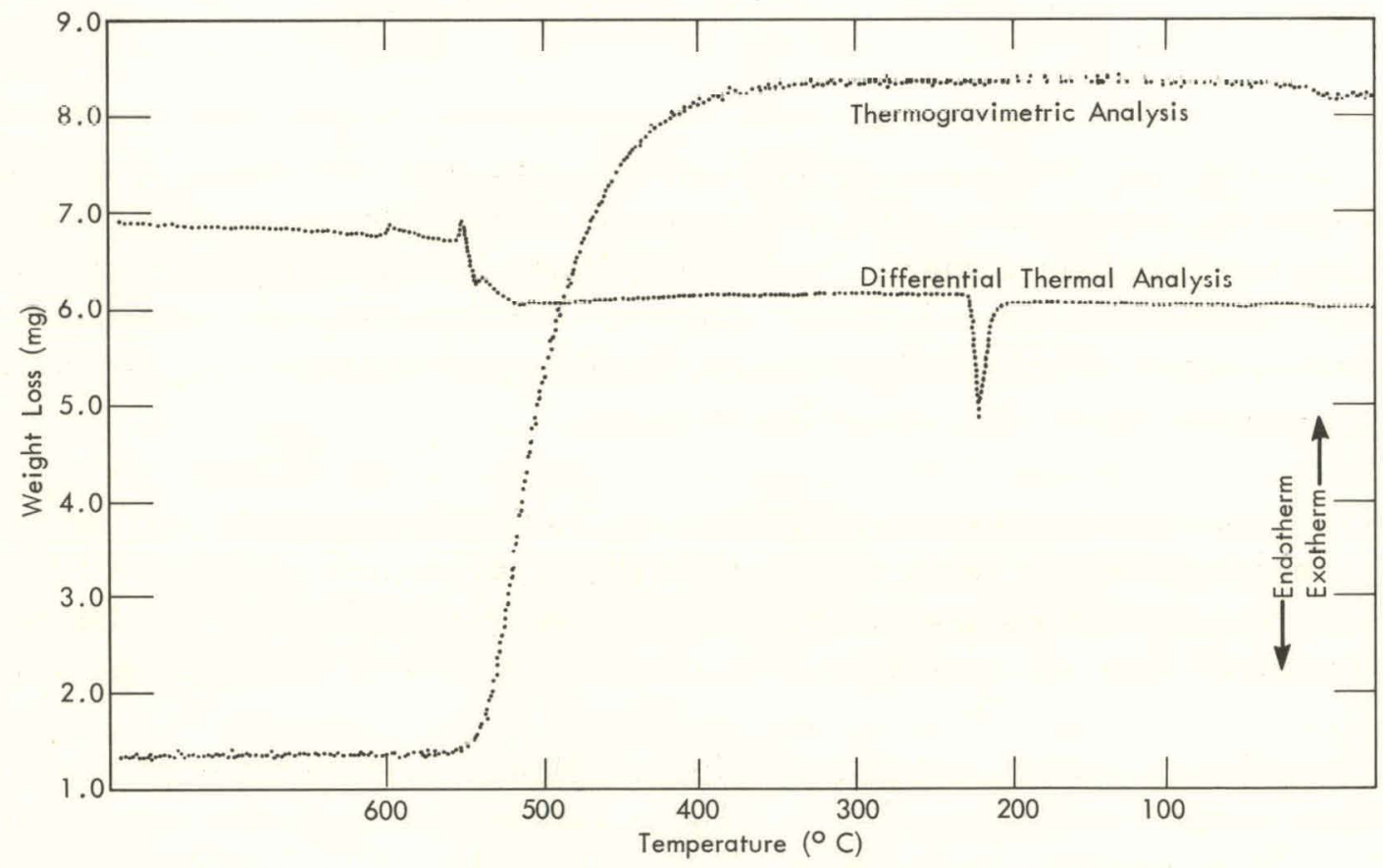

Figure 17. THERMOGRAM OF ISOTRUXENE. ( $87.4 \mathrm{mgs)}$ 


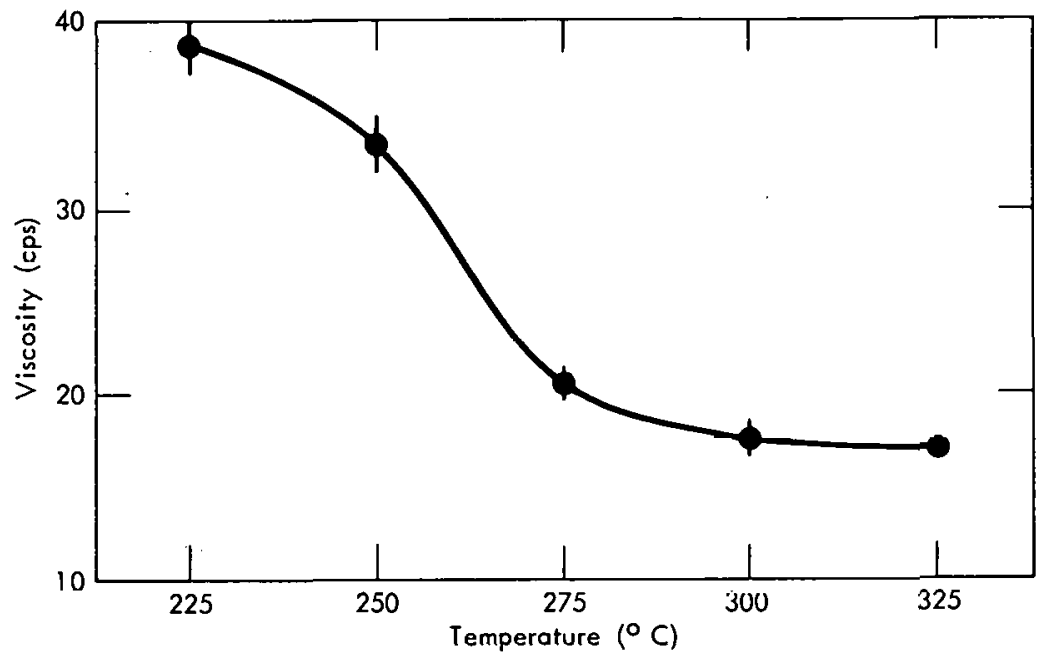

Figure 18. VISCOSITY OF MOLTEN ISOTRUXENE AS A FUNCTION OF THE TEMPERATURE.

Characterization of the Polymeric Impurity Phase that is Coproduced with Isotruxene - The polymeric impurity content in isotruxene products was observed to vary with such reaction conditions as: reaction time, methods of mixing the reactants, and the efficiency of water collection during the initial stages of the reaction. Analysis by GPC offered a method of monitoring product composition since resolution of the two major components was sufficient to allow a quantitative determination of the areas under each curve. As indicated in Figure 19, the impurity phase has a column retention time that is less than that of isotruxene, and thus apparently has a larger molecular size.

Identity of the two major components that are depicted by GPC scans of isotruxene products was confirmed by fractionation of a product mixture using GPC techniques. Elution volumes corresponding to the two components shown in Figure 20 were collected individually, and those corresponding to each fraction were subsequently combined. Each fraction was recovered by evaporating the solvent (THF), which resulted in a residue contaminated with an inhibitor (2,6-di-t-butyl-p-cresol). (14) Removal of this inhibitor was accomplished by an ether $\left[\left(\mathrm{C}_{2} \overline{\mathrm{H}}_{5}\right)_{2} \mathrm{O}\right]$ wash. Mass spectrometric analysis of the two fractions showed that the one with the longer column retention time was isotruxene (Mass 342); the mass of the second fraction or impurity phase was indicated to be 344 , with a minor content of Mass $458-460$.

Thus, the impurity phase was initially thought to be a trimeric derivative of indene, but subsequent data indicated a tetrameric derivative. The material is colorless and was observed to fuse at approximately $300^{\circ} \mathrm{C}$ with decomposition. Decomposition of a sample under controlled conditions at $350^{\circ} \mathrm{C}$ produced a liquid condensate having a mass of 116 (indene) and a residue 


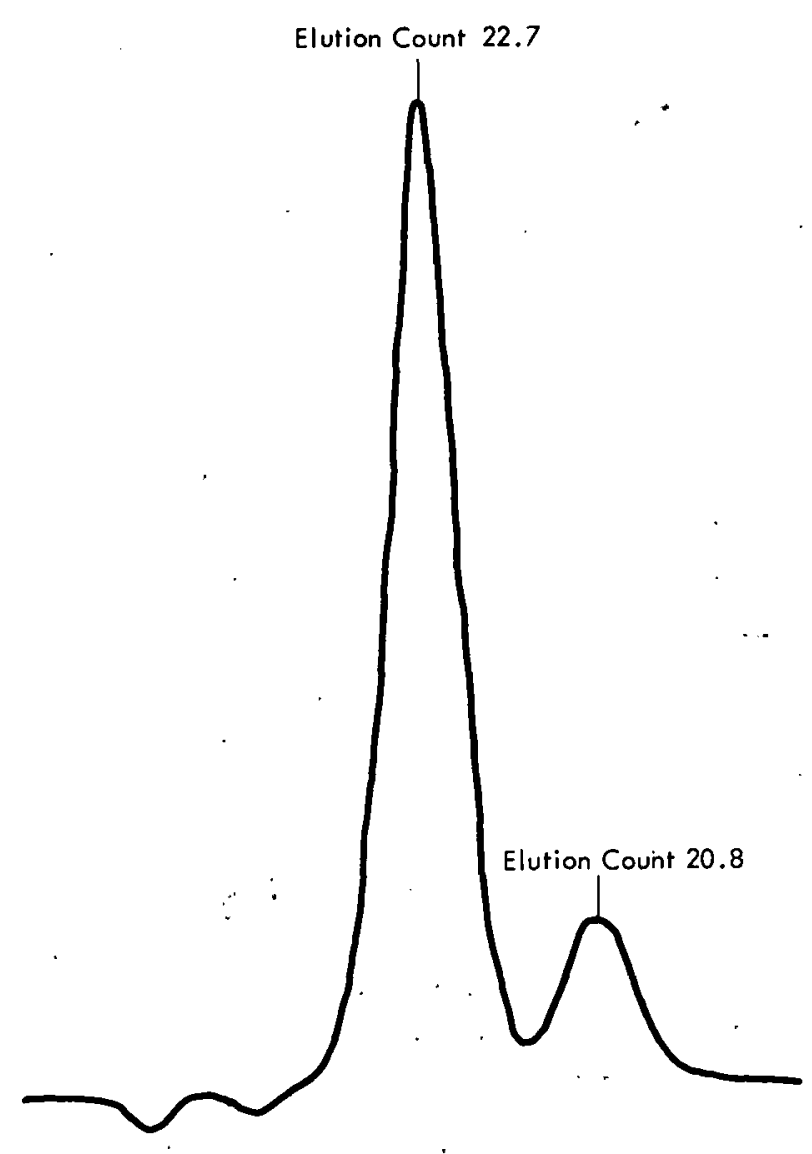

Figure 19. GEL PERMEATION CHROMATOGRAPHIC SCAN OF CRUDE ISOTRUXENE. (Batch 10-99-69C).

containing largely isotruxene. Molecular distribution of the impurity phase before and after heat treatment can be seen in Figure 21. Additional data were obtained by heat treating (at $350^{\circ} \mathrm{C}$ ) a sample of the impurity phase that initially contained 20 percent isotruxene. The change in the molecular distribution is emphasized in Figure 22. Thus, the production of indene and trimeric products on decomposition of the impurity phase was in.support of a tetrameric structure. The average molecular weight of the impurity phase, as determined by vapor pressure osmometry, was 458 , which compares favorably with the calculated mass of a tetramer (464).

Efforts to reconcile the differences in molecular weight and mass spectrometry data that were obtained on analysis of the impurity phase resulted in a search for metastable masses which would signal a fragmentation of the material during mass spectrometric analysis. Metastable masses $\left(m^{*}\right)$ may be calculated as follows: (15) 


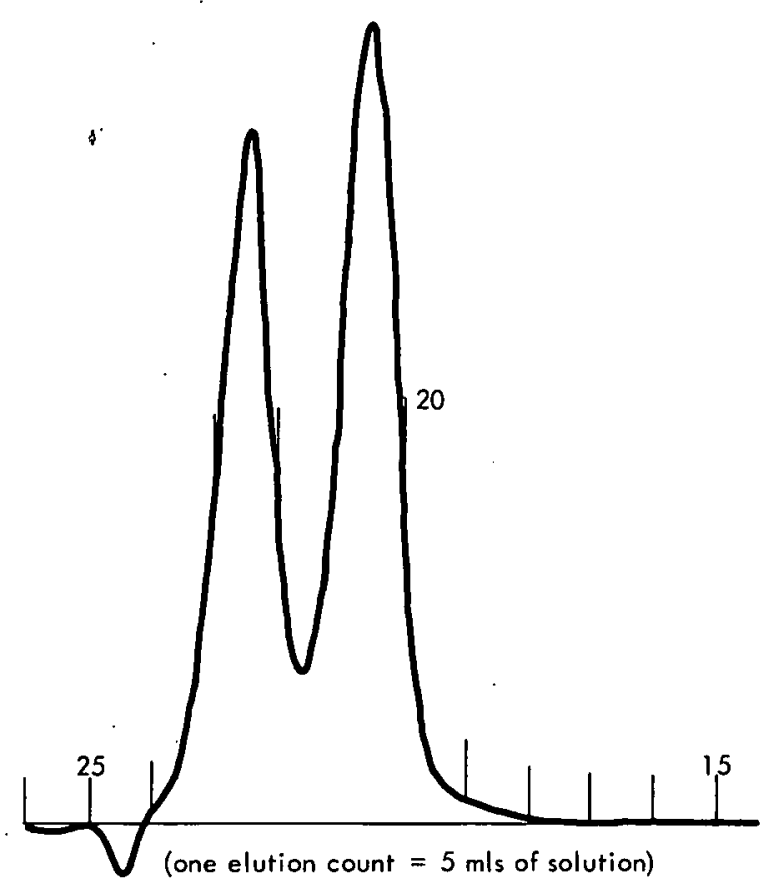

Figure 20. GEL PERMEATION CHROMATOGRAPHIC SCAN OF THE PRODUCT OBTAINED ON BELATED ADDITION OF 1,3-TMBDA TO A PREHEATED MIXTURE OF INDENE AND 1,4-NAPHTHOQUINONE. (Batch 4CO19B)

$$
m^{*}=\frac{\left(m_{d}\right)^{2}}{m_{p}}
$$

where:

md represents the mass of the daughter or fragment, and

$m_{p}$ that of the parent or molecular species.

A metastable mass of 258.4 would result from the decomposition of Mass 458 to Mass 344, while decomposition of Mass 460 to Mass 344 result in a metastable mass of 257.3. Examination of the mass spectrum of the impurity phase showed a metastable mass covering two mass units with a peak at 257.3. These data would support the conjecture that the impurity phase was a tetramer which decomposes in the electron-beam source of the mass spectrometer to yield a trimeric fragment of Mass 344 and a neutral species which is not seen.

Recovery of the impurity material relatively free of isotruxene was accomplished by washing with chloroform those products having a high impurity content. Isotruxene, being more solublc in chloroform, was leached from the mixture. 


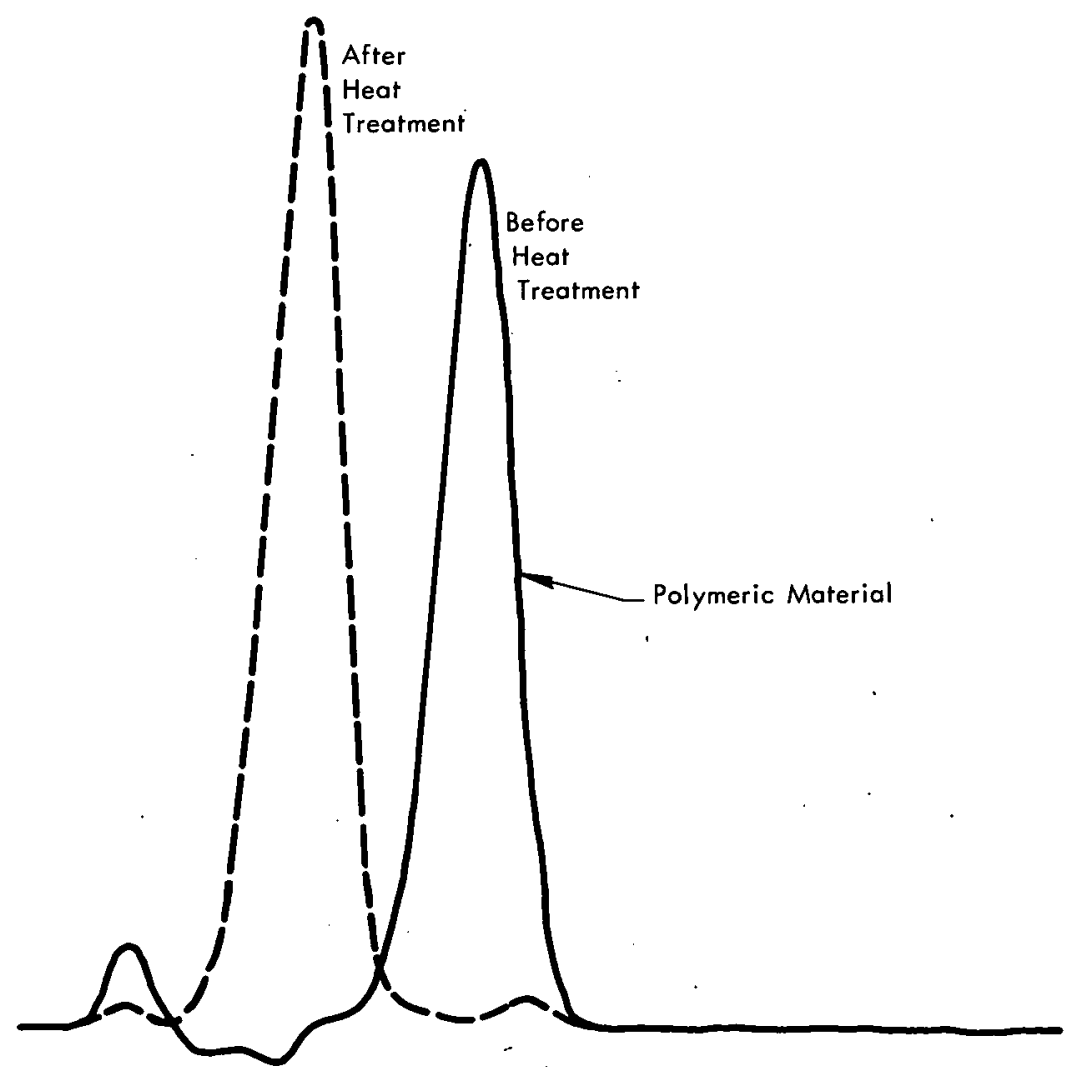

Figure 21. GEL PERMEATION CHROMATOGRAPHIC SCANS SHOWING THE CHANGE IN THE COLUMN RETENTION TIME ON HEATING A SAMPLE OF A TETRAMERIC DERIVATIVE OF INDENE FOR TWO HOURS AT $3500 \mathrm{C}$. (Inert Atmosphere)

The resulting product would appear to have a narrow molecular weight distribution, as depicted in previous GPC scans (see Figure 21). The exact structure of the impurity phase is not known, but its lack of color would indicate a lower degree of conjugation than exists for isotruxene. The mass range (458-460) indicates a partially oxidized tetrameric form, with a structure which favors the formation of indene and isotruxene on thermal degradation. An IR spectrum of the impurity phase is given in Figure 23.

Factors which control the content of the impurity phase in isotruxene products were investigated. Since the reaction time was known to have a significant influence on the isotruxene content in the products, the composition of a reaction mixture of indene, 1,4-naphthoquinone, and TMBDA was determined as a function of the heating time from 0 to 48 . hours. GPC techniques were used to monitor the formulation at various time intervals. The resulting data, presented in Figure 24 , show a rapid decline in the indene monomer content and a rapid increase in the content of the impurity phase during the initial four-hour heating period. Production of isotruxene during this period is at a much slower rate. After 12 


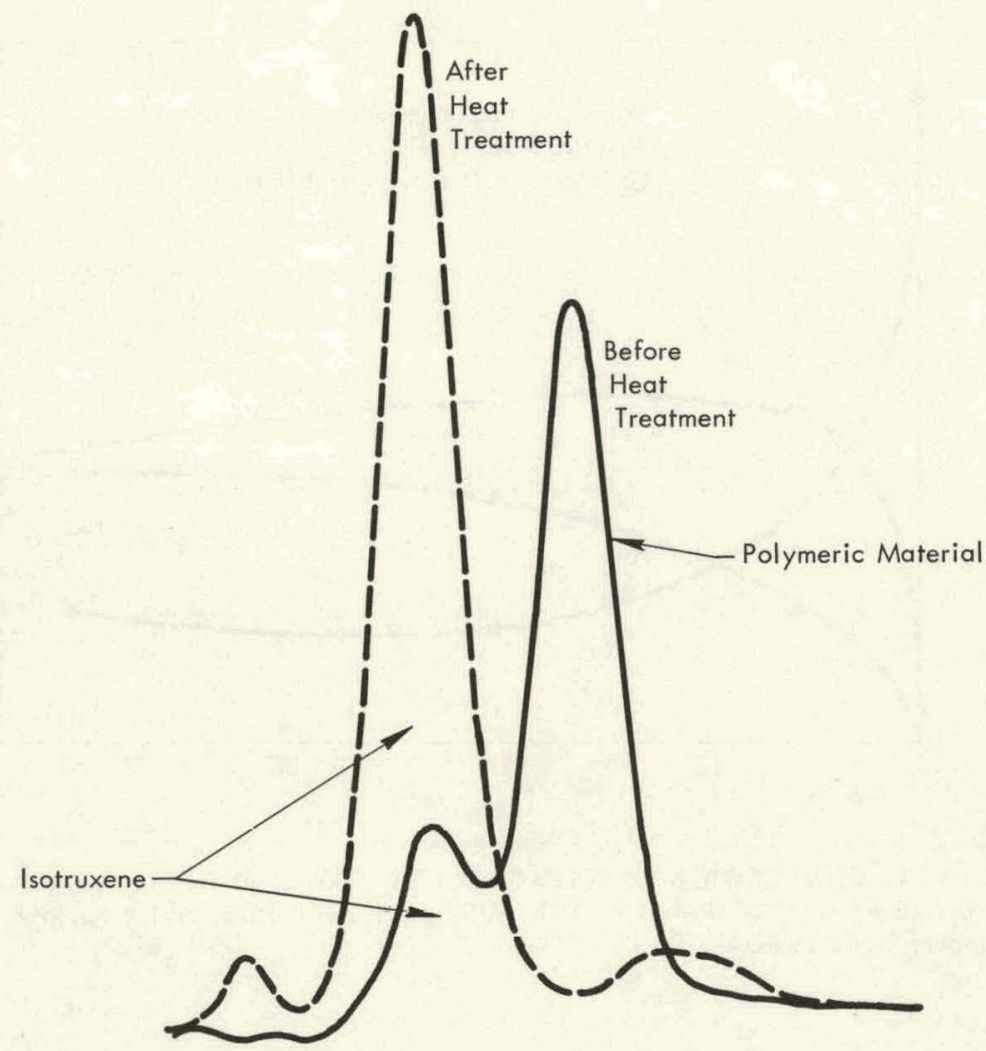

Figure 22. GEL PERMEATION CHROMATOGRAPHIC SCANS SHOWING THE CHANGE IN MOLECULAR DISTRIBUTION ON HEATING, AT $350^{\circ} \mathrm{C}$ IN AN INERT ATMOSPHERE FOR TWO HOURS, A SAMPLE THAT WAS INITIALLY 80 PERCENT INDENE TETRAMER AND 20 PERCENT ISOTRUXENE.

hours, the content of the impurity phase not only ceased to increase but actually underwent a minor decrease, matched by a slight increase in the monomer content. The isotruxene content increased slowly, becoming essentially constant after 24 hours.

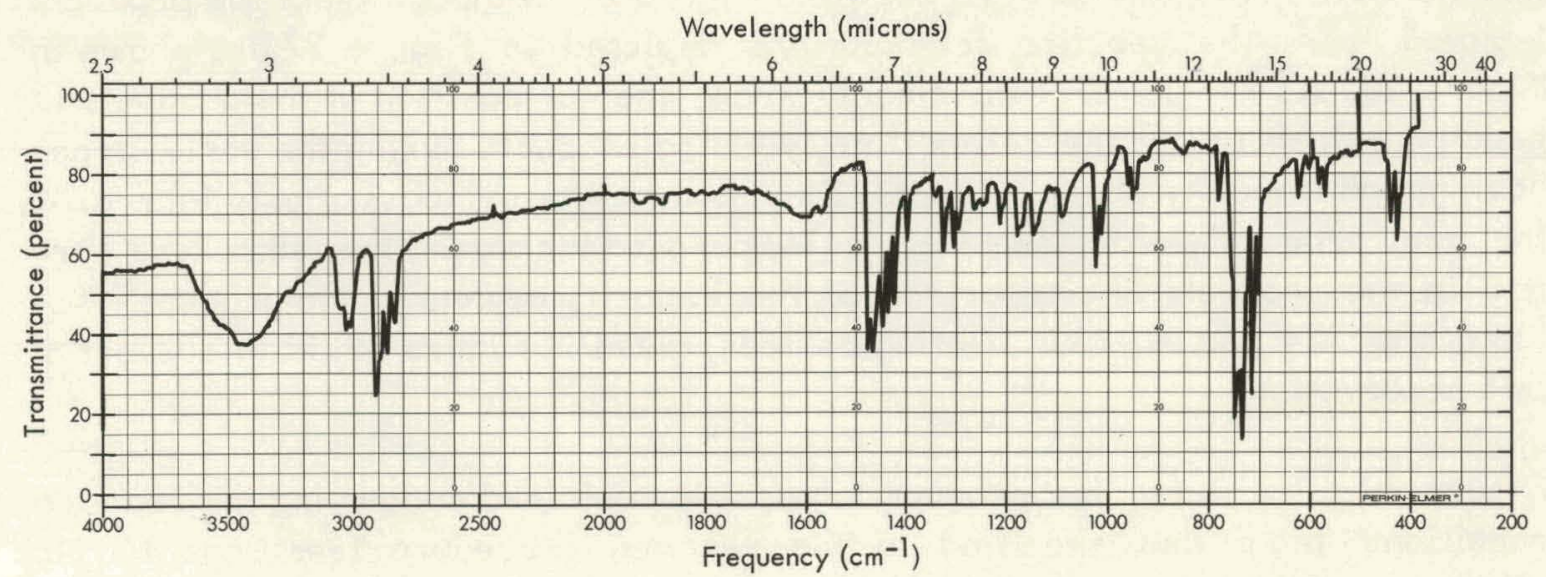

Figure 23. INFRARED SPECTRUM OF THE IEIRAMERIC INDENE PRODUCT. 


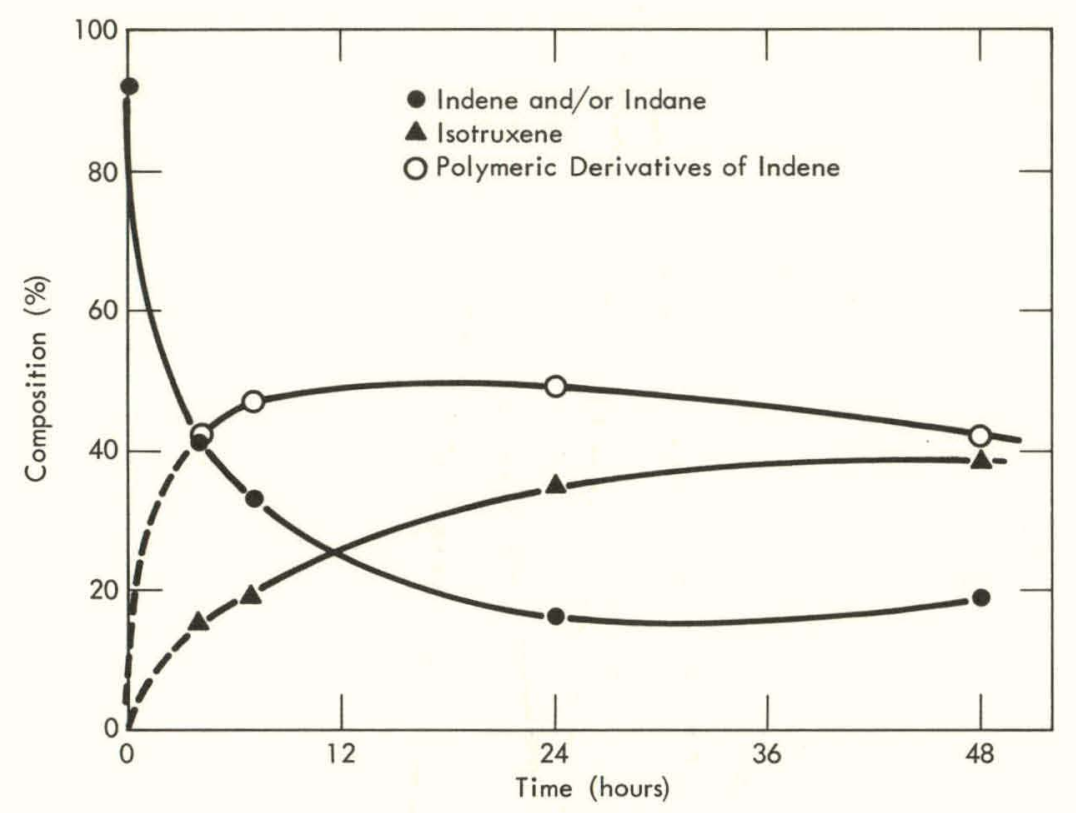

Figure 24. COMPOSITION OF A REACTION MIXTURE USED TO PREPARE ISOTRUXENE AS A FUNCTION OF TIME. (200 gms Indene, $15.8 \mathrm{gms}$ 1,4-naphthoquinone, 2 gms TMBDA)

Identification of the components in these reaction mixtures was accomplished by mass spectrometric analysis of samples obtained by fractionation of a reaction mixture which had been heated under reflux for 24 hours. Molecular distribution of the reaction mixture is indicated in Figure 25. Indane (Mass 118) was the only monomeric form of indene present after a 24-hour heating period. The polymeric impurity species were considered collectively, reducing the composition to three major species, as shown in Figure 24. The initial molecular distribution of a reaction formulation may be compared in Figure 26 with that observed after a 48-hour reflux period. Molecular distributions observed for intermediate reflux periods are shown in Figure 27. Composition of the products isolated from the reaction formulations depicted in Figure 27 are shown in Figure 28. As the latter data clearly show, the composition of the products is greatly influenced by the reflux time, yielding products during the early stages having high impurity phase contents. Extended cooking periods not only increased the total product yields (see Figure 14) but also increased the isotruxene content in the product. A comparison of the impurity content of the products isolated after 24 and 48-hour heating periods, given in Figure 29, is in support of this observation.

Figure 29 also shows the product composition obtained on varying the reaction conditions from that specified in the reaction procedure (see Page 37 ). No effect on product purity was noted when the reaction formulations were allowed to remain for various periods at room temperature prior to reflux. This result 


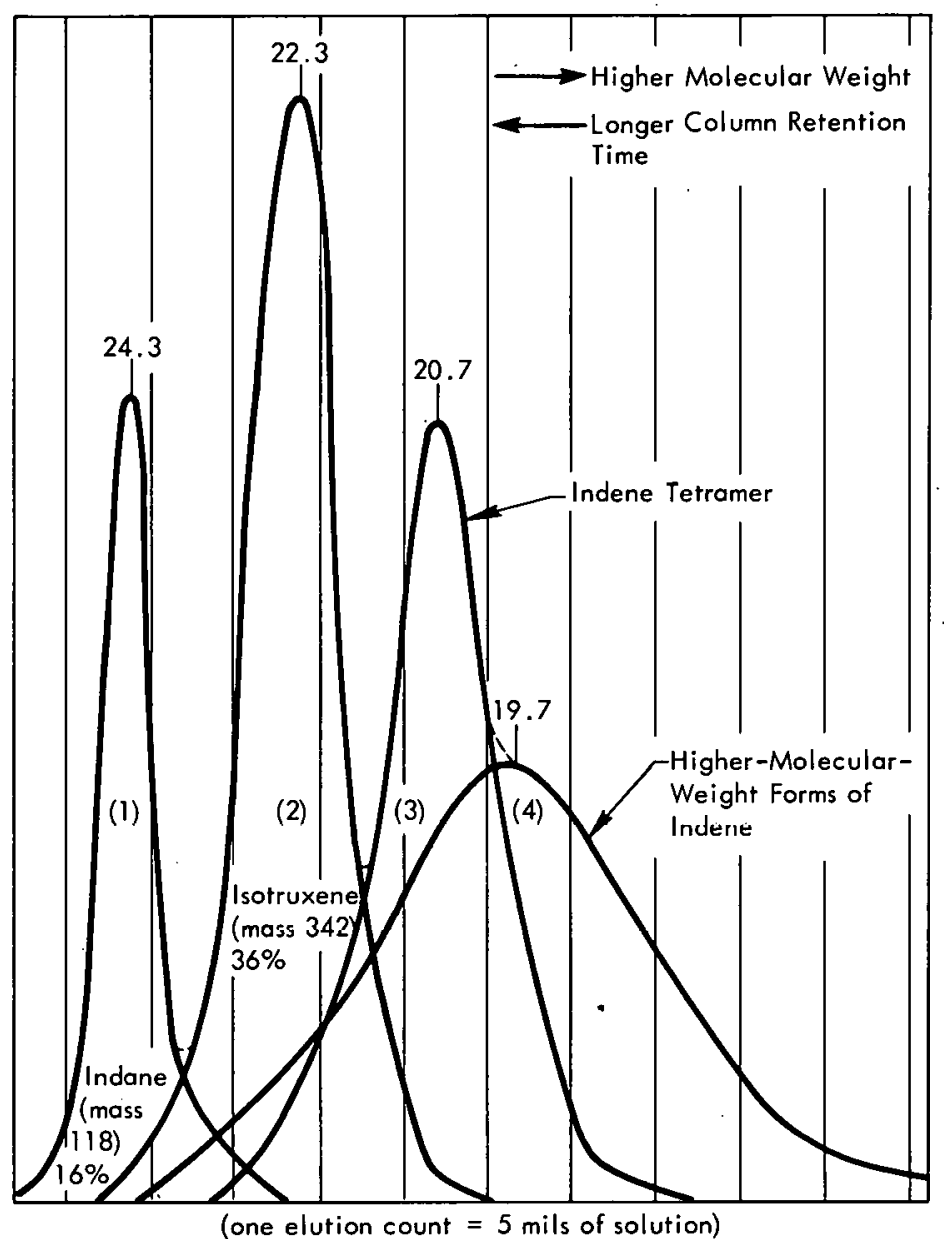

Figure 25. GEL PERMEATION CHROMATOGRAPHIC SCANS OF REACTION MIXTURES OBTAINED ON HEATING A MIXTURE OF INDENE 1,4-NAPHTHOQUINONE, AND TMBDA UNDER REFLUX FOR 24 HOURS.

was apparent by comparing molecular distributions in Figure 29, Curves (a) and (b). Curve (d) of Figure 29 shows the molecular distribution of a product isolated from a reaction which was carried out by adding the 1,4-naphthoquinone dropwise (via an indene solution) to a refluxing solution of indene and TMBDA. After completing the addition, the reaction mixture was heated for 24 hours under reflux. This addition procedure apparently promotes formulation of the polymeric impurity materials and inhibits the formation of isotruxene. Other variations in the reaction procedures included preheating the reaction formulations for various periods of time at subrefluxtemperatures followed by heating periods under reflux. This procedure resulted in increased purity for the smaller batch sizes, but had little effect on the larger batches.

Mechanism - Isolation of isotruxene from a reaction mixture of indene, 1,4-napthoquinone, and TMBDA was not expected, and led to an investigation of the mechanism by which it was formed and the role of each of 


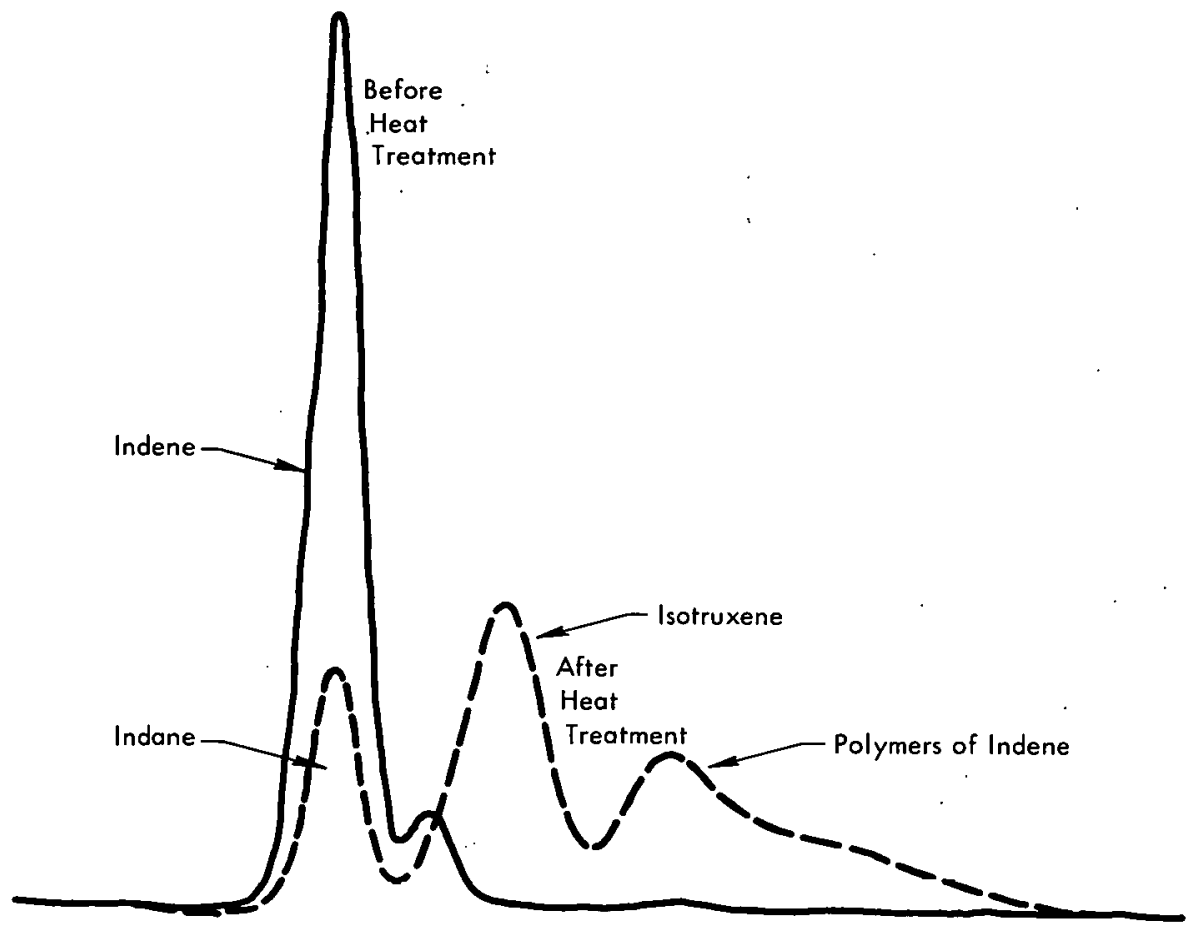

Figure 26. GEL PERMEATION CHROMATOGRAPHIC SCANS SHOWING THE MOLECULAR DISTRIBUTION OF THE REACTION FORMULATION USED TO PRODUCE ISOTRUXENE BEFORE AND AFTER HEATING FOR 48 HOURS AT APPROXIMATELY $180^{\circ} \mathrm{C}$ UNDER REFLUX. (200 gms Indene, 15.9 gms 1,4-naphthoquinone, 2.0 gms TMBDA)

the three starting reagents in this mechanism. As previously stated, standard ratio of the reactants used in preparing isotruxene consisted of 100 parts indene, ten parts 1,4-naphthoquinone, and one part TMBDA. Though the stoichiometry of this equation was not established, the presence of both 1,4-naphthoquinone and TMBDA was found to be essential to the production of isotruxene from indene.

Little change in the properties of indene was observed on heating indene and TMBDA in the absence of 1,4-naphthoquinone. However, a product was isolated in quantity when indene and 1,4-naphthoquinone were heated under reflux in the absence of TMBDA. This product did not fuse below $250^{\circ} \mathrm{C}$ and contained no isotruxene, but mass spectrometric analysis indicated a significant content of Mass 342 material; which was apparently truxene. A second material present in significant quantities had a mass of 38.4 and was presumed to be due to a combination of two indene molecules and one molecule of 1,4-naphthoquinone to form, through oxidation, a molecular structure analogous to that of isotruxene where a quinone molecule was substituted for one of the indene molecules. This fact would explain the presence of the small oxygen content $(-3 \%)$ in this product. 


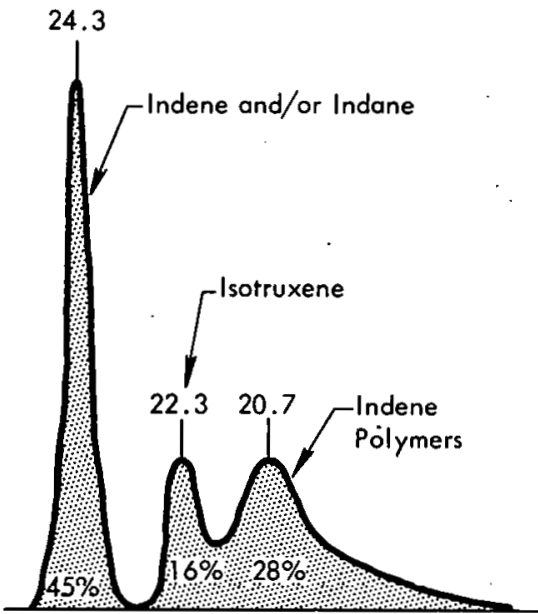

(a) Four Hours

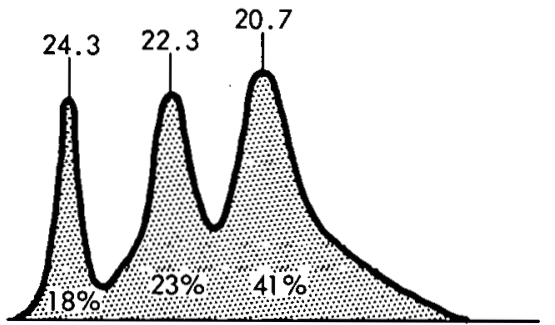

(c) Twelve Hours

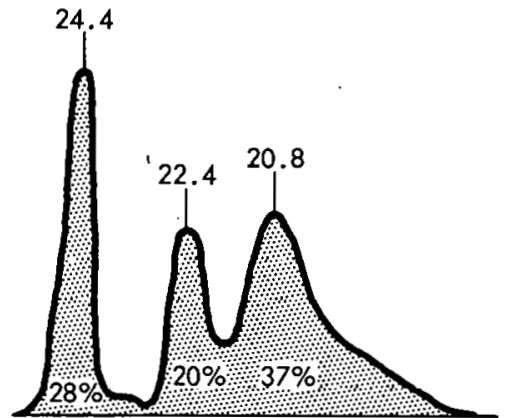

(b) Eight Hours

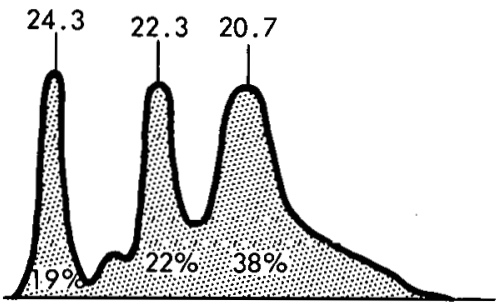

(d) Sixteen Hours

Figure 27. GEL PERMEATION CHROMATOGRAPHIC SCANS OF REACTION MIXTURES OBTAINED ON HEATING INDENE UNDER REFLUX IN THE PRESENCE OF 1,4-NAPHTHOQUINONE AND TMBDA.

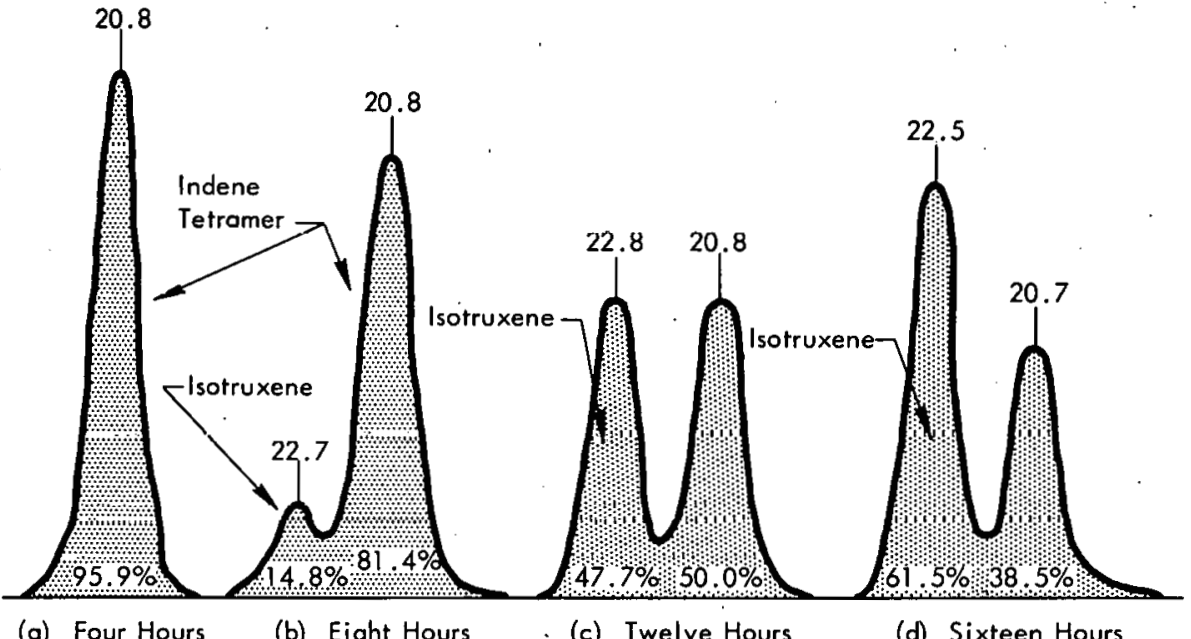

(a) Four Hours

(b) Eight Hours

(c) Twelve Hours

(d) Sixteen Hours

Figure 28. GEL PERMEATION CHROMATOGRAPHIC SCANS SHOWING THE COMPOSITION OF THE SOLID PRODUCTS ISOLATED ON HEATING INDENE UNDER REFLUX FOR VARIOUS TIME PERIODS IN THE PRESENCE OF 1,4-NAPHTHUQUINONE AND TMBOA. 


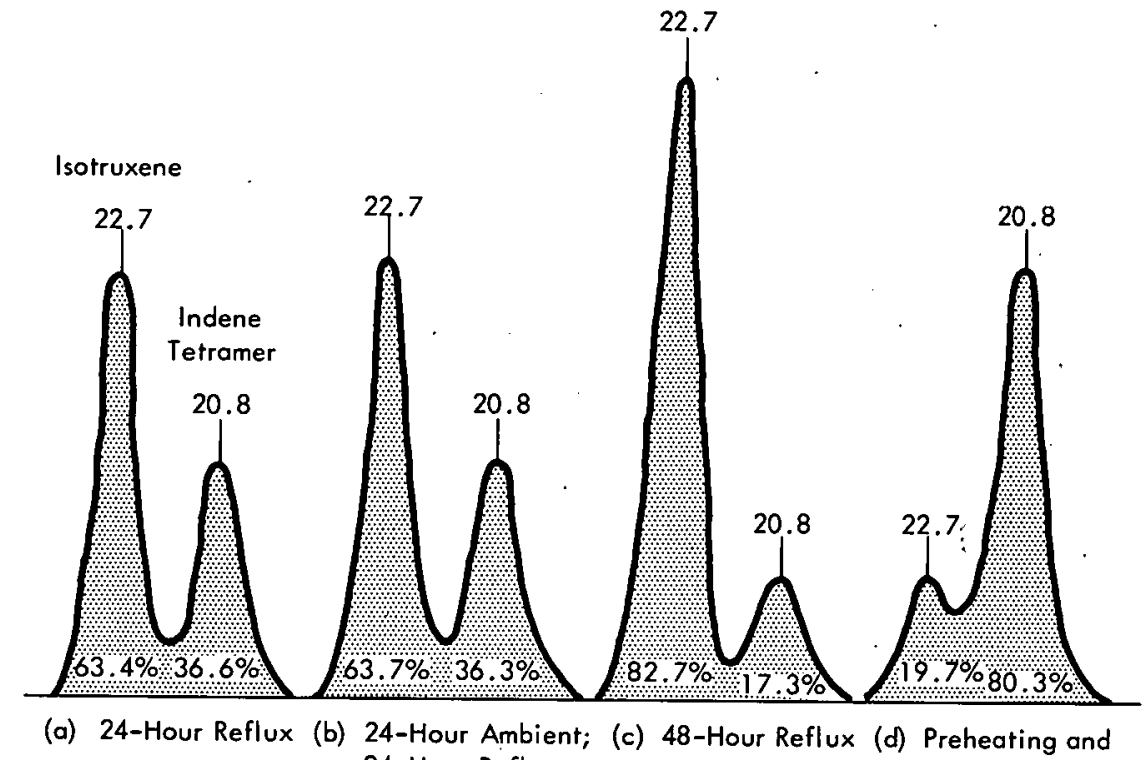
24-Hour Reflux

24-Hour Reflux

Figure 29. GEL PERMEATION CHROMATOGRAPHIC SCANS SHOWING THE COMPOSITION OF THE SOLID PRODUCTS ISOLATED ON REACTING INDENE IN THE PRESENCE OF 1,4-NAPHTHOQUINONE AND TMBDA UNDER VARIOUS CONDITIONS.

Though the presence of the amine was essential to the production of isotruxene, the reaction did not appear highly sensitive to small changes in the quantity of the amine. The yield of isotruxene was, however, observed to be directly proportional to the quantity of 1,4-naphthoquinone in the reaction formulation. Though quinones readily undergo reduction to form hydroquinones, the relatively small amount of 1,4-naphthoquinone in the mixtures could account for only a small part of the oxidation process. This fact, in conjunction with the knowledge that this formulation produces only one of two possible isomeric forms, indicates that 1,4-naphthoquinone is playing an additional role in the reaction mechanism. In the presence of an amine, 1,4-naphthoquinone appeared to promote an autooxidationreduction reaction of indene to produce isotruxene and various other partially oxidized polymers of indene along with reduced forms of indene of which indane was the most prevalent.

The ease of converting quinones to hydroquinones with the presence of quinhydrone or semiquinone intermediates $(16)$ introduces the possibility that 1,4-naphthoquinone could act as a radical initiator leading to the production of dimeric and trimeric forms of indene which are readily convertible to isotruxene. Quinhydrone compounds are dimeric forms that result from hydrogen bonding between a quinone and the corresponding hydroquinone. The interconversion of these quinone forms is shown by the following equations: 

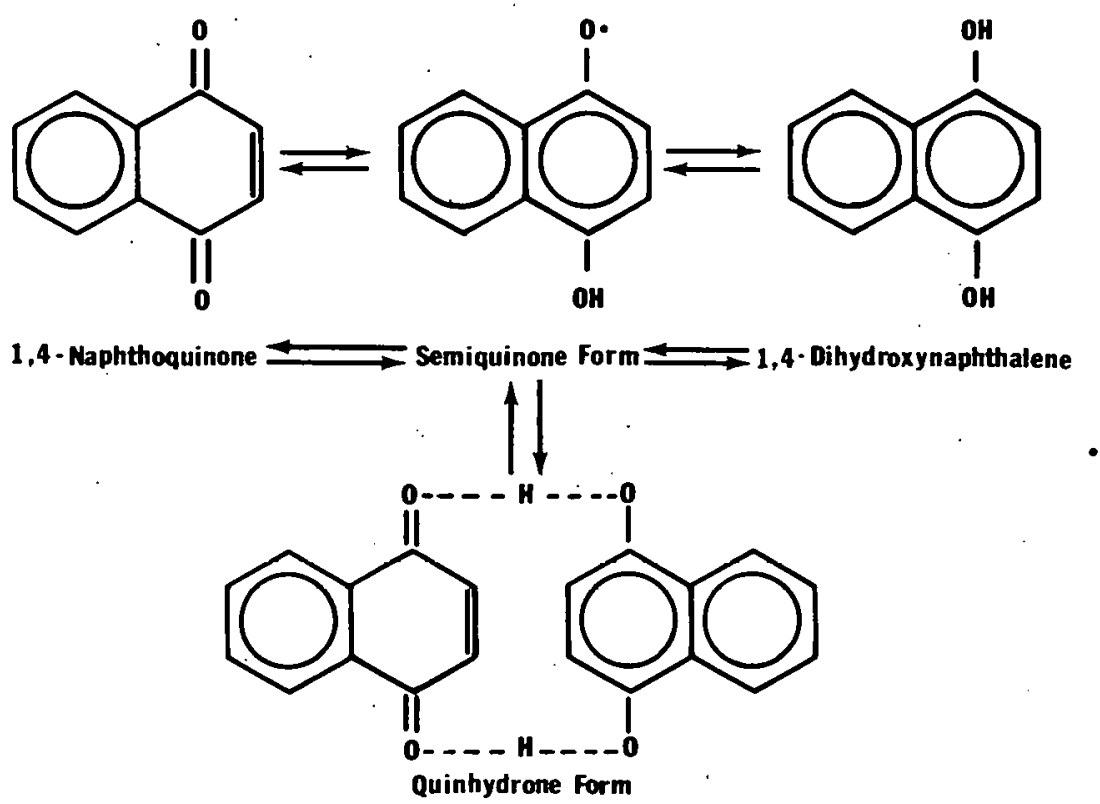

These interconversion reactions would probably be promoted by the presence of TMBDA.

The substitution of 1,4-dihydroxynaphthalene for 1,4-naphthoquinone in the reaction formulation resulted in the production of isotruxene even in the absence of TMBDA, though the sample was somewhat lower in purity than when 1,4-naphthoquinone and TMBDA were used. Production of the intermediate quinone species from 1,4-dihydroxynaphthalene is probable and lends some support to the previous postulation. On the other hand, 1,5-dihydroxynaphthalene produced no isotruxene when reacted with indene. Since the structure of 1,5-dihydroxynaphthalene will not accommodate a quinoidal form, lack of producing isotruxene from this material was again indicative of the importance of the quinone/hydroquinone interconversion reactions.

Production of water from the reaction of indene, 1,4-naphthoquinone, and TMBDA is also indicative of a reaction involving 1,4-naphthoquinone since this is the only source of oxygen in the mixture. Thus, 1,4-naphthoquinone loses its identity during the early stages of the reaction, which is in agreement with the data that indicate a preferential reaction of 1,4naphthoquinone with the amine rather than indene. The quantity of water produced corresponded roughly to 50 percent of the theoretical quantity that could be produced from 1,4-naphthoquinone. Failure to continuously remove the water will prohibit the formation of isotruxene and results in the formation of small quantities of polymeric naphthoquinone products.

The data presented thus far would indicate that the early interaction of TMBDA and 1,4-naphthoquinone was fundamental to the reaction sequence 
which produces isotruxene. TMBDA aids in converting 1,4-naphthoquinone to forms which prevent its combination with indene to form trimeric materials and which promote the conversion of indene to isotruxene. This observation prompted a study of the interaction of 1,4-naphthoquinone and tertiary amines. Reactions included heating 1,4-naphthoquinone and tertiary amines in toluene, indene, and acetic acid solutions. The insoluble products were collected on cooling. Data on these reactions are given in Table 6. In general, the products consisted of high-melting, green-colored materials which were subsequently identified as partially reduced forms of triphthaloylbenzene. $(17,18)$. The structure of triphthaloylbenzene, which is yellow in color, along with a reduced form and a partially dehydrated form is shown below.<smiles>O=c1c2ccccc2c(=O)c2c1c1c(=O)c3ccccc3c(=O)c1c1c(=O)c3ccccc3c(=O)c21</smiles>

Triphthaloylbenzene

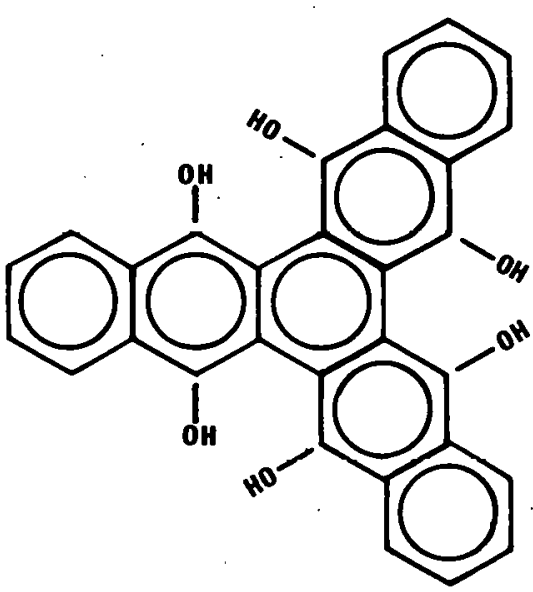

Reduced Form

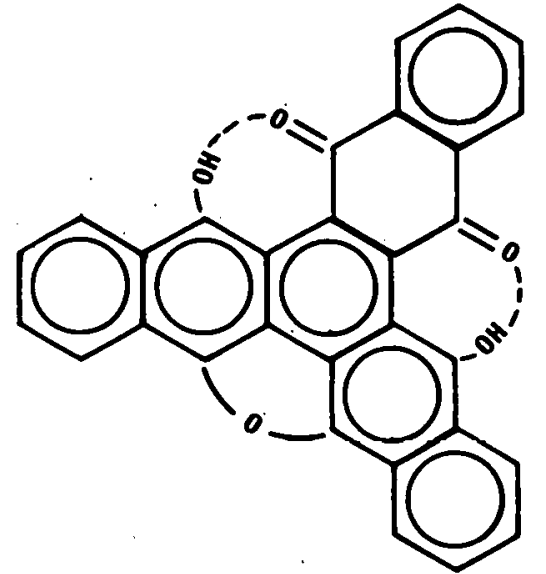

Partially Reduced, Partially Dehydrated Form 
Table 6

POLYMERIZATION OF 1,4-NAPHTHOQUINONE

\begin{tabular}{llcccc}
\hline \multicolumn{1}{c}{ Solvent } & Catalyst & $\begin{array}{c}\text { Reaction } \\
\text { Temperature } \\
(\circ \mathrm{C})\end{array}$ & $\begin{array}{c}\text { Corbon } \\
(\%)\end{array}$ & $\begin{array}{c}\text { Hydrogen } \\
(\%)\end{array}$ & $\begin{array}{c}\text { Oxygen } \\
(\%)\end{array}$ \\
\hline Indene & Quinoline & $\sim 100$ & 76.6 & 4.3 & - \\
Tolvene & Quinoline & 110 & 75.5 & 3.4 & 21.1 \\
Tolvene & TMBDA(1) & 110 & 74.0 & 4.8 & 20.9 \\
Acetic Acid & Pyridine & 120 & 77.6 & 3.3 & - \\
Toluene & Pyridine & 110 & 75.0 & 3.6 & - \\
Acetic Acid & Pyridine & 120 & 77.7 & 3.1 & - \\
$\quad$ Toluene & Quinoline & 125 & 77.6 & 3.4 & - \\
Acetic Acid & Pyridine & 110 & - & - & - \\
\hline
\end{tabular}

(1) $N, N, N^{\prime}, N^{\prime}$-tetramethyl-1, 3-butanediamine.

Reactions carried out in indene at approximately $100^{\circ} \mathrm{C}$ produced only derivatives of 1,4-naphthoquinone and no isotruxene, indicating that the interaction of amine and 1,4-naphthoquinone is somewhat independent of indene under these conditions and would occur prior to a reaction between indene and 1,4-naphthoquinone in the sequence of reactions that produce isotruxene. Elemental compositions of the products shown in Table 6 were quite similar, and seemed to be independent of the solvent or the amine used. The theoretical composition of triphthaloylbenzene consists of 77 percent carbon, 20.5 percent oxygen, and 2.5 percent hydrogen; while that of the reduced form of triphthaloylbenzene consists of 76 percent carbon, 20.2 percent oxygen, and 3.8 percent hydrogen. The hydrogen content of the products listed in Table 6 would indicate that a predominate portion of the product was the reduced form, as depicted in the structural formulas. Partially reduced forms would allow the formation of quinhydrone-type hydrogen bonding (see Page 53). This polymeric form of 1,4-naphthoquinone was also prepared by heating a slurry of 1,4-naphthoquinone and pyridine to approximately $50^{\circ} \mathrm{C}$, at which point an exothermic reaction began and temperatures increased to approximately $150^{\circ} \mathrm{C}$. After cooling, the solid mass was crushed and washed with hydrocarbon solvents to produce a green-colored powder.

This reduced form of triphthaloylbenzene was oxidized by heating in concentrated nitric acid to produce a yellow material which was indicative of a fully ketonic form. The green color of the partially reduced form is apparently due to the presence of some quinhydrone bonding, since naphthoquinhydrone is green in color.

Both the oxidized and reduced forms of triphthaloylbenzene were reacted with indene in the absence of an amine catalyst to produce isotruxene. 
No triphthaloylbenzene derivatives were isolated with the product as they were apparently degraded during the reaction. The isolation of isotruxene from these reactions that omitted an amine again indicated that the function of the amine is to interact with 1,4-naphthoquinone to form intermediates which promote the formation of isotruxene. These intermediates can include 1,4-dihydroxynaphthalene, naphthoquinhydrone, and various forms of triphthaloylbenzene, all of which tend to promote the formation of isotruxene from indene. The role of the triphthaloylbenzene derivatives in directing the production of isotruxene rather than truxene or an isotruxene-truxene mixture is unknown, but the use of 1,4-naphthoquinone derivatives with substituents in Position 2 in reactions with indene did not result in the production of isotruxene but rather produced truxene. These derivatives of 1,4-naphthoquinone cannot form triphthaloylbenzene derivatives. These facts indicate that the triphthaloylbenzene-derived intermediates were responsible for determining the course of the reaction which results in production of isotruxene.

To summarize, the factor which determines the structure on trimerization of indene is the structure of the dimeric intermediate. Structures of certain dimeric forms will result in the production of only isotruxene when combined with a third indene molecule, while another leads to the production of either isomer. These forms are (see Page 15 for numbering of positions in the indene molecule):

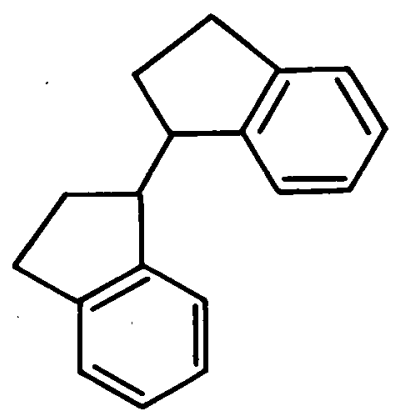

$1,1^{\prime} ; 1,3^{\prime} ; 3,3^{\prime}$ Bonding

A

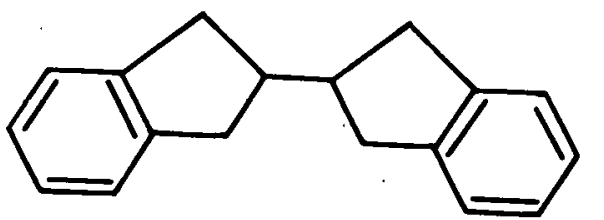

2,2' Bonding

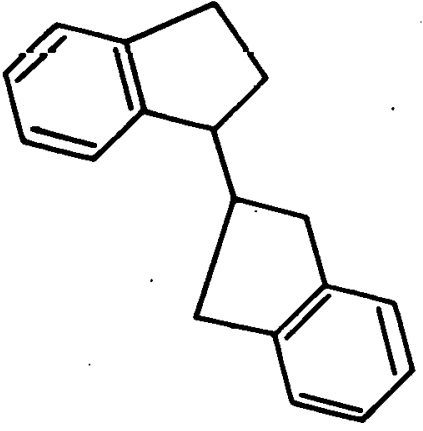

1,2'; 3,2' Bonding

C

B

A third molecule of indene can combine with each of these dimeric forms to produce isotruxene. This fact is illustrated as follows: 


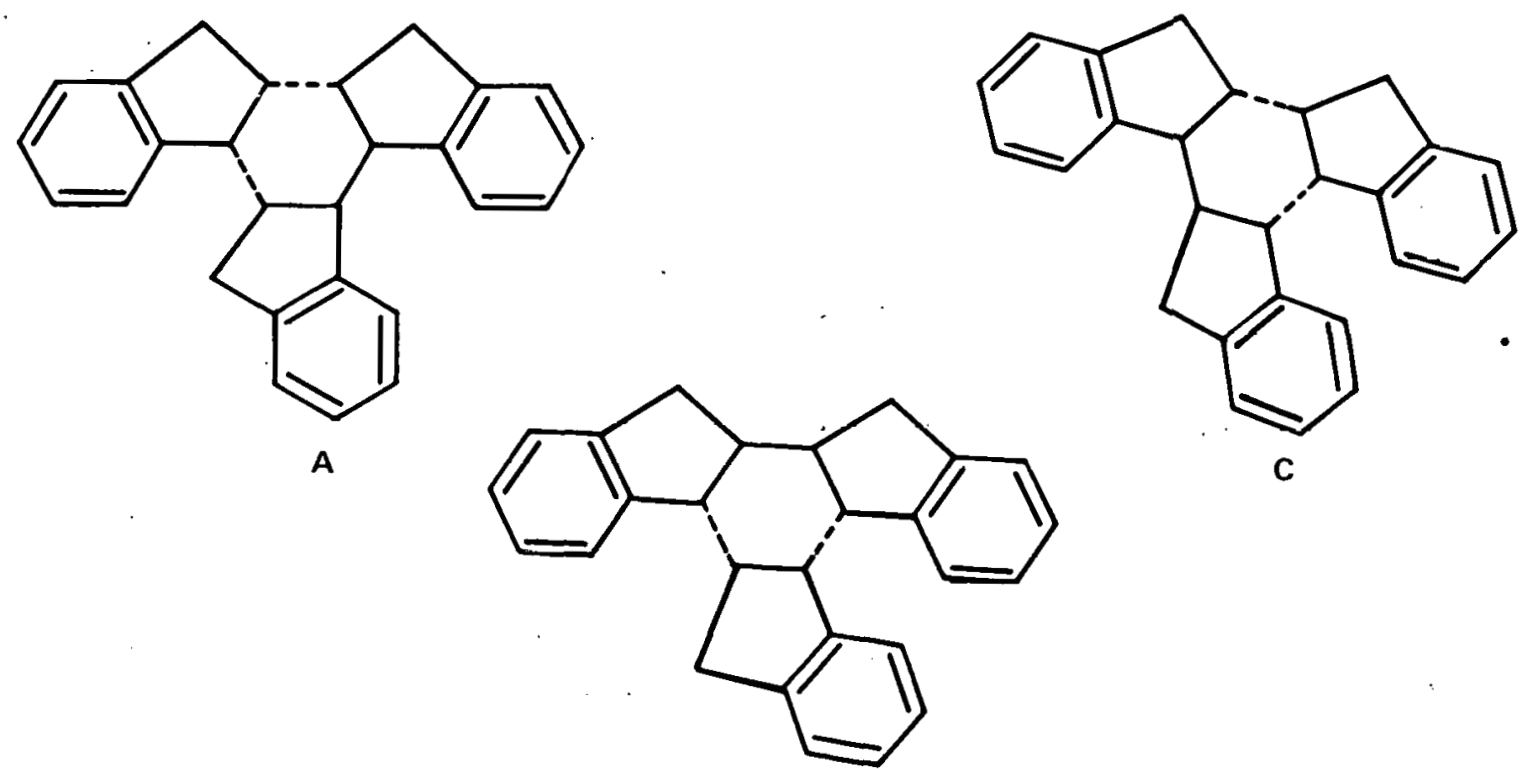

B

However, only one of the dimeric forms can combine with a third indene molecule to form truxene, this being the form coupled by $1,2^{\prime}$ (or $3,2^{\prime}$ ) bonding which can lead to the production of either isomer. The following diagram depicts the formation of truxene from this dimeric form:

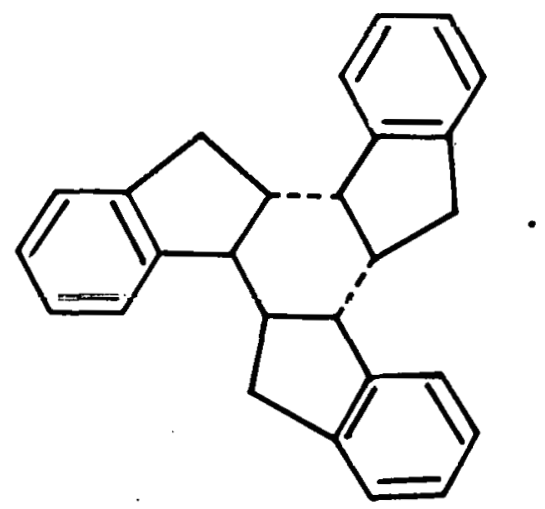

Due to the bond strain in the isotruxene molecule, the formation of the more thermally stable isomer (truxene) would be favored from the latter dimeric form. Thus, the course of the reaction is determined by the structure of the intermediate dimer forms and those factors which influence the structure of these dimers. Apparently, 1,4-naphthoquinone and the intermediates derived therefrom lead to the production of specific dimeric forms of indene. 


\section{Synthesis of Isotruxene Using Other Amines and Carbonyl Compounds}

Isotruxene was prepared by heating indene in the presence of compounds other than TMBDA and 1,4-naphthoquinone. Table 7 lists the amine compounds that were included in the formulations and the data on the resulting products. The ability of an amine to function in promoting the formation of isotruxene in good yield was related to the basicity of the amine. Tertiary aliphatic amines tended to produce isotruxene while aromatic amines promoted the formation of mixtures of isotruxene with other higher-melting compounds similar to those obtained in the absence of an amine (see Page 50). It was interesting to note that dimethylbenzylamine was sufficiently basic while tribenzylamine apparently was not. The use of melamine produced relatively high yields of a product mixture containing some isotruxene. In general, TMBDA appeared to be most satisfactory for producing isotruxene from indene and 1,4-naphthoquinone.

Table 7

SYNTHESIS OF ISOTRUXENE USING VARIOUS AMINE CATALYSTS

\begin{tabular}{|c|c|c|c|c|}
\hline Amine Catalyst (1) & $\begin{array}{c}\text { Yield Per } \\
\text { Mole of } \\
\text { 1,4-Naphthoquinone } \\
\text { (gms) }\end{array}$ & $\begin{array}{l}\text { Melting Point } \\
\text { of Crude } \\
\text { Product } \\
\left({ }^{\circ} \mathrm{C}\right)\end{array}$ & $\begin{array}{c}\text { Melting } \\
\text { Point of } \\
\text { Recrystallized } \\
\text { Product(2) } \\
\left({ }^{\circ} \mathrm{C}\right) \\
\end{array}$ & $\begin{array}{l}\text { Isotruxene } \\
\text { Content } \\
\text { of Crude } \\
\text { Product (3) } \\
\text { (wt \%) } \\
\end{array}$ \\
\hline $\begin{array}{l}N, N, N^{\prime}, N^{\prime} \text {-tetramethyl-1, } \\
\text { 3-butanediamine }\end{array}$ & 347 & $207-211$ & - & 68.4 \\
\hline $\begin{array}{l}N, N, N^{\prime}, N^{\prime} \text {-tetramethyl-1, } \\
\text { 3-butanediamine (4) }\end{array}$ & 308 & $202-210$ & - & 70.5 \\
\hline $\begin{array}{l}N, N, N^{\prime}, N^{\prime} \text {-tetramethyl-1, } \\
\text { 4-butanediamine }\end{array}$ & 343 & $200-210$ & $217-219$ & 69.3 \\
\hline $\begin{array}{l}N, N, N^{\prime}, N^{\prime} \text {-tetramethyldiamino- } \\
\text { methane }\end{array}$ & 316 & $207-214$ & $219-222$ & 79.1 \\
\hline $\begin{array}{l}N, N, N^{\prime}, N^{\prime} \text {-tetramethyl-1, } \\
\text { 6-thexanediamine }\end{array}$ & 339 & $205-208$ & $213-224$ & 74.0 \\
\hline$N$-methylmorpholine & 344 & $198-208$ & $210-221$ & 58.4 \\
\hline M-phenylenediamine & 221 & $210-285$ & - & - \\
\hline Tripropylamine & 313 & $210-215$ & $215-219$ & $41.5(5)$ \\
\hline Tribenzylamine & 69 & $220-300$ & - & $-(6)$ \\
\hline $\begin{array}{l}\text { p, po-tetramethyldiamino- } \\
\text { diphenylmethane }\end{array}$ & 40 & $250-270$ & - & $-(7)$ \\
\hline Hexamethylenetetramine & 298 & $200-210$ & $219-225$ & 92.5 \\
\hline Melamine & 543 & $203-290$ & - & - \\
\hline Dimethylbenzylamine & 285 & $203-215$ & $215-220$ & 63.3 \\
\hline
\end{tabular}

(1) Reactant ratio of indene, 1,4-naphthoquinone, and catalyst was 100:10:1 by weight.

(2) Products recrystallized from hot xylene.

(3) Isotruxene content determined from GPC scans.

(4) Reactant ratio of indene, 1,4-naphthoquinone, and catalyst was 100:10:1.3 by weight.

(5) Two impurity bands of equal intensity were observed on GPC scan.

(6) Product contained 2.6 percent oxygen.

(7) Product contained 2.0 percent oxygen. 
Carbonyl compounds other than 1,4-naphthoquinone were used to produce isotruxene. These substances are included in Table 8. In general, products of higher yield and purity were obtained when using 1,4-naphthoquinone.

Table 8

PRODUCTS FROM THE REACTION OF CARBONYL COMPOUNDS WITH INDENE

\begin{tabular}{|c|c|c|c|c|c|}
\hline \multirow[b]{2}{*}{ Carbonyl Compound (1) } & \multirow[b]{2}{*}{ Product } & \multirow[b]{2}{*}{$\begin{array}{l}\text { Melting } \\
\text { Point } \\
\left({ }^{\circ} \mathrm{C}\right)\end{array}$} & \multicolumn{2}{|c|}{ Molecular Weight } & \multirow{2}{*}{$\begin{array}{c}\text { Infrared Absorption } \\
\text { in } 800-700 \mathrm{gm}^{-1} \\
\text { Region }(2) \\
\left(\mathrm{cm}^{-1}\right) \\
\end{array}$} \\
\hline & & & $\begin{array}{l}\text { By Vapor } \\
\text { Pressure } \\
\text { Osiriumeler }\end{array}$ & $\begin{array}{c}\text { By Mass } \\
\text { Spectrometer }\end{array}$ & \\
\hline 2,5-dichloro-1,4-benzoquinone & Isotruxene & $223-225$ & 336 & 342 & 754,718 \\
\hline 1,4-naphthoquinone & Isotruxene & $219-223$ & 341 & 342 & 754,713 \\
\hline 2-methyl-1,4-naphthoquinone & Truxene & $378(3)$ & 308 & - & 730 \\
\hline 2,3-dichloro-1, 4-naphthoquinone & Truxene & - & 353 & 342 & 730 \\
\hline Anthraquinone & Truxene & $379(3)$ & 334 & 342 & 730 \\
\hline 2-methylanthraquinone & Truxene & $387(3)$ & 345 & - & 730 \\
\hline 2-chloroonthraquinone & Isotruxene & $224-228$ & 340 & - & 754,714 \\
\hline 1,4-dihydroxynaphthalene(1) & Isotruxene & $222-224$ & 339 & - & 753,712 \\
\hline Terephthaldehyde & Truxene & $385(3)$ & 343 & 342 & 728 \\
\hline $\begin{array}{l}9,10 \text {-dioxo-1, } 4,9,10,11,12- \\
\text { hexahydro-1, 4-methylenanthracene }\end{array}$ & Isotruxene & 215 & 350 & 342 & 760,716 \\
\hline $\begin{array}{l}9,10 \text {-dioxo-1, } 4,5,8,9,10,11,12, \\
13,14 \text {-decahydro- } 1,4,5,8 \text {-di- } \\
\text { methylanthracene }\end{array}$ & Truxene & $>290$ & 1,162 & - & 730 \\
\hline 2,5-dipheny!-1,4-benzoquinone & Mixture & 225 & 388 & 342 & $730,752,713$ \\
\hline
\end{tabular}

(1) 1,4-dihydroxynaphthalene, a reduced form of 1,4-naphthoquinone, is included.

(2) $\mathrm{C}-\mathrm{H}$ wagging region for aromatic compounds having four adjacent hydrogen atoms in one six-membered ring.

(3) Melting points from differential thermul analysis.

Synthesis of Truxene from Rcactions of Indene and Terephthaldehyde

The production of pure truxene was accomplished by reacting indene and terephthaldehyde under reflux temperatures $\left(180-220^{\circ} \mathrm{C}\right)$. As previously discussed (Page 31), the reaction of indene and terephthaldehyde in a methanolpotassium hydroxide solution at room temperature occurred by an aldoltype condensation, producting a benzofulvene derivative. However, when heated under reflux for 40 - 48 hours in the presence of an amine, indene and terephthaldehyde reacted to produce truxene. The experimental procedure consisted of dissolving 268 grams of terephthaldehyde in a mixture of 1,500 grams of indene and 15 grams of $N, N, N^{\prime}, N^{\prime}$-tetramethyl-1,3-butanediamine (TMBDA), followed by heating under reflux for 48 hours. (Pot temperature may rise to $230-250^{\circ} \mathrm{C}$.) The molten reaction mixture was cooled to approximately $100^{\circ} \mathrm{C}$ and diluted with an equal volume of methyl ethyl ketone (MEK). After cooling 
to room temperature with stirring, the product was collected by filtration. The fusion temperature of the product was approximately $370^{\circ} \mathrm{C}$, as shown in the thermogram in Figure 30. Product yields ranged from 200 to 250 grams, representing approximately $13-17$ percent of the initial weight of indene.

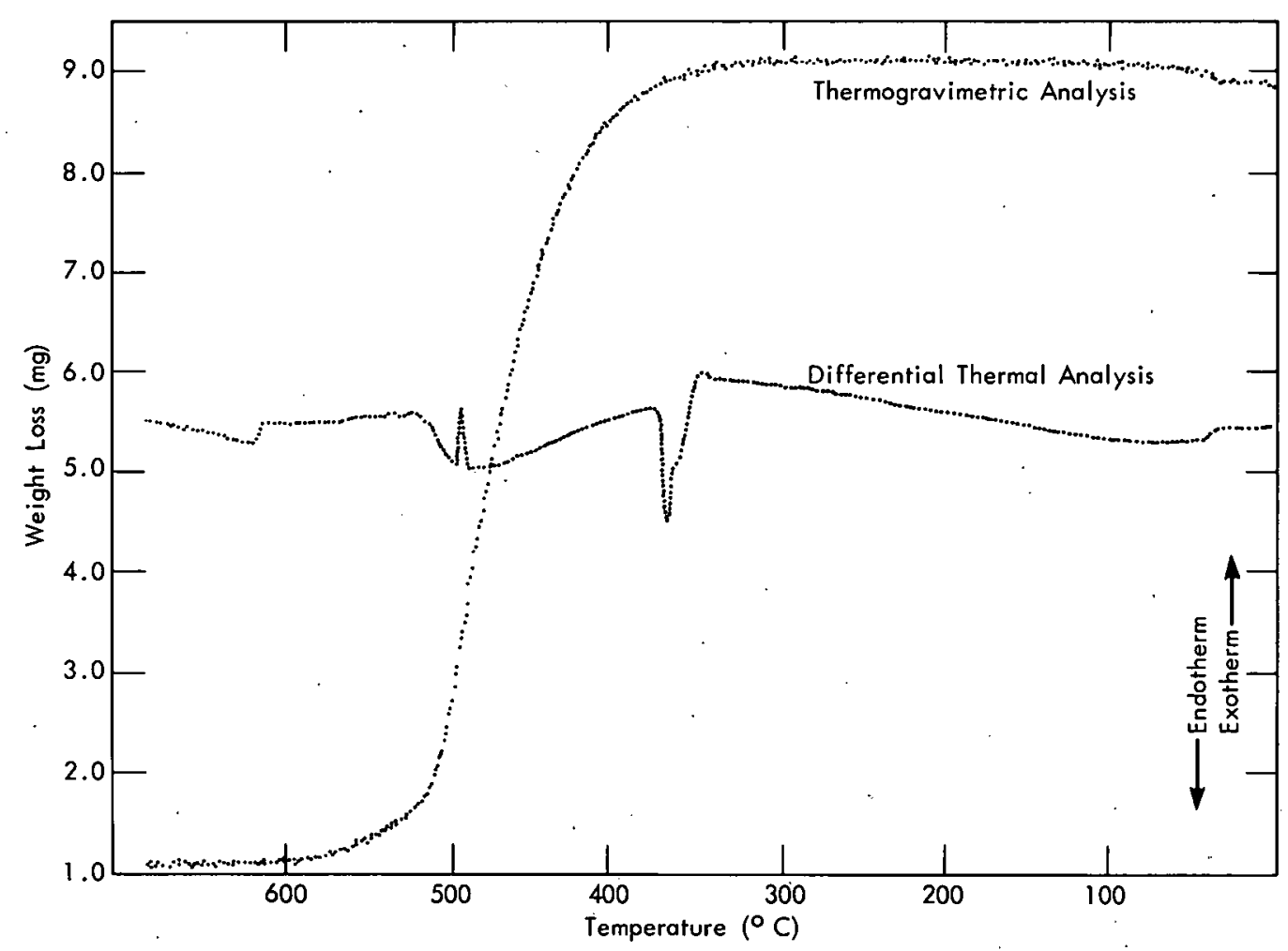

Figure 30. THERMOGRAM OF TRUXENE. (11.7 mgs)

The influence of the amine in this reaction system is unknown and open to question since truxene has been made in its absence. The amine did not react with terephthaldehyde to form reactive intermediates as occurred with 1,4naphthoquinone. Though the presence of an amine did appear to enhance the reaction rate, the extended heating period was more fundamental to the production of truxene by this method.

Other dicarbonyl compounds which were reacted with indene to produce truxene are included in Table 8. As previously stated, 1,4-naphthoquinone compounds with substituents in Position 2 do not promote the formation of isotruxene but rather result in the production of truxene.

Synthesis of Isomeric Mixtures of Truxene and Isotruxene by Autoclave Treatment of Indene

Truxene-isotruxene mixtures were prepared by heating indene under pressure in an autoclave. This process, which is described elsewhere in the literature, ${ }^{(8)}$ 
resulted in an approximate 25 percent conversion of indene into truxene and/or isotruxene. The experimental procedure consisted of heating indene in an autoclave at $200-350^{\circ} \mathrm{C}$ and under pressures of $500-800$ psi. Products were isolated by dilution of the reaction mixture with an equal volume of MEK followed by filtration of the insoluble precipitate.

The composition of these isomeric mixtures of truxene and isotruxenè was determined without fractionation by using ultraviolet absorption techniques. Isotruxene absorbs strongly at an energy corresponding to a wavelength of 3,375 A, while absorption by truxene in this region is negligible. A calibration curve was determined by measuring the absorption intensities as a function of the isotruxene content in standard mixtures of truxene and isotruxene. The absorption intensities of production samples were then compared to this standard curve, and the isotruxene content was recorded. Though representative sampling is of utmost importance, the method appears reproducible to \pm 1 percent. (19)

The yield and composition of the isomeric product mixtures appeared to be influenced by the reaction time and temperature, but quite insensitive to variable pressures in the range from 300 to 1,000 psi. Data on a series of autoclave reactions that were run at temperatures of 250,300 , and $350^{\circ} \mathrm{C}$, and for heating periods of 1, 2, 4, 6, and 24 hours, are summarized in Table 9. Each sample, consisting of 2,000 grams of indene, was placed in a five-liter autoclave that was initially pressurized to 300 psi. The heating times represent the hold time at the designated reaction temperature.

The data reported in Table 9 and presented graphically in Figure 31 indicate that the product yield and composition were essentially constant with the heating time for a reaction temperature of $250^{\circ} \mathrm{C}$. The slight maximum in product yield after four hours has not been confirmed as yet, but it does coincide with the maximum observed after four hours for a temperature of $300^{\circ} \mathrm{C}$. The composition of the product after two hours appeared incompatible with the rest of the data; and, therefore, may be justifiably questioned. Thus, heating periods of lengths greater than one hour at $250^{\circ} \mathrm{C}$ offer no distinct advantages in terms of product yield and composition. As stated, a maximum in the product yield was also observed after four hours for samples of indene heated at $300^{\circ} \mathrm{C}$. In general, data obtained at this temperature closely parallel that described for reactions carried out at $250^{\circ} \mathrm{C}$. There is an exception in that product yields at the higher temperature were slightly greater, as was the isotruxene content in the product mixtures, though the latter values were somewhat scattered.

At a reaction temperature of $350^{\circ} \mathrm{C}$, a product yield maximum was clearly achieved after a two to four-hour heating period, though this maximum value is no greater than those observed for 250 and $300^{\circ} \mathrm{C}$. The low yield after one 
Table 9

PREPARATION OF ISOMERIC MIXTURES OF TRUXENE AND ISOTRUXENE BY HEATING INDENE UNDER. PRESSURE IN AN AUTOCLAVE

\begin{tabular}{|c|c|c|c|c|c|}
\hline Batch (1) & $\begin{array}{c}\text { Temperature } \\
(\circ \mathrm{C})\end{array}$ & $\begin{array}{c}\text { Time } \\
\text { at } \\
\text { Temperature } \\
\text { (hrs) }\end{array}$ & $\begin{array}{c}\text { Product } \\
\text { Yield (2) } \\
(\%)\end{array}$ & $\begin{array}{l}\text { Isotruxene } \\
\text { Content } \\
\text { in } \\
\text { Product (3) } \\
(\%)\end{array}$ & $\begin{array}{l}\text { Isotruxene } \\
\text { Yield(4) } \\
\text { (\%) }\end{array}$ \\
\hline $\begin{array}{l}\text { LI }-127-9 \\
\text { LI }-107-9 \\
\text { LI }-128-9 \\
\text { LI }-110-9 \\
\text { LI }-126-9\end{array}$ & $\begin{array}{l}250 \\
250 \\
250 \\
250 \\
250\end{array}$ & $\begin{array}{r}1 \\
2 \\
4 \\
6 \\
24\end{array}$ & $\begin{array}{l}22.7 \\
22.6 \\
24.3 \\
22.3 \\
23.5\end{array}$ & $\begin{array}{l}60.3 \\
52.3 \\
60.6 \\
62.0 \\
66.3\end{array}$ & $\begin{array}{l}13.7 \\
11.8 \\
14.7 \\
13.8 \\
15.6\end{array}$ \\
\hline $\begin{array}{l}\text { LI -134-9 } \\
\text { L1 -101-9 } \\
\text { L1 -135-9 } \\
\text { L1 - 109-9 } \\
\text { L1 -129-9 }\end{array}$ & $\begin{array}{l}300 \\
300 \\
300 \\
300 \\
300\end{array}$ & $\begin{array}{l}1 \\
2.25 \\
4 \\
6 \\
24\end{array}$ & $\begin{array}{l}23.8 \\
24.1 \\
26.3 \\
24.5 \\
25.3\end{array}$ & $\begin{array}{l}65.9 \\
62.1 \\
68.9 \\
56.4 \\
67.6\end{array}$ & $\begin{array}{l}15.7 \\
15.0 \\
18.1 \\
13.8 \\
17.1\end{array}$ \\
\hline $\begin{array}{l}\text { L2 -05-9 } \\
\text { 니 }-100-9 \\
\text { 니-108-9 } \\
\text { LI }-139-9 \\
\text { L1 }-140-9\end{array}$ & $\begin{array}{l}350 \\
350 \\
350 \\
350 \\
350\end{array}$ & $\begin{array}{r}1 \\
2 \\
4 \\
6 \\
24\end{array}$ & $\begin{array}{l}16.8 \\
23.5 \\
22.7 \\
19.2 \\
15.1\end{array}$ & $\begin{array}{l}45.6 \\
65.9 \\
54.6 \\
45.0 \\
31.3\end{array}$ & $\begin{array}{r}7.7 \\
15.5 \\
12.4 \\
8.6 \\
4.7\end{array}$ \\
\hline
\end{tabular}

(1) Samples of 2,000 gms of indene were heated in a five-liter autoclave at an initial pressure of 300 psi.

(2) Product yields of the isomeric mixtures of truxene and isotruxene represented the precentage of the initial indene sample that was isolated as a solid product.

(3) Estimated by ultraviolet spectrometry by comparing the absorption intensities of isotruxene in the samples with those of standard mixtures of truxene and isotruxene.

(4) Represents that fraction of the indene sample that was isolated as isotruxene.

hour at $350^{\circ} \mathrm{C}$ was hard to reconcile with the higher product yields after one hour at 250 and $300^{\circ} \mathrm{C}$, but the data were confirmed by duplicating the reaction. It would appear that the formation of dimeric and other intermediate forms of indene is accomplished more rapidly at the lower temperatures. Possibly, their formation is somewhat inhibited at the higher temperature because of certain mass-action relationships involving the formation and dissociation of these intermediates. The susceptibility of polymers of indene to fragmentation at temperatures above $300^{\circ} \mathrm{C}$ was previously noted. Prolonged heating of the product mixture at $350^{\circ} \mathrm{C}$ resulted in a decrease in product yield which was closely paralleled by a decrease in the isotruxene content. Isotruxene is apparently degraded on prolonged heating at $350^{\circ} \mathrm{C}$ rather than converted to the more thermally stable isomer (truxene). Thus, product yield and composition are quite sensitive to heating times for a reaction temperature of $350^{\circ} \mathrm{C}$.

In summation, it would appear that this product mixture can be produced at $250^{\circ} \mathrm{C}$ without loss in conversion efficiency rather than $350^{\circ} \mathrm{C}$, as recommended elsewhere in the literature, $(8)$ and that heating periods longer than one hour 


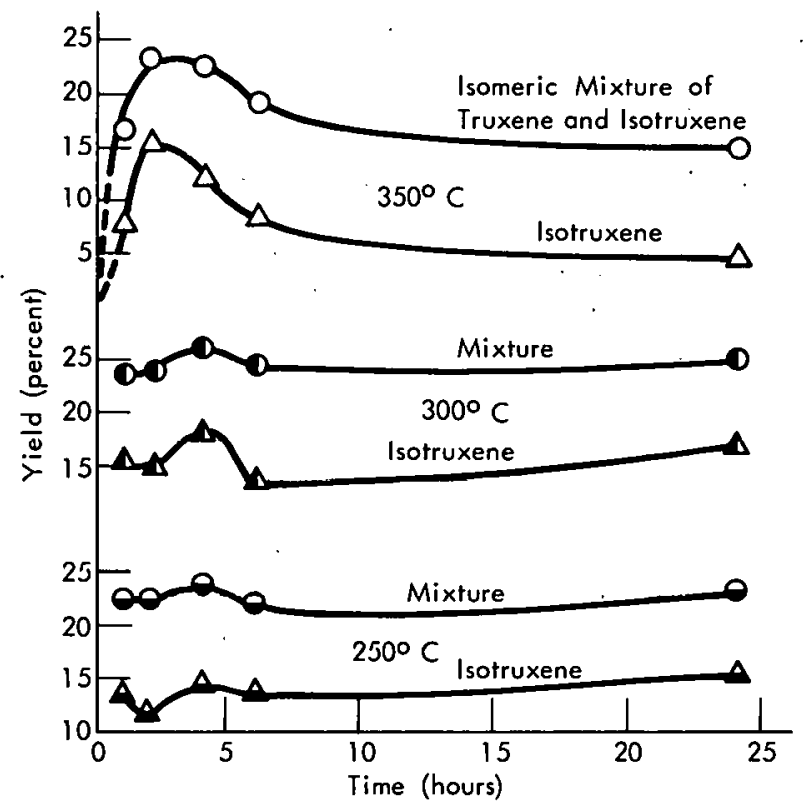

Figure 31. PRODUCT YIELDS OF TRUXENE AND ISOTRUXENE OBTAINED FROM INDENE AS A FUNCTION OF THE HEAT-TREATMENT TIME AND TEMPERATURE IN AN AUTOCLAVE.

are unnecessary at lower temperatures and may even be detrimental at high $\left(350^{\circ} \mathrm{C}\right)$ reaction temperatures. Initial experiments conducted at $200^{\circ} \mathrm{C}$ indicated that product yields were reduced in dropping from 250 to $200^{\circ} \mathrm{C}$. A yield of only 14 percent was obtained after heating a reaction mixture for 24 hours at $200^{\circ} \mathrm{C}$.

The composition of these isomeric mixtures would indicate that all three of the dimeric forms previously listed (see Page 56) are being formed as intermediates during thermal polymerization of indene. As previously stated, two of the dimeric structures would lead to the production of isotruxene only and a third could theoretically result in producing either isomer, although the formation of truxene would be favored due to less bond strain and higher thermal stability. The fact that truxene was not formed on thermal degradation of isotruxene indicated that the fragments did not include the dimeric precursor to truxene.'

Formulations consisting of indene and various carbonyl compounds that were known to produce either truxene or isotruxene on heating under reflux were subjected to heat treatment in an autoclave $\left(350^{\circ} \mathrm{C}\right.$ for two hours) after being heated under reflux for 24,48 , and 72 hours. Data on these reactions and the resulting products are listed in Table 10. Mixtures of the isomeric truxenes - were recovered after an autoclave treatment rather than a single specific isomer, as occurs on reflux. Of the carbonyl compounds used, 1,4-naphthoquinone 
Table 10

PRODUCTION OF ISOMERIC MIXTURES OF TRUXENE AND

ISOTRUXENE BY. HEATING MIXTURES OF INDENE AND

CARBONYL COMPOUNDS UNDER REFLUX PRIOR TO

HEAT TREATMENT IN AN AUTOCLAVE AT $350^{\circ} \mathrm{C}$ FOR TWO HOURS

\begin{tabular}{|c|c|c|c|c|}
\hline \multirow[b]{2}{*}{ Batch } & \multirow[b]{2}{*}{$\begin{array}{c}\text { Reflux Time } \\
\text { Prior to } \\
\text { Autoclave Heat } \\
\text { Treatment } \\
\text { (hrs) }\end{array}$} & \multicolumn{3}{|c|}{ Data After Autoclave Heat Treatment } \\
\hline & & $\begin{array}{c}\text { Product } \\
\text { Yield(1) } \\
(\%)\end{array}$ & $\begin{array}{c}\text { Isotruxene } \\
\text { Content in } \\
\text { Product(2) } \\
(\%) \\
\end{array}$ & $\begin{array}{c}\text { Isotruxene } \\
\text { Yield } \\
(\%)\end{array}$ \\
\hline $\begin{array}{l}L 1-104-9 A(3) \\
L 1-104-9 B(3) \\
L 1-104-9 C(3)\end{array}$ & $\begin{array}{l}24 \\
48 \\
96\end{array}$ & $\begin{array}{l}30.5 \\
32.5 \\
32.7\end{array}$ & $\begin{array}{l}50.2 \\
71.4 \\
65.9\end{array}$ & $\begin{array}{l}15.3 \\
23.2 \\
21.6\end{array}$ \\
\hline $\begin{array}{l}L 1-105-9 A(4) \\
L 1-105-9 B(4) \\
L 1-105-9 C(4)\end{array}$ & $\begin{array}{l}24 \\
48 \\
96\end{array}$ & $\begin{array}{l}34.1 \\
34.4 \\
38.0\end{array}$ & $\begin{array}{l}44.8 \\
50.3 \\
50.8\end{array}$ & $\begin{array}{l}15.3 \\
17.3 \\
19.3\end{array}$ \\
\hline $\begin{array}{l}L 1-106-9 A(5) \\
L 1-106-9 B(5) \\
L 1-106-9 C(5)\end{array}$ & $\begin{array}{l}24 \\
48 \\
96\end{array}$ & $\begin{array}{l}24.5 \\
27.8 \\
30.3\end{array}$ & $\begin{array}{l}52.7 \\
49.8 \\
51.7\end{array}$ & $\begin{array}{l}12.9 \\
13.9 \\
15.7\end{array}$ \\
\hline
\end{tabular}

(1) Weight of solid product mixture relative to starting weight of indene.

(2) Determince by ultraviolet absorption spectrometry by comparing absorption intensities of isotruxene in the product with those of standard mixtures of truxene and isotruxene.

(3) Reaction formulation consisted of 1,500 gms indene and $158 \mathrm{gms}$ 1,4naphthoquinone.

(4) Reaction formulation consisted of 1,500 gms indene and 222 gms 2-methylanthraquinone.

(5) Reaction formulation consisted of 1,500 gms indene and $134 \mathrm{gms}$ terephthaldehyde.

was known to produce isotruxene while 2-methylanthraquinone and terephthaldehyde were known to produce truxene. The product yields obtained on autoclave treatment of these preheated formulations were higher than those realized from indene alone, and the yield of any one formulation appeared to increase with increasing length of the preheating period. The isotruxene content in the products isolated from formulations including 2-methylanthraquinone and terephthaldehyde (which produce truxene on extended refluxing with indene) was lower than that observed when indene was heated alone (at $350^{\circ} \mathrm{C}$ for two hours). The isotruxene content in the product resulting from the formulation, including 1,4-naphthoquinone, was not significantly different from that obtained by heating indene alone. While these preheat methods resulted in an increase in product yield over that obtained on heating indene alone (at $250^{\circ} \mathrm{C}$ for two hours), and the inclusion of the carbonyl compound did alter within limits the composition of the products, the additional heating times of 24 or more hours would be undesirable for production processes when compared to a single heating step of one-hour duration.

Fractionation of these isomeric mixtures of truxene and isotruxene by solvent extraction is possible due to significant differences in the solubility of the two isomers. Extraction methods consisted of a room-temperature extraction of 
the mixture with chloroform in which isotruxene is preferentially soluble. The insoluble truxene is filtered and may be leached with hot xylene to remove any remaining isotruxene. The isotruxene fraction is recovered by evaporating the chloroform extract, producing a residue with a residual truxene content that is directly proportional to the quantity of chloroform used in the extraction of a unit weight of the mixture.

The major volatile by-product of this autoclave process for converting indene to the isomeric truxenes is indane. After completing a reaction, the indane was recovered by vacuum distillation of the filtrate in a yield which was equivalent to 60 percent of the starting weight of the filtrate. Thus, recovery of this product could be accomplished in the process operation and could be marketed or possibly cracked back to indene for recycling.

\section{REACTIONS OF ISOTRUXENE}

Little is known about the reactivity of isotruxene toward substitution, addition, or oxidation reactions, so each of these reaction types was included in the present study. Substitution reactions involved an electrophilic attack (attack by a positive entity at a position of high electron density) and was carried out by reacting bromine and isotruxene; addition reactions included vinylation of isotruxene at the methylene site by heating under acetylene pressure (see Page 20); oxidation of isotruxene was accomplished by heating in the presence of oxygen gas and by reacting with chromium trioxide.

\section{Electrophilic Substitution Reactions}

Electrophilic attack can occur at any of twelve possible aromatic positions on the periphery of the isotruxene molecule, as shown by the following structure (the truxene structure is included for purposes of comparison):

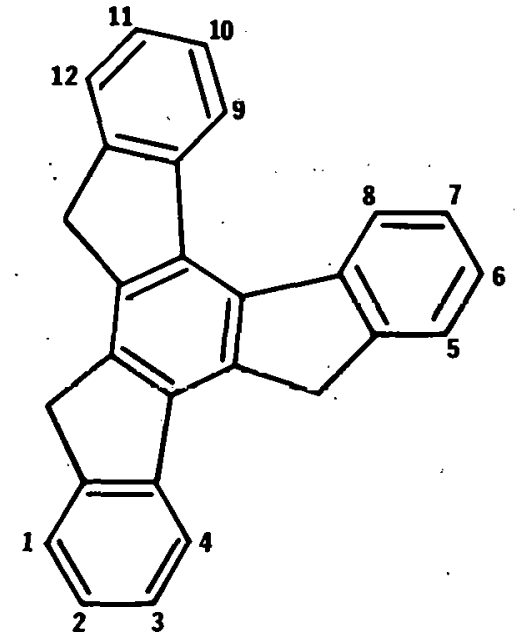

Isot ruxene

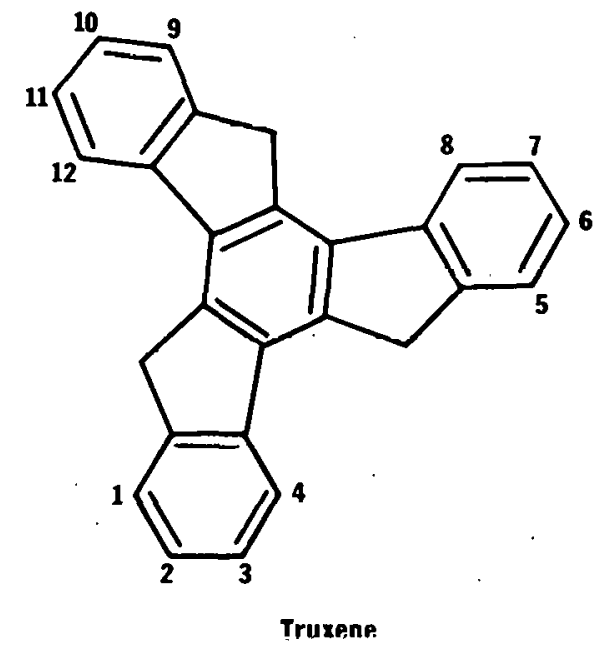


However, there is not an equal probability of a reaction at each position, but the reaction is influenced by the steric properties and resonance stabilization that results from an attack at a given position. Electrophilic attack at any one of the twelve aromatic positions will result in resonance forms which accommodate and tend to stabilize the positively charged intermediate. The greater the number of intermediate resonance forms, the greater the stability of the intermediate and the lower the energy required to initiate a reaction at the position giving these resonance forms. The isotruxene structure that follows represents one possible resonance form that would result from electrophilic attack at Position 11 by a positively charged group $\left(A^{+}\right)$.

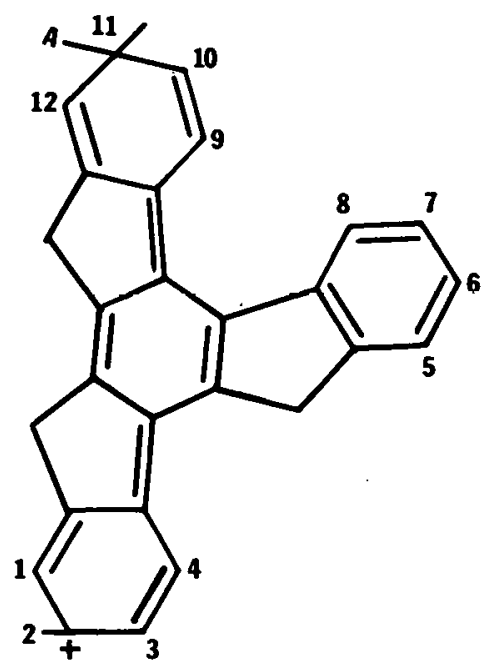

The positive charge thus introduced into the structure is depicted as localized at Position 2. This example represents one of twelve possible sites that the charge might occupy and one of twelve resonance structures which can be depicted for an electrophilic attack at Position 11. The number of resonance forms that are possible by an attack at each of the twelve aromatic positions is given in Table. 11 for both truxene and isotruxene. As listed, Positions 9 and 11 in the isotruxene structure allow the largest number of stabilizing resonance forms. Thus, these two positions should be the most reactive to electrophilic attack if all other factors are assumed to be constant. This, however, is not true in that Position 9 has a high degree of steric hinderance due to the proximity of Position 8. Models of these molecules indicate that the proximity of the hydrogens at these positions is such as to cause bond strain in the isotruxene molecule. Position 11 then emerges as the most reactive of the twelve aromatic positions. The second most reactive position in the molecule would be one of the four positions having nine possible resonance forms since a reaction is prohibited at Position 9. Of the four positions having nine possible resonance forms, Positions 4 and 8 are sterically hindered, leaving Positions 2 and 6 to compete 
for an electrophilic entity. Ignoring mass and solubility effects, the reactivity of the mono and disubstituted forms should thus be equal. In practice, however, disubstituted products would form at a faster rate than trisubstituted products since the monosubstituted product would of greater solubility and mobility than the disubstituted product.

In theory, isotruxene should form a monosubstituted product when reacted with an equimolar quantity of an electrophilic reagent, and the substitution should occur at Position 11 . When reacted in a 2:1 molar ratio, an equilibrium mixture of mono, di, and trisubstituted products would theoretically result; when reacted in a 3:1 molar ratio, a 2, 6, 11-trisubstituted product should result. Reactions of bromine with isotruxene were carried out in order to compare the experimental data with that predicted by theory. The reaction which produced a monosubstituted compound is:
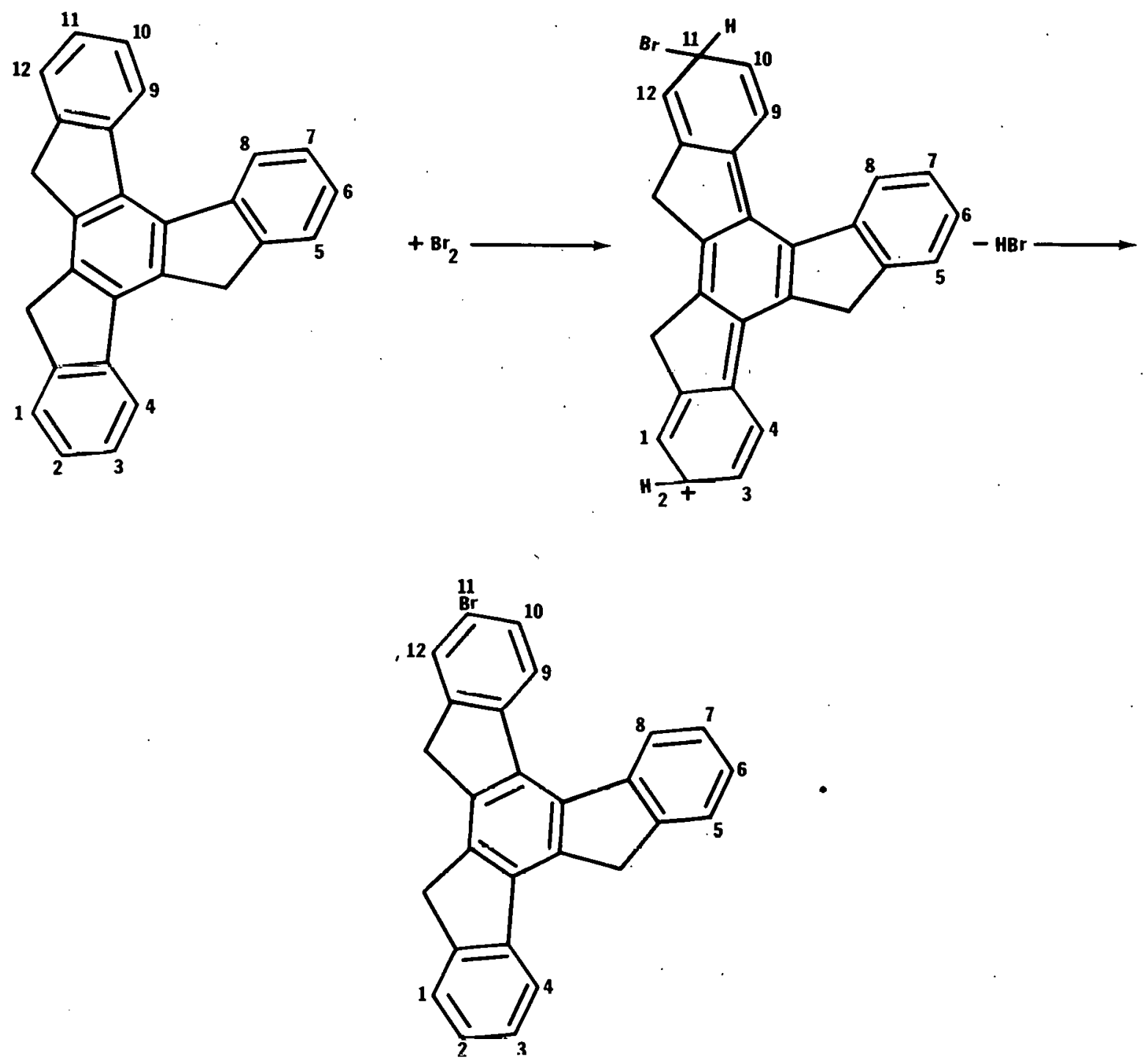
Table 11

INTERMEDIATE RESONANCE FORMS POSSIBLF FOR MOLECULES OF TRUXENE AND ISOTRUXENE DURING ELECTROPHILIC ATTACK

\begin{tabular}{ccc}
\hline $\begin{array}{c}\text { Position of } \\
\text { Atrock }(1)\end{array}$ & \multicolumn{2}{c}{ Resonance Forms Possible } \\
\cline { 2 - 3 } 1 & Truxene & Isotruxene \\
2 & 3 & 3 \\
3 & 6 & 9 \\
4 & 3 & 3 \\
5 & 6 & 9 \\
6 & 3 & 3 \\
7 & 6 & 9 \\
8 & 3 & 3 \\
9 & 6 & 9 \\
10 & 3 & 12 \\
11 & 6 & 3 \\
12 & 3 & 12 \\
\hline
\end{tabular}

(1) See Page 65.

The electrophilic agent in these reactions is presumed to be the $\mathrm{Br}^{+}$ion.

Experimentally, 34.2 grams of isotruxene (1 mole) were suspended in 250 milliliters of chloroform, and 5.5 milliliters of bromine (in $25 \mathrm{mls}$ of $\mathrm{CHCl}_{3}$ ) were added dropwise with stirring at room temperature. After 12 hours, the solids were collected by filtration and washed with chloroform. The product was observed to melt at $210-212^{\circ} \mathrm{C}$ (found - $19.1 \% \mathrm{Br}$; calculated for $\mathrm{C}_{27} \mathrm{H}_{17} \mathrm{Br}$ $19.0 \% \mathrm{Br}$ ). Mass spectroscopy indicated a monobromoisotruxene compound containing trace amounts of di and tribrominated products. Due to the nature of the substituent, the monobrominated compound will allow ten rather than nine resonance forms for subsequent electrophilic attack at Positions 2 and 6 . This additional resonance form for an attack at Position 2 is:

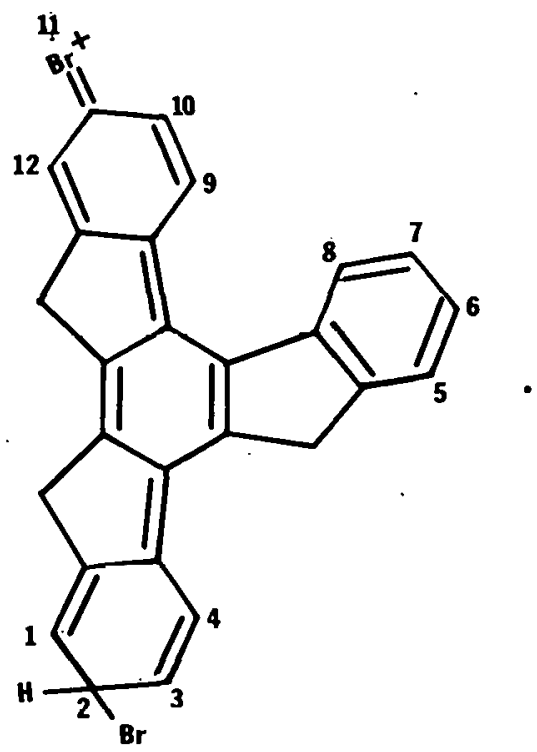


Bromine was reacted with isotruxene in a 2:1 molar ratio by adding the bromine dropwise to a solution of isotruxene in chloroform. Analysis of the insoluble product by mass spectrometry indicated a mixture of mono, di, and tribrominated products, as was previously predicted. The composition of the mixture was not determined.

When bromine and isotruxene were reacted in a 3.2:1 molar ratio, a highly insoluble product, melting at $298-301^{\circ} \mathrm{C}$, was isolated (found $-39.6 \% \mathrm{Br}$; calculated for $\mathrm{C}_{2} \mathrm{H}_{15} \mathrm{Br} 3-41.4 \% \mathrm{Br}$ ). Mass analysis indicated the compound to be largely tribromoisotruxene with a contamination of dibromoisotruxene.

The reaction position on each ring was not determined, but infrared data indicated substitution at equivalent positions in each ring. As the bromine/isotruxene ratio increased, aliphatic $\mathrm{C}-\mathrm{H}$ stretching absorptions $\left(2,880 \mathrm{~cm}^{-1}\right)$ increased in intensity relative to the aromatic $\mathrm{C}-\mathrm{H}$ stretch absorption $\left(3,000-3,080 \mathrm{~cm}^{-1}\right)$, denoting substitution of protons at the aromatic positions. Absorption denoting unsymmetrical trisubstitution increased in intensity while that denoting g-disubstitution decreased.

Vinylation Reactions

Vinylation of isotruxene by heating in toluene solutions under acetylene pressure at $150-250^{\circ} \mathrm{C}$ resulted in the production of low-melting, noncrystalline materials. A one-liter autoclave was charged with isotruxene ( $34.2 \mathrm{gms})$, potassium hydroxide $(6 \mathrm{gms})$, water $(2 \mathrm{mls})$, and tolvene $(200 \mathrm{mls})$, and the system pressurized to 250 psi with acetylene. Samples were thus heated for five hours at 150,200 , and $250^{\circ} \mathrm{C}$. The products were recovered in a manner similar to that described for indene (Page 21). The product resulting from the heat treatment at $150^{\circ} \mathrm{C}$ consisted, in part (50\%), of unreacted isotruxene in crude form (average molecular weight, 381). A second portion was a noncrystalline product with an average molecular weight of 422 . Products from the reactions at 200 and $250^{\circ} \mathrm{C}$ had average molecular weights of 418 and 473 , respectively, and were observed to fuse at approximately $70^{\circ} \mathrm{C}$. The molecular distribution of the $200^{\circ} \mathrm{C}$ product may be compared with that of isotruxene in Figure 32. An even higher polymeric content was observed in GPC scans of the $250^{\circ} \mathrm{C}$ product. Little change in the properties of isotruxene occurred on heating samples to $200^{\circ} \mathrm{C}$ in the absence of acetylene, as was determined by staging "blank" reactions. Thus, the polymerization of isotruxene was not due to heat treatment in the presence of potassium hydroxide, but apparently resulted from an intermediate vinylated derivative.

\section{Oxidation Reactions}

The oxidation of isotruxene by chromium trioxide can be depicted by the following equation: $(8)$ 
<smiles>c1ccc2c(c1)Cc1c-2c2c(c3c1-c1ccccc1C3)-c1ccccc1C2</smiles>

Isotruxene

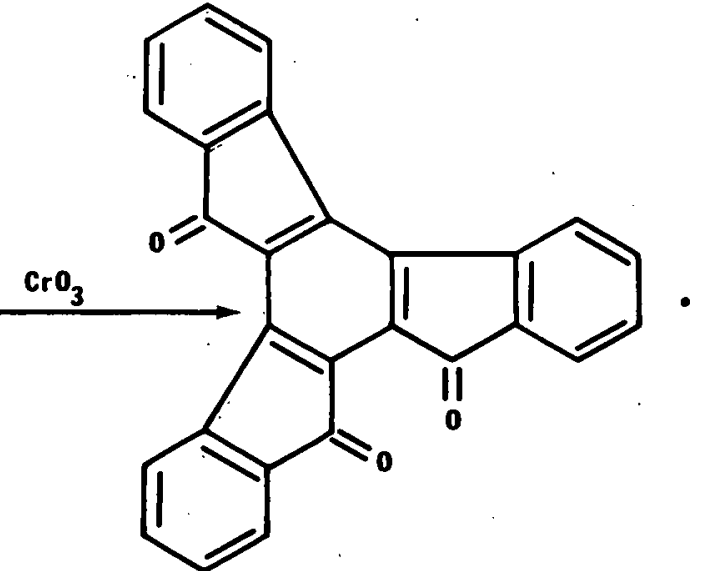

Tricarbonyl Compourid

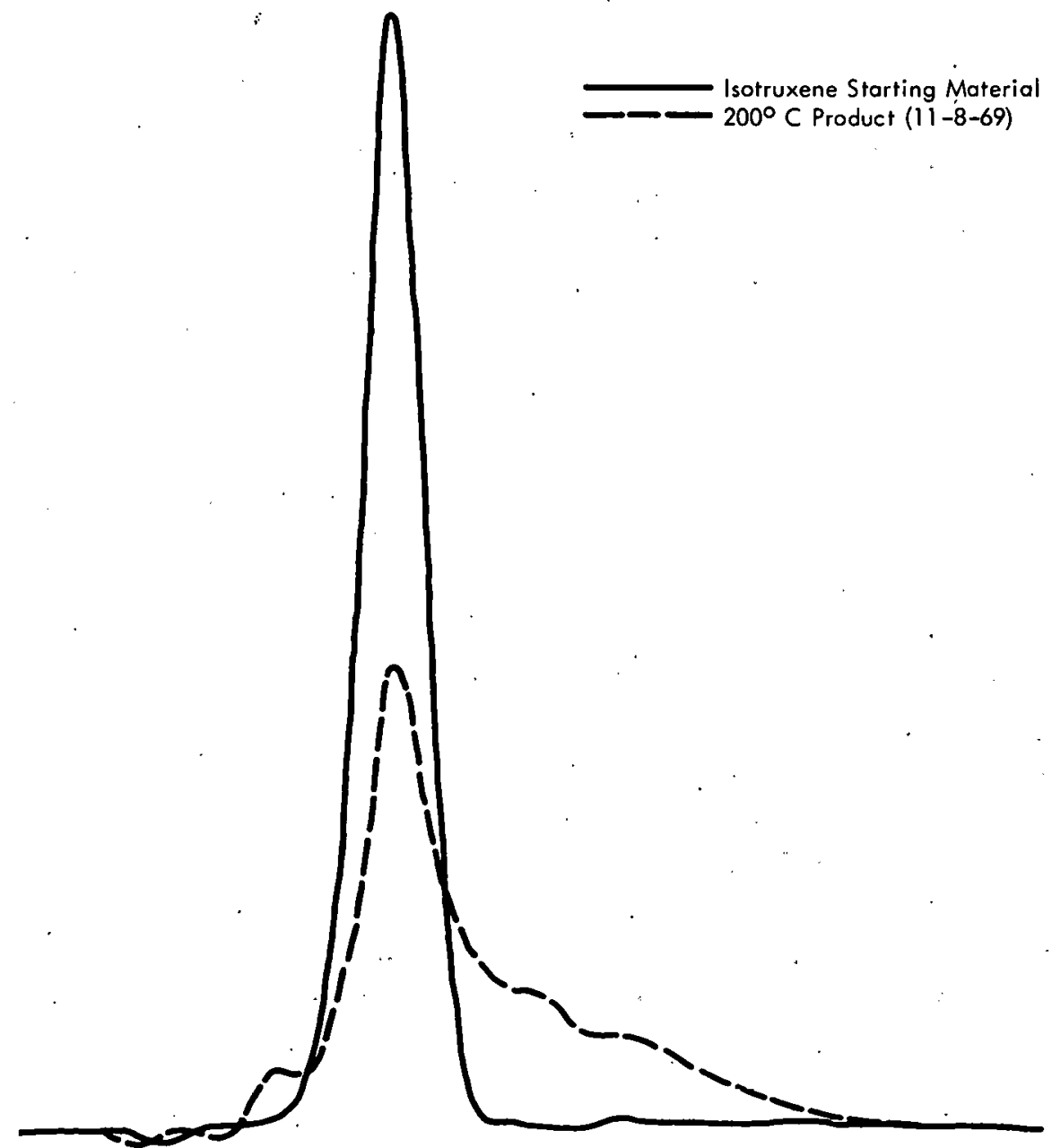

Figure 32. MOLECULAR DISTRIBUTION OF ISOTRUXENE BEFORE AND AFTER HEAT TREATMENT UNDER ACETYLENE PRESSURE AT $200^{\circ} \mathrm{C}$. 
Isotruxene was converted into a tricarbonyl compound through oxidation with chromiun trioxide in boiling glacial acetic acid. Isotruxene was dissolved in boiling glacial acetic acid, and a solution of chromium trioxide in water was added dropwise. After one hour, the mixture was allowed to cool and the insolubles collected. Analysis indicated the presence of 11 percent oxygen and some residual chromium $(\mathrm{l} \%)$. The tricarbonyl compound $\left(\mathrm{C}_{27} \mathrm{H}_{12} \mathrm{O}_{3}\right)$ should have an oxygen content of 12.5 percent, indicating possible contamination from a dicarbonyl compound $\left(\mathrm{C}_{2} 7 \mathrm{H}_{14} \mathrm{O}_{2}\right)$ which has an oxygen content of 8.65 percent. The product was dissolved in chloroform and passed through a column containing chromatographic-grade alumina. After evaporation of the solvent, the residue was sublimed to yield a brick-red material melting at $285-295^{\circ} \mathrm{C}$. This material was apparently still contaminated with the dicarbonyl compound.

Infrared absorption spectra of the product showed no methylenic hydrogen absorption at $2,880 \mathrm{~cm}^{-1}$, as is characteristic of isotruxene, but did show absorption at $1,700 \mathrm{~cm}^{-1}$, which is characteristic of carbonyl compounds.

Oxidation reactions of isotruxene were also carried out by bubbling oxygen gas through molten isotruxene. This procedure converts the isotruxene into a pitch-like material which initially decreases in its melting point with heating time as a eutectic mixture of oxidation products is formed. Heating for extended periods results in increases in the fusion temperatures. The change in fusion temperature with heating time is shown in Figure 33.

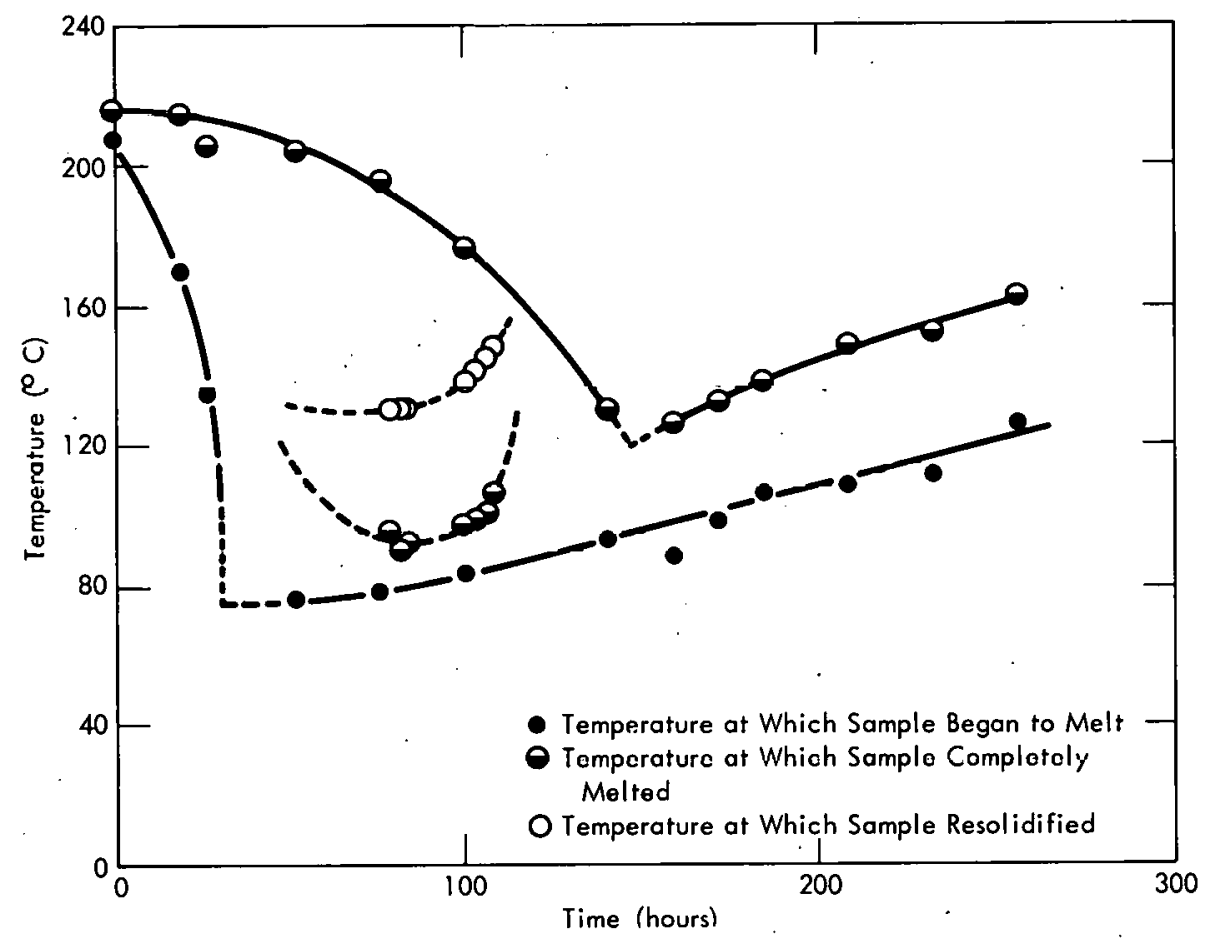

Figure 33. FUSION PROPERTIES OF ISOTRUXENE AS A FUNCTION OF TIME HEATED IN A FLOW OF OXYGEN. (245 $\left.\mathrm{C} ; 40 \ldots \mathrm{O}_{2} / \mathrm{min}\right)$ 
Mass spectrometric analysis of this product mixture indicates that, in addition to Mass 342 material (isotruxene), there are mono, di, and trioxo derivatives having masses of 356, 370, and 384, respectively. These masses indicate oxidation at the methylene sites with the simultaneous displacement of the methylenic protons. The presence of higher-molecular-weight products was apparent from GPC scans, as shown in Figure 34. In general, heat treatment of isotruxene decreased crystallinity and increased solubility, both of which are desirable for certain applications. Heat treatment in the presence of oxygen also results in significant increases in the coke yield of isotruxene.

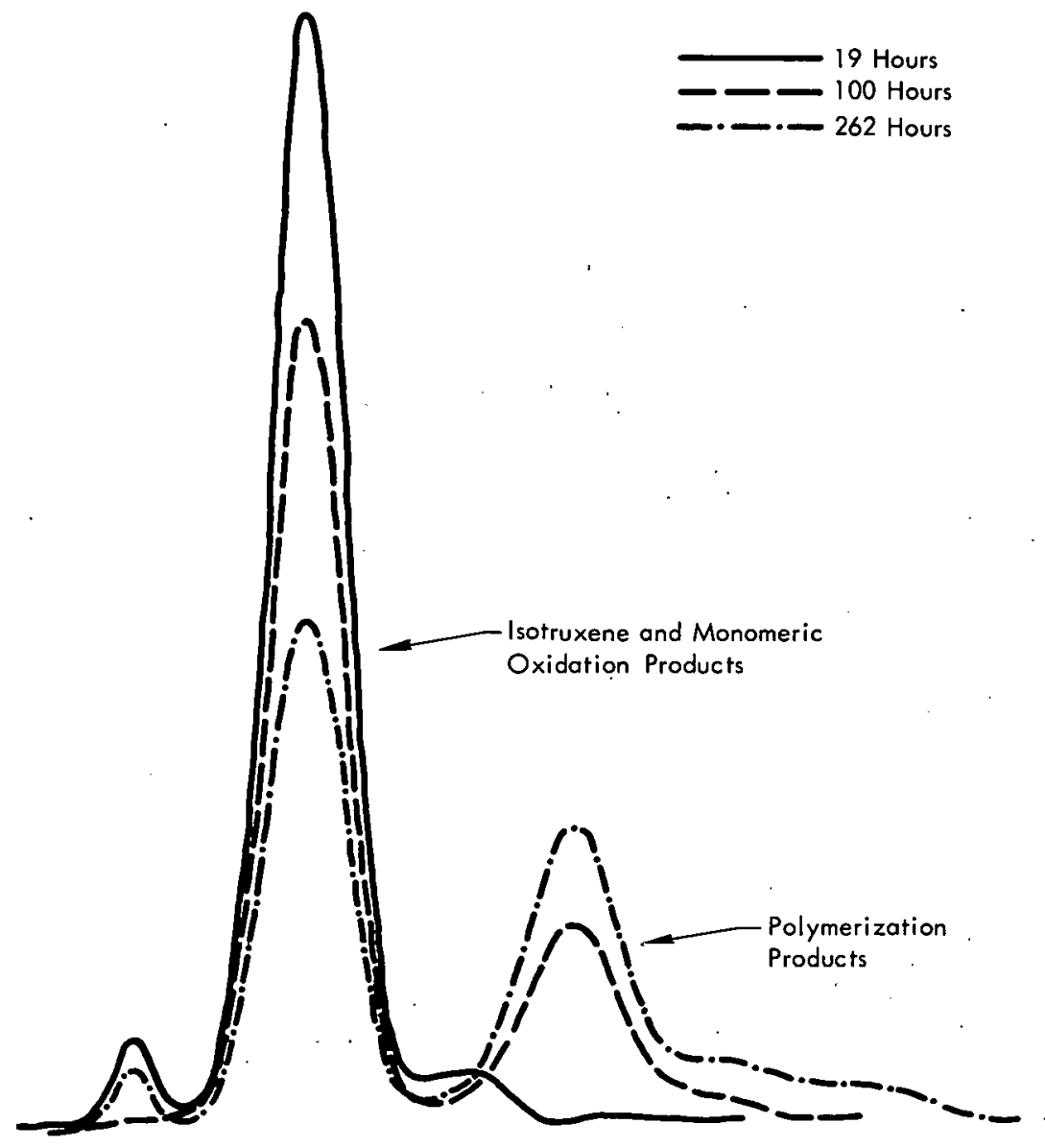

Figure 34. GEL PERMEATION CHROMATOGRAPHIC SCANS SHOWING THE MOLECULAR DISTRIBUTION OF ISOTRUXENE ON HEATING AT $245^{\circ} \mathrm{C}$ IN THE PRESENCE OF OXYGEN. (Flow Rate $=40 \mathrm{cc} / \mathrm{min}$ )

\section{CONCLUSIONS}

Certain of the indene-derived materials described in this report show promise as carbon precursor materials: (1) cinnaylideneindene, which can be obtained by a relatively simple synthetic procedure, is readily polymerized on heating 
above its melting temperature $\left(190^{\circ} \mathrm{C}\right)$ and yields approximately 50 weight percent carbon on pyrolysis at one atmosphere; (2) isotruxene, which can be selectively synthesized from indene, yields a graphitic carbon and appears to be useful as a precursor to binder or substrate carbon; (3) truxene yields a nongraphitic carbon and appears to be somewhat limited in binder applications due to its physical properties, but may be useful in combinations with isotruxene to induce variance in the graphitic properties of the subsequent carbons; (4) $\mathrm{p}$-xylylideneindene yields an infusible resin on heat treatment in air, and thus a nongraphitic carbon is formed on pyrolysis. Due to thermosetting properties, this material may have unique applications such as the formation of carbon spheres, or inclusion in thermoplastic materials to induce thermosetting properties in the resin and alter the properties of a subsequent carbon; (5) the grafting of vinyl groups onto organic molecules by heating under acetylene pressure represents a potentially useful way of inducing crosslinking in a polymeric system. 


\section{REFERENCES}

(1) Patai, S.; The Chiemistry of the Carbonyl Group, p 593; Interscience Publishers, New York (1966).

(2) Karrar, P.; Organic Chemistry, pp 404, 653; Elsevier Publishing Co, New York (1950).

(3) Indene Bulletin No. 1-R; Nelville Chemical Co, Pittsburgh, Pennsylvania (1963).

(4) Thiele, J. and Buhner, A.; "Kondensation von Inden mit Aldehyden", Ann, 347, pp 249-274 (1906).

(5) Thiele, J. and Merch, K.; "Kondensation von Inden mit Ketonen", Ann, $\underline{4}$, pp 257-273 (1918).

(6) Bernthsen, W.; "Condensation of Arylated Indene with Aldehydes", J Chem Soc, 114, I, pp 486-488 (1918).

(7) Courtot, C.; "Etude dans la Serie de Fulvenes", Ann Chim, 4, pp 58-136 (1915).

(8) Lang, K. F., Sander, M., and Theiling, E. E.; "Isotruxene", Chem Ber, $\underline{\underline{93}}$, pp $321-325$ (1960).

(9) Weast, R. C., ed; Handbook of Chemistry and Physics, 47th Edition, p. C375; The Chemical Rubber Company, Cleveland, Ohio (-1966).

(10) Ben-Ami, F., Mirelanan, D., and Zilkha, A.; "Anionic Heterogeneous Polymerization of Acrylonitrile by Butyllithium (I)", J of Applied Polymer Science, 9 , pp 2459-2474 (1965).

(11) Karpukhin, P. P. and Levchenko, A. I.; "Vinylation of Cyclic Hydrocarbons", Zhur Priklad Khim, 32, pp 1354-1359 (1959).

(12) Norman, R. 0. C.; Principles of Organic Chemistry, pp 231-233; Methuen and Co, Ltd, London (1968).

(13) Thiele, J.; "Ueher Kondensations: Producte des Indens", Ber d Deutsch Chem Ges, 33 pp 3395. 
(14) Williams, N. J. and Creech; E. T.; Personal Communication, Oak Ridge Y-12 Plant.

(15) Rainey, W. T.; Personal Communication, Oak Ridge National Laboratory.

(16) Noller, C. R.; Chemistry of Organic Compounds, 2nd Edition, pp 523, 511; W. B. Saunders Co, Philadelphia, Pennsylvania (1957).

(17) Pummerer, R., et al; "Polymerization Processes. Condensation of 1,4naphthoquinone to Triphthaloylbenzene with Pyridine", Ber, 71B, pp 25692583 (1938).

(18) Fierz-David, H. E., Blangey, L., and Krannichfeldt, W. V.; "Preparation of Some Substituted Triphthaloybenzenes as Starting Materials for Green Vat Dyes", Helv Chim Acta, 30, pp 816-838 (1947).

(19) Williams, N. J.; "Ultraviolet Spectrophotometric Determination of Isotruxene in Autoclave-Produced Indene Polymers", Y-1704; Union Carbide Corporation-Nuclear Division, Oak Ridge Y-12 Plant, Oak Ridge, Tennessee; January $13,1970$. 


\section{ACKNOWLEDGEMENTS}

The authors wish to express their thanks to N. J. Williams and E. T. Creech of the $Y-12$ Analytical Laboratory for their assistance in analyzing and characterizing the materials described in this report; to $\dot{W}$. T. Rainey, Jr of the ORNL Analytical Chemistry Division for obtaining and evaluating the mass spectral data; and to J. M. Napier of $Y-12$ Development Division for making equipment and technology available that were useful in the carbonization studies. In addition, the authors wish to thank J. M. Googin, UCC-ND Senior Staff Consultant, and J. F. Eastham of the University of Tennessee for valuable consultations during this study. 